\title{
Hormone replacement therapy in postmenopausal women: endometrial hyperplasia and irregular bleeding
}

\author{
Lethaby A, Farquhar C, Sarkis A, Roberts H, Jepson R, Barlow D
}
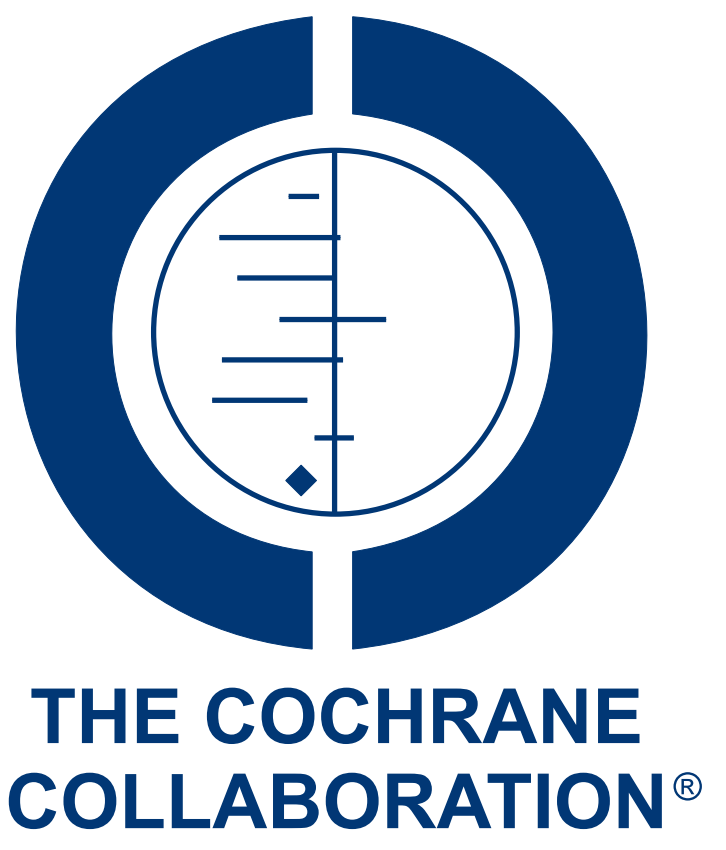

This is a reprint of a Cochrane, prepared and maintained by The Cochrane Collaboration and published in The Cochrane Library 2004, Issue 2

http://www.thecochranelibrary.com

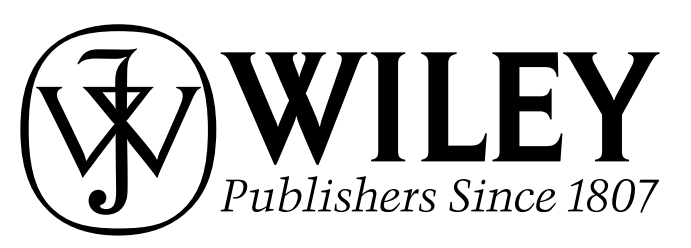

Hormone replacement therapy in postmenopausal women: endometrial hyperplasia and irregular bleeding Copyright $\odot 2004$ The Cochrane Collaboration. Published by John Wiley \& Sons, Ltd 
TABLE OF CONTENTS

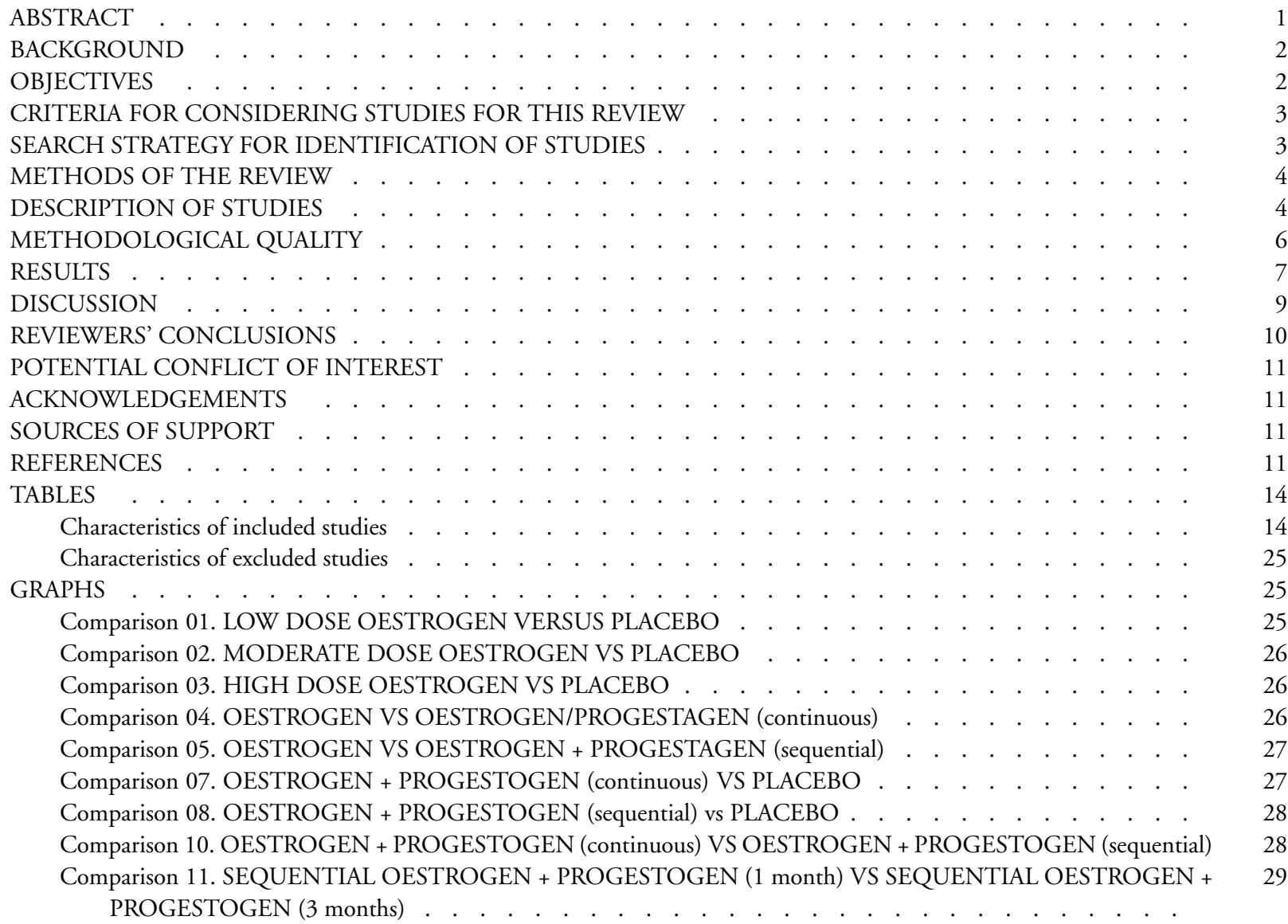

COVER SHEET . . . . . . . . . . . . . . . . . . . . . . . . . . . . . . . . . . . . $\quad 29$

GRAPHS AND OTHER TABLES . . . . . . . . . . . . . . . . . . . . . . . . . . . . . . . . . . . . . .

Comparison 11. Endometrial hyperplasia at 6 months . . . . . . . . . . . . . . . . . . . . . . . . . . . . . 30

Comparison 11. Endometrial hyperplasia at 12 months . . . . . . . . . . . . . . . . . . . . . 31

Comparison 11. Endometrial hyperplasia at 18-24 months . . . . . . . . . . . . . . . . . . . . . . . . . 32

Comparison 11. Endometrial hyperplasia at 36 months . . . . . . . . . . . . . . . . . . . . . . . . . . . . . 33

Comparison 11. Unscheduled biopsy or D \& C . . . . . . . . . . . . . . . . . . . . . . . . . . . . . . . . .

Comparison 11. Endometrial cancer . . . . . . . . . . . . . . . . . . . . . . . . . . . . . . . . . . 33

Comparison 11. Irregular bleeding patterns $<6$ mths from treatment . . . . . . . . . . . . . . . . . . . . . 34

Comparison 11. Irregular bleeding patterns $>=6 \mathrm{~m}$ ths from treatment . . . . . . . . . . . . . . . . . . . . . . . 34

Comparison 11. Non adherence to therapy . . . . . . . . . . . . . . . . . . . . . . . . . . 35

Comparison 11. Endometrial hyperplasia at 6 months . . . . . . . . . . . . . . . . . . . . . . . . . . . 35

Comparison 11. Endometrial hyperplasia at 12 months . . . . . . . . . . . . . . . . . . . . . . . . . . . . . 36

Comparison 11. Endometrial hyperplasia at 18-24 months . . . . . . . . . . . . . . . . . . . . . . . . . 37

Comparison 11. Endometrial hyperplasia at 36 months . . . . . . . . . . . . . . . . . . . . . . . . . . 38

Comparison 11. Unscheduled biopsy or D \& C . . . . . . . . . . . . . . . . . . . . . . . . . . . . . . . . .

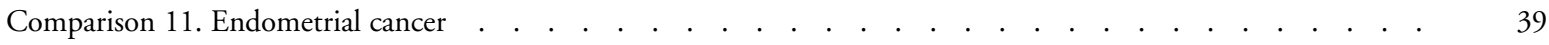

Comparison 11. Irregular bleeding patterns $<6 m$ ths from treatment . . . . . . . . . . . . . . . . . . . . . 39

Comparison 11. Irregular bleeding patterns $>=6 \mathrm{~m}$ ths from treatment . . . . . . . . . . . . . . . . . . . 40

Comparison 11. Non adherence to therapy . . . . . . . . . . . . . . . . . . . . . . . . . . . . . . . 40

Comparison 11. Endometrial hyperplasia at 6 months . . . . . . . . . . . . . . . . . . . . . . . . . . . . 41

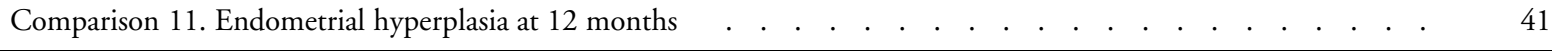

Hormone replacement therapy in postmenopausal women: endometrial hyperplasia and irregular bleeding

Copyright () 2004 The Cochrane Collaboration. Published by John Wiley \& Sons, Ltd 
Comparison 11. Endometrial hyperplasia at 24 months $\quad . \quad$. . . . . . . . . . . . . . . . . . . . . . . . 42

Comparison 11. Endometrial hyperplasia at 36 months . . . . . . . . . . . . . . . . . . . . . . 42

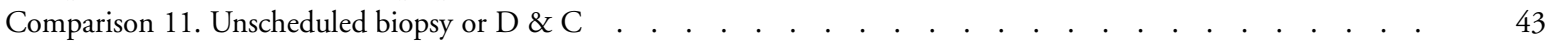

Comparison 11. Endometrial cancer . . . . . . . . . . . . . . . . . . . . . . . . . . . . . . . . . . . . . 443

Comparison 11. Irregular bleeding patterns $<6$ mths from treatment . . . . . . . . . . . . . . . . . . . . . . 43

Comparison 11. Irregular bleeding patterns $>=6 \mathrm{~m}$ ths from treatment . . . . . . . . . . . . . . . . . . . . . . 44

Comparison 11. Non adherence to therapy . . . . . . . . . . . . . . . . . . . . . . . . . . . . . . . 44

Comparison 11. Endometrial hyperplasia at 6 months . . . . . . . . . . . . . . . . . . . . . . . . . . . . 45

Comparison 11. Endometrial hyperplasia at 12 months . . . . . . . . . . . . . . . . . . . . . . . . . . . . . . 46

Comparison 11. Endometrial hyperplasia at 24 months . . . . . . . . . . . . . . . . . . . . . . . . . . . . 48

Comparison 11. Endometrial hyperplasia at 36 months . . . . . . . . . . . . . . . . . . . . . . . . . . . . 49

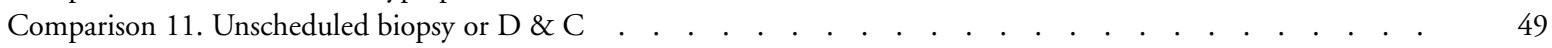

Comparison 11. Endometrial cancer . . . . . . . . . . . . . . . . . . . . . . . . . . . . . . . . . . $\quad 50$

Comparison 11. Irregular bleeding patterns $<=6$ months after treatment . . . . . . . . . . . . . . . . . . . 50

Comparison 11. Irregular bleeding patterns $>6$ months after treatment . . . . . . . . . . . . . . . . . . 51

Comparison 11. Number of cycles with irregular bleeding at 12 months . . . . . . . . . . . . . . . . . . . 52

Comparison 11. Number of cycles with irregular spotting at 12 months . . . . . . . . . . . . . . . . . . . . 52

Comparison 11. Non adherence to therapy . . . . . . . . . . . . . . . . . . . . . . . . . . . . . . 53

Comparison 11. Endometrial hyperplasia at 6 months . . . . . . . . . . . . . . . . . . . . . . . . . . . 53

Comparison 11. Endometrial hyperplasia at 12 months . . . . . . . . . . . . . . . . . . . . . . . . 54

Comparison 11. Endometrial hyperplasia at 24 months . . . . . . . . . . . . . . . . . . . . . . . . . . 55

Comparison 11. Endometrial hyperplasia at 36 months . . . . . . . . . . . . . . . . . . . . . . . . . 56

Comparison 11. Unscheduled biopsy or D \& C . . . . . . . . . . . . . . . . . . . . . . . . . . . . . . . . $\quad . \quad 56$

Comparison 11. Endometrial cancer . . . . . . . . . . . . . . . . . . . . . . . . . . . . . . . . . 57

Comparison 11. Irregular bleeding patterns $<6$ months after $\mathrm{Rx}$. . . . . . . . . . . . . . . . . . . . . . . . $\quad . \quad 57$

Comparison 11. Irregular bleeding patterns $>6$ months after $\mathrm{Rx}$. . . . . . . . . . . . . . . . . . . . . . . . 58

Comparison 11. Number of cycles of irregular bleeding $\quad . \quad$. . . . . . . . . . . . . . . . . . . . . . . . . . . . . 58

Comparison 11. Number of cycles of irregular spotting . . . . . . . . . . . . . . . . . . . . . . . . . . . . . . 59

Comparison 11. Non adherence to therapy . . . . . . . . . . . . . . . . . . . . . . . . . . . . . . . 59

Comparison 11. Endometrial hyperplasia at 6 months . . . . . . . . . . . . . . . . . . . . . . . . . . . . . 60

Comparison 11. Endometrial hyperplasia at 12 months . . . . . . . . . . . . . . . . . . . . . . . 61

Comparison 11. Endometrial hyperplasia at 24 months . . . . . . . . . . . . . . . . . . . . . . . . . 62

Comparison 11. Endometrial hyperplasia at 36 months . . . . . . . . . . . . . . . . . . . . . . . . . . 63

Comparison 11. Unscheduled biopsy or D \& C . . . . . . . . . . . . . . . . . . . . . . . . . . . . . . . . . $\quad 63$

Comparison 11. Endometrial carcinoma . . . . . . . . . . . . . . . . . . . . . . . . . . . . . . . . . . 64

Comparison 11. Irregular bleeding patterns $<6$ months after treatment . . . . . . . . . . . . . . . . . . . . 65

Comparison 11. Irregular bleeding patterns $>=6$ months after treatment . . . . . . . . . . . . . . . . . . . . . . 65

Comparison 11. Non adherence to therapy . . . . . . . . . . . . . . . . . . . . . . . . . . . . 66

Comparison 11. Endometrial hyperplasia at 12 months . . . . . . . . . . . . . . . . . . . . . . . . . . 66

Comparison 11. Endometrial hyperplasia at 24 months c . . . . . . . . . . . . . . . . . . . . . . . . . . . . . $\quad 67$

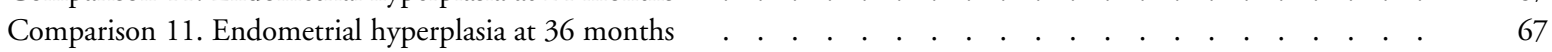

Comparison 11. Unscheduled biopsy or D \& C . . . . . . . . . . . . . . . . . . . . . . . . . . . . . . . . . . 68

Comparison 11. Endometrial cancer . . . . . . . . . . . . . . . . . . . . . . . . . . . . . . . . . 68

Comparison 11. Irregular bleeding patterns $<6$ months after treatment . . . . . . . . . . . . . . . . . . . . . . . $\quad 69$

Comparison 11. Irregular bleeding patterns $>=6$ months after treatment . . . . . . . . . . . . . . . . . . . . . . . 69

Hormone replacement therapy in postmenopausal women: endometrial hyperplasia and irregular bleeding 


\title{
Hormone replacement therapy in postmenopausal women: endometrial hyperplasia and irregular bleeding
}

\author{
Lethaby A, Farquhar C, Sarkis A, Roberts H, Jepson R, Barlow D
}

This record should be cited as:

Lethaby A, Farquhar C, Sarkis A, Roberts H, Jepson R, Barlow D. Hormone replacement therapy in postmenopausal women: endometrial hyperplasia and irregular bleeding. The Cochrane Database of Systematic Reviews, Issue . Art. No.: CD000402. DOI: 10.1002/14651858.CD000402.

This version first published online: 26 April 1999 in Issue , .

Date of most recent substantive amendment: 24 February 1999

\section{A B S T R A C T}

\section{Background}

The decline in circulating oestrogen around the time of the menopause often induces unacceptable symptoms that affect the health and well being of women. Hormone replacement therapy (both unopposed oestrogen and oestrogen and progestogen combinations) is an effective treatment for these symptoms. In women with an intact uterus, unopposed oestrogen may induce endometrial stimulation and increase the risk of endometrial hyperplasia and carcinoma. The addition of progestogen reduces this risk but may cause unacceptable symptoms, bleeding and spotting which can affect adherence to therapy.

\section{Objectives}

The objective of this review is to assess which hormone replacement therapy regimens provide effective protection against the development of endometrial hyperplasia and/or carcinoma with a low rate of abnormal vaginal bleeding.

\section{Search strategy}

Electronic searches for relevant randomised controlled trials of the Cochrane Menstrual Disorders and Subfertility Group Register of Trials, MEDLINE, EMBASE, PsycLIT, Current Contents, Biological Abstracts, Social Sciences Index and CINAHL were performed. Attempts were also made to identify trials from citation lists of review articles and drug companies were contacted for unpublished data. In most cases, the corresponding author of each included trial was contacted for additional information.

\section{Selection criteria}

The inclusion criteria were randomised comparisons of unopposed oestrogen therapy, combined continuous oestrogen-progestogen therapy and sequential oestrogen-progestogen therapy with each other and placebo administered over a minimum treatment period of six months. Trials had to assess which regimen was the most protective against the development of endometrial hyperplasia/carcinoma and/or caused the lowest rate of irregular bleeding.

\section{Data collection and analysis}

Twenty three RCTs were identified and five were excluded. The reviewers assessed the eighteen included studies for quality, extracted the data independently and odds ratios for dichotomous outcomes were estimated. Outcomes analysed included frequency of endometrial hyperplasia or carcinoma, frequency of irregular bleeding and unscheduled biopsies or dilation and curettage, and adherence to therapy.

\section{Main results}

Unopposed moderate or high dose oestrogen therapy was associated with a significant increase in rates of endometrial hyperplasia with increasing rates at longer duration of treatment and follow up. Odds ratios ranged from 5.4 (1.4-20.9) for 6 months of treatment to 16.0 (9.3-27.5) for 36 months of treatment with moderate dose oestrogen (in the PEPI trial, $62 \%$ of those who took moderate dose oestrogen had some form of hyperplasia at 36 months compared to $2 \%$ of those who took placebo). Irregular bleeding and non adherence to treatment were also significantly more likely under these unopposed oestrogen regimens with greater effects with higher dose therapy. There was no evidence of increased hyperplasia rates, however, with low dose oestrogen.

Hormone replacement therapy in postmenopausal women: endometrial hyperplasia and irregular bleeding

Copyright $(2004$ The Cochrane Collaboration. Published by John Wiley \& Sons, Ltd 
The addition of progestogens, either in continuous combined or sequential regimens, helped to prevent the development of endometrial hyperplasia and improved adherence to therapy (odds ratios of 3.7 for sequential therapy and 6.0 for continuous therapy). Irregular bleeding, however, was more likely under a continuous than a sequential oestrogen-progestogen regimen $(\mathrm{OR}=2.3$, 95\% CI 2.12.5) but at longer duration of treatment, continuous therapy was more protective than sequential therapy in preventing endometrial hyperplasia $(\mathrm{OR}=0.3,95 \% \mathrm{CI} 0.1-0.97)$. There was evidence of a higher incidence of hyperplasia under long cycle sequential therapy (progestogen given every three months) compared to monthly sequential therapy (progestogen given every month). No increase in endometrial cancer was seen in any of the treatment groups during the limited duration (maximum of three years) of these trials.

\section{Reviewers' conclusions}

There is strong and consistent evidence in this review that unopposed oestrogen therapy, at moderate and high doses, is associated with increased rates of endometrial hyperplasia, irregular bleeding and consequent non adherence to therapy. The addition of oral progestogens administered either cyclically or continuously is associated with reduced rates of hyperplasia and improved adherence to therapy. Irregular bleeding is less likely under sequential than continuous therapy but there is a suggestion that continuous therapy over long duration is more protective than sequential therapy in the prevention of endometrial hyperplasia. Hyperplasia is more likely when progestogen is given every three months in a sequential regimen compared to a monthly progestogen sequential regimen.

\section{B A C K G R O U N}

Menopause means the cessation of menstruation and typically occurs between 45-55 years of age with a mean age of about 51 years. Women are said to be postmenopausal when menstruation has ceased for 12 months. The decline in circulating oestrogen around the time of the menopause can induce symptoms that affect the well being and health of women; hot flushes, insomnia, declining bone mass, night sweats, mood disturbances and urogenital atrophy have all been reported. As the population continues to grow older, there has been an increased focus on the effects of ageing. Oestrogen replacement therapy has been utilised for the treatment of many of the menopausal symptoms, particularly hot flushes and dry vagina.

Several studies have suggested a causal relationship between unopposed oestrogen replacement therapy (daily use of oestrogen without the addition of progestogen) and the induction of endometrial hyperplasia and carcinoma (Ziel 1975; Smith 1977; Gardan 1977; Antunes 1979; Grady 1995). Endometrial hyperplasia is regarded as a precursor of endometrial cancer but progression is dependent on type of hyperplasia (Kurman 1985; Terakawa 1997). The risk of hyperplasia and/or carcinoma appears to increase with higher doses and increased duration of unopposed oestrogen treatment. Adding a progestogen to oestrogen replacement therapy significantly reduces the risk of hyperplasia (Whitehead 1977; Cust 1990; Udoff 1995), but can result in premenstrual symptoms and vaginal bleeding and spotting, which is undesirable to many women. This is often given as a reason not to continue hormone replacement therapy (Ellerington 1992).

The endometrial histology shows an inactive phase in $100 \%$ of the women given continuous daily progestogen but in only $25 \%$ of those on cyclic (sequential) progestogen (both in conjunction with continuous oestrogen). Withdrawal bleeding occurs with cyclic (sequential) regimens (daily use of oestrogen with cyclical use of progestogen) in the majority of women, whereas irregular bleeding and spotting occurs with continuous (daily use of oestrogen and progestogen) or oestrogen alone regimens in approximately $50 \%$ of women, but these bleeding episodes diminish with time in those on continuous progestogen and oestrogen. For women who are considering long term hormone replacement therapy for the prevention of osteoporosis or reduction of risk of cardiovascular events, most prefer a continuous regimen of oestrogen-progestogen for the maintenance of an atrophic endometrium with no bleeding.

The aim of this review is to assess which of the hormone replacement regimens, unopposed oestrogen or oestrogen-progestogen administered either continuously or cyclically, provides the best protection against the development of endometrial hyperplasia or carcinoma and the lowest rate of irregular bleeding and non adherence to therapy.

\section{O B J E C T I V E S}

To assess which of the hormone replacement therapy regimens provides the most effective protection against the development of endometrial hyperplasia and/or carcinoma and the lowest rate of abnormal vaginal bleeding.

We wished to assess the following:

1. Effect of unopposed oestrogen therapy on the frequency of endometrial hyperplasia/carcinoma and irregular vaginal bleeding when compared to placebo.

2. Effect of unopposed oestrogen therapy on the frequency of endometrial hyperplasia/carcinoma and irregular vaginal bleeding when compared to oestrogen and progestogen therapy.

3. Effect of oestrogen and progestogen therapy on the frequency of endometrial hyperplasia/carcinoma and irregular vaginal bleeding when compared to placebo. 
4. Effect of continuous oestrogen plus progestogen therapy on the frequency of endometrial hyperplasia/carcinoma and irregular vaginal bleeding when compared with sequential oestrogen plus progestogen therapy.

5. Effect of sequential oestrogen plus progestogen therapy (progestogens given once a month) on the frequency of endometrial hyperplasia/carcinoma and irregular vaginal bleeding when compared with sequential oestrogen plus progestogen therapy (progestogens given once every 3 months).

\section{CRITERIA FOR CONSIDERING STUDIES FOR THIS REVIEW}

\section{Types of studies}

All randomised controlled trials of oestrogen or combined oestrogen/progestogen therapy versus placebo, oestrogen versus combined oestrogen/progestogen (sequential and continuous therapy), oestrogen/progestogen (continuous) versus oestrogen/progestogen (sequential), and sequential $\mathrm{O}+\mathrm{P}$ (progestogen once a month) versus $\mathrm{O}+\mathrm{P}$ (progestogen once every 3 months) with a minimum treatment period of 6 months. This review has not included 'dose finding' trials where different doses of oestrogen and/or progestogen are compared. These trials will be included in a separate review.

\section{Types of participants}

Postmenopausal women with an intact uterus, defined as women who have not menstruated for more than six months and who have a serum FSH greater than or equal to $40 \mathrm{IU} / \mathrm{L}$. It is recognised that this criterion is more liberal than the more usual definition of postmenopausal status (last menses greater than or equal to 12 months prior) but the majority of trials use this more liberal criterion and postmenopausal status is often further confirmed by FSH levels. The definition includes women who have undergone a natural menopause and women who have had bilateral oophorectomy (removal of both ovaries).

The participants can be recruited from any health care setting or from advertisements.

Exclusion criteria:

Perimenopausal women (menstruation less than 6 months prior to study)

Intercurrent major disease

Previous HRT (hormone replacement therapy) within one month of commencement of the study

Any contraindication to HRT (either unopposed oestrogen or oestrogen + progestogen therapy)

\section{Types of intervention}

Interventions administered for a period of 6 months or greater. 1. Oestrogen versus placebo
2. Oestrogen versus combined oestrogen/progestogen, either sequential (cyclic) or continuous

3. Combined oestrogen/progestogen (sequential or continuous) versus placebo

4. Combined oestrogen/progestogen (continuous) versus oestrogen/progestogen (sequential)

5. Sequential oestrogen/progestogen (progestogen once a month) versus sequential oestrogen/progestogen (progestogen once every 3 months).

\section{Types of outcome measures}

1. Frequency of endometrial hyperplasia (of any type) or carcinoma (assessed by endometrial biopsy or histology)

2. Irregular bleeding patterns, either number of women with irregular bleeding and/or spotting or number of cycles with irregular bleeding/spotting

3. Requirements for other medical and surgical therapy (unscheduled endometrial biopsies or dilatation and curettage (D\&C))

4. Adherence/compliance to therapy

\section{SEARCH STRATEGY FOR IDENTIFICATION OF STUDIES}

\section{See: search strategy}

Electronic searches were performed of the Trials Register of the Cochrane Menstrual Disorders and Subfertility Group, MEDLINE, EMBASE, Current Contents, Biological Abstracts, Social Sciences Index, PsycLIT and CINAHL for publications which described randomised trials of oestrogen versus oestrogen-progestogen or placebo or oestrogen-progestogen versus placebo or combined continuous oestrogen-progestogen versus sequential oestrogen-progestogen therapy and their impact on endometrial hyperplasia and bleeding patterns in menopausal women. The search strategy developed by the Cochrane Menstrual Disorder and Subfertility Group was used together with the additional terms:

exp climactericl

exp menopause/

climacter\$.tw.

menopaus\$.tw.

“postmenopaus\$”.tw.

“post-menopaus\$”.tw.

“post menopaus\$”.tw.

endometrial hyperplasia/

(endometri\$ adj5 hyperplasia).tw.

exp estrogens/

contraceptives, oral, combined/

estrogen replacement therapy/

progestational hormones/

hormone replacement therapy.tw. 
HRT.tw.

progest $\$$.tw.

bleeding pattern $\$$. tw.

Citation lists of included trials, conference abstracts and relevant review articles were also searched, relevant journals handsearched for additional trials (see Review Group details for more information) and drug companies contacted for details of unpublished trials. It was planned to contact the corresponding author of included trials where data were not in a form suitable for extraction or where information relating to the study was not made explicit.

\section{METHODS OF THEREVIEW}

Selection of trials

The selection of trials for inclusion in the review was performed by three of the reviewers (AL, AS and RJ) after employing the search strategy described previously.

Quality assessment

Included trials were assessed independently by four of the reviewers (AL, and either RJ, AS, or HR) for the following quality criteria and methodological details:

Trial characteristics

1. Method of randomisation

2. Presence or absence of blinding to treatment allocation

3. Quality of allocation concealment

4. Number of women randomised, excluded or lost to follow up

5. Whether an intention to treat analysis was done

6. Whether a power calculation was done

6. Duration, timing and location of the study

Characteristics of the study participants

1. Age and any other recorded characteristics of women in the study

2. Other inclusion criteria

3. Exclusion criteria

Interventions used

1. Doses and types of unopposed oestrogen therapy used

2. Doses, types and regimens of oestrogen-progestogen therapy used

Outcomes

1. Methods used to measure endometrial hyperplasia

2. Types of endometrial hyperplasia

Data management

Data extraction was performed independently by four of the reviewers (AL, and either AS, CF or HR) using forms designed according to Cochrane guidelines. Any discrepancies were resolved by discussion. Quality of allocation concealment was graded as either A (adequate), B (unclear) or C (inadequate). Three of the reviewers (CF, HR and AS) were experts on clinical issues and two reviewers had statistical or methodological expertise (AL and RJ). Where necessary, additional information on trial methodology or actual original trial data was sought from the corresponding author of any trials that appeared to meet the eligibility criteria.

\section{Statistical analysis}

Statistical analysis was performed in accordance with the guidelines for statistical analysis developed by the Menstrual Disorders and Subfertility Group. Heterogeneity between the results of different studies was examined by inspecting the scatter in the data points and the overlap in their confidence intervals and, more formally, by checking the results of the chi-squared tests. A priori, it was planned to look at the possible contribution of differences in trial design to any heterogeneity identified in this manner. Where possible, the outcomes were pooled statistically.

For dichotomous data (for example, proportion of patients with hyperplasia or carcinoma), results for each study were expressed as a odds ratio with $95 \%$ confidence intervals and combined for metaanalysis with RevMan software using the Peto-modified MantelHaenszel method. All of the outcomes were categorised so that a high value represented a harm or negative consequence rather than a benefit of treatment. Thus, a negative consequence of treatment is represented in the graphs as a mean and confidence interval on the right of the centre line.

The main analyses were based on eighteen trials although not all trials assessed all of the outcomes. However, we also planned a priori sensitivity analyses based on:

i) Trials with adequate concealment (score A) versus trials with uncertain or inadequate methodology (score B or C).

ii) Trials with double blinding versus trials with either single or no blinding.

iii) Trials with intention to treat analysis versus those without ITT analysis.

iv) Trials with $<20 \%$ withdrawals versus those with $>20 \%$ withdrawals.

v) Trials with details on type of hyperplasia diagnosed (trials where all types of hyperplasia are included in the assessment versus trials with simple hyperplasia excluded from the assessment of hyperplasia).

Post-hoc sensitivity analysis was also performed based on: i) Trials where the primary outcomes were the outcomes assessed in this review versus trials where incidence of hyperplasia and irregular bleeding were secondary or merely reported incidentally.

\section{DESCRIPTION OF STUDIES}

Twenty three studies were identified but five of these were subsequently excluded. Two of the excluded studies were located by handsearching and published in abstract form and it was unclear 
whether women were randomised to treatment groups. The participants for another excluded study were hospitalised for chronic diseases, which is an exclusion criterion. For the remaining two studies, some participants had diagnosed endometrial hyperplasia at baseline (see Excluded Studies Table).

Data extraction was performed on the eighteen included trials, which involved a total of 5247 participants, although not all of these completed the total period of, follow up or were included in an intention to treat analysis.

The trials took place in Chile (1), Denmark (5), Canada (1), Finland (1), Japan (1), multi centre trial in Scandinavia (1), USA (7, some of which were multi centre) and a large trial with $33 \%$ of the total trial participants considered in the review was distributed in 99 centres in the USA and Europe (MSG 1994). Most of the included trials required that women be postmenopausal and this was defined in all but 2 trials as cessation of bleeding for 6 months or more prior to entry into the study. In these two trials, participants were required to have an FSH>=40IU/L or within "the postmenopausal range". Participants ranged in age from 40 to 65 years although most patients were in the early menopause with the requirement that women should be within five or less years of their last spontaneous menstrual bleeding. Results can thus be generalised only to women in the early postmenopause rather than all postmenopausal women. Most of the trials also required that women have an intact uterus or this was implied by the requirement for an endometrial biopsy at baseline, exclusion criterion of previous gynaecological operation or the nature of the primary outcomes. Full details of the inclusion and exclusion criteria are found in the Table of Included Studies. Common exclusion criteria were malignancy, chronic illness, or use of contraindicated medications.

A wide variety of oestrogen alone or oestrogen and progestogen combinations were used as interventions in the included trials. Unopposed oestrogens included conjugated equine oestrogen (CEE), ethinyl oestradiol (EE), micronised 17B-estradiol (E2), estrone sulphate (EIS) and esterified oestrogens (ESE). Most of the unopposed oestrogen studies compared different doses of the same drug with placebo. These oestrogens cannot be considered equal. They vary in their dose equivalency and have different metabolic effects on different tissues or end organs. In order to make meaningful comparisons, oestrogens were grouped into 'low', 'moderate' and 'high' dose subgroups. The allocations of different types and doses of oestrogens to these groupings were made according to the advice of experts (France 1998; MacLennan 1998; Ansbacher 1994; O'Connell 1998). Disagreement persists among clinical experts, however, regarding categorisation of oestradiol in the moderate range and two different doses ( 1 and $2 \mathrm{mg}$ ) of this oestrogen have been included in this category.

In some trials, unopposed oestrogen treatment $(\mathrm{O})$ was compared with oestrogen/progestogen combined treatment $(\mathrm{O}+\mathrm{P})$, either continuous or sequential (cyclic). Progestogens used in the com- bined treatment included norethisterone acetate (NA), medroxyprogesterone acetate (MPA), micronised progesterone (MP), cyproterone acetate (CPA), desogestrel (DG), and levonorgestrel (LNG).

In the analysis, continuous and sequential $\mathrm{O}+\mathrm{P}$ regimens were evaluated separately. For each type of regimen, different doses were compared and then combined in a total estimate of effect between $\mathrm{O}$ and $\mathrm{O}+\mathrm{P}$.

The effects of sequential therapy were evaluated separately for different doses and duration of progestogen treatment and then combined in a pooled estimate. In this review, duration of progestogen therapy varied from 11 to 14 days and was given at different times in the treatment cycle. There is evidence that progestogens must be taken for at least ten days per month to reduce the risk of endometrial hyperplasia and carcinoma (Whitehead 1981) but some more recent studies suggest that progestogens could be given for at least 12 days (Sturdee 1994; Whitehead 1987). It was planned to assess separately the effects of cyclical progestogen given for less than and more than ten days but none of the included studies were in the former category. A future review is planned to compare duration and dosage of cyclical progestogen therapy.

Where there was only one comparison group of unopposed oestrogen and two or more groups with different $\mathrm{O}+\mathrm{P}$ doses (MSG 1994; PEPI 1995), it was necessary to combine the two $\mathrm{O}+\mathrm{P}$ groups so the comparative unopposed oestrogen group was not double counted.

The effects of $\mathrm{O}+\mathrm{P}$ treatment, continuous and sequential, versus placebo were also evaluated separately. In these comparisons, where there was only one comparison group of placebo, the groups with different dosages of $\mathrm{O}+\mathrm{P}$ were combined (CHART 1996).

Duration of treatment in the included trials ranged from six months to three years but the majority of studies assessed treatment over either one or two years.

The primary outcomes were frequency of endometrial hyperplasia or carcinoma and frequency of unscheduled or irregular bleeding but not all of the trials evaluated both of these. Endometrial hyperplasia was invariably confirmed by endometrial biopsy and reported at six, 12, 24 and 36 months but not by all studies. Most studies included any type of hyperplasia as a hyperplasia outcome but in three studies, the different types of hyperplasia were distinguished. Sensitivity analysis was performed with the results of the trials where simple hyperplasia was excluded from the assessment of hyperplasia compared with the results of trials where all types of hyperplasia were included in the assessment. Incidence of endometrial carcinoma was measured as an outcome in some studies but no trials were not of sufficient size or duration to adequately determine this outcome.

Unscheduled or irregular bleeding was either recorded daily on a calendar by participants or elicited from questioning the patient 
about their bleeding patterns. In one trial (MSG 1994), 'spotting' was distinguished from 'bleeding' and the number of cycles of irregular bleeding and irregular spotting were evaluated separately. All other studies assessing bleeding patterns reported on the proportion of women in the treatment group with breakthrough or irregular bleeding. This was evaluated separately in the review as bleeding occurring within six months or occurring at a longer duration of time. All included trials assessing these outcomes distinguished carefully between 'unscheduled' (irregular or 'unexpected') bleeding and regular or withdrawal bleeding. Regular bleeding was invariably defined as bleeding occurring during the treatment free week during sequential therapy or from day 21 of the treatment cycle to day one of the following cycle. Withdrawal bleeding, which usually accompanies sequential $\mathrm{O}+$ $\mathrm{P}$ treatment, was not considered in this review since it is an expected outcome of this type of regimen.

A small number of trials (Ettinger 1992; Hagen 1982; Harris 1991; Notelovitz 1996; Heikkinen 1997; Mizunuma 1997) assessed change in bone density, lipid profile and climacteric symptoms as the primary outcomes and effects on the endometrium and frequency of unscheduled bleeding were secondary outcomes. A proportion of participants in most of these trials had a hysterectomy and endometrial effects and bleeding were separately assessed in subgroups. This was taken into account in a sensitivity analysis.

The frequency of unscheduled biopsies or dilation and curettage was measured in one large trial (PEPI 1995) and non adherence to treatment because of adverse events related to treatment was assessed in 10 trials.

One trial, written in Spanish, was translated by Ms Christine Aguilar of the San Antonio Cochrane Centre.

\section{METHODOLOGICALQUALITY}

All eighteen studies were randomised but in nine no details were provided of the method. One trial had randomisation by "random sampling numbers" but no details were given of adequate concealment of allocation. These ten trials were classified with an allocation score of $\mathrm{B}$ (unclear allocation concealment). The remaining eight trials were classified as $\mathrm{A}$, adequate concealment prior to allocation. All of the trials were double blinded except for six; in three of these (Marslew 1991; Marslew 1992; Williams 1990), the assessor was blinded and not the participants and in the remaining three trials blinding was not clear. Twelve of the trials had a placebo control group. In the remaining six trials, one trial compared two different doses of unopposed oestrogen with the same doses of $\mathrm{O}$ combined with cyclic progestogen for 11 days (Gelfand 1989), one trial compared a standard dose of unopposed oestrogen with two different continuous $\mathrm{O}+\mathrm{P}$ regimens and two different sequential O + P regimens (MSG 1994), one trial compared a standard dose of unopposed oestrogen with two different continuous $\mathrm{O}+\mathrm{P}$ regimens and a no treatment group (Mizunuma 1997), one trial compared a short cycle sequential O + P regimen with a long cycle $\mathrm{O}+\mathrm{P}$ regimen (progestogen given once a month compared to progestogen given once every three months cyclically) (Scandinavia 1996) and two trials compared multiple continuous $\mathrm{O}+\mathrm{P}$ regimens with a sequential O + P regimen (Williams 1990, Luciano 1993).

Unblinding occurred in 38 women in the PEPI trial (31 of those receiving the unopposed oestrogen regimen, four receiving one of the oestrogen and progestogen regimens and three receiving placebo) because of endometrial biopsy results classified as complex hyperplasia, atypia or cancer.

The included trials ranged in size from 36 to 1724 participants with the three largest including more than 500 women (CHART 1996, $n=1265$; MSG 1994, $n=1724$; PEPI 1995, $n=596$ ). Six of the large trials were multi centre trials and in the remaining 12 trials women were recruited from a single centre. All trials had a parallel group design. Two trials had performed a power calculation for sample size and analysis was by intention to treat (ITT) (Harris 1991; PEPI 1995), two trials had power calculations and no ITT analysis (CHART 1996; MSG 1994), one trial had performed a power analysis (with no ITT) but the numbers of participants were not adequate (Mizunuma 1997) and one trial had only ITT analysis (Notelovitz 1996).

Losses to follow up and withdrawals were common, particularly in the larger trials and trials with long duration. In the CHART study, 570 women (45\%) had withdrawn (out of a total of 1265) by the conclusion of the trial at two years. In this trial, a priori stopping rules were applied for participants who developed hyperplasia and consequently a proportion of subjects in Group eight (10mcg daily of oral ethinyl estradiol (EE2) continuously) were terminated from the study early owing to a high rate of hyperplasia. All remaining treatment groups had similar rates of withdrawal that ranged from $22 \%$ to $30 \%$ and excluding the high dose oestrogen group, over $73 \%$ of the subjects completed the study. In the other study with a very high proportion of withdrawals (Gelfand 1989), 54 women (31\%) withdrew during the study for medical reasons but the withdrawals were not comparable between treatment groups. A further 24 women (14\%) were under treatment at the conclusion of the study and went on to complete their medication but their data were not included in the final analyses because their treatment was not complete. Of the remaining trials, three had withdrawals greater than 20\% (Harris 1991, 23\%; Marslew 1991, 22\%; Mizunuma 1997, 31\%) but the former study had ITT analysis for one of the outcomes, frequency of irregular bleeding. The other 12 trials had withdrawals ranging from $4 \%$ to $20 \%$ and in one trial (Scandinavia 1996), the proportion of women completing the trial was unclear. In another trial (Ettinger 1992), the number of women randomised to treatment groups was not specified. In the PEPI trial, $12 \%$ of the original participants failed 
to undergo endometrial biopsy at the end of three years but were included in an ITT analysis.

\section{R E S U L T S}

The incidence of endometrial hyperplasia was assessed at six, 12, 24 and 36 months. Not all of the studies reported the incidence rates at these time intervals. No differentiation was made in the analysis between the type of hyperplasia (simple, atypical or complex), although this was reported in some studies. Where a study had only one comparison or control group and several different doses of the experimental group, it was necessary to combine the groups with different doses in the analysis to avoid counting the control group more than once.

The odds ratio (OR) was used instead of the relative risk because there was an increase in events in the treatment group as the length of follow up increased.

\section{OESTROGEN VERSUS PLACEBO}

Low dose

There were no significant differences overall in rates of endometrial hyperplasia at six, 12 or 24 months or rates of irregular bleeding. However, there was an increasing, although non-significant, trend in rates of hyperplasia by duration of treatment for unopposed oestrogen users for the largest study with 490 participants when the dose of 10 ug of ethinyl oestradiol was used compared to the lower doses (1ug, 2.5ug and 5ug) in the treatment group (CHART 1996) (data not shown but is displayed in the publication). Adherence to therapy was also not significantly different between treatment groups in one small study.

\section{Moderate Dose}

There were significant differences in rates of endometrial hyperplasia at 6 months $(\mathrm{OR}=5.4,95 \% \mathrm{CI} 1.4-20.9), 12$ months $(\mathrm{OR}=8.3$, 95\% CI 4.2-16.2), 24 months (OR=9.6, 95\% CI 5.9-15.5) and 36 months (OR=16.0, 95\% CI 9.3-27.5) under oestrogen treatment with increasing rates at longer duration of treatment and follow up. Unscheduled biopsies or dilatation and curettage were also significantly more likely under unopposed oestrogen treatment (OR=19.9, 95\% CI 12.0-33.1). In addition, irregular bleeding was more likely after 6 months of treatment (OR=1.9, 95\% CI 1.1-3.5) and a greater proportion of women did not adhere to their treatment regimens $(\mathrm{OR}=3.6,95 \% \mathrm{CI} 2.3-5.5)$. There was no significant difference in rates of endometrial carcinoma between treatment groups.

\section{High Dose}

Highly significant rates of endometrial hyperplasia were reported with unopposed oestrogen therapy when compared with placebo at all durations of follow up: at 6 months (OR=9.1, 95\% CI, 3.622.9), 12 months (OR=10.7, 95\% CI 4.6-25.1) and 24 months $(\mathrm{OR}=13.1,95 \%$ CI 5.9-29.0), showing an increasing association with increasing duration of treatment. Rates of irregular bleeding were also higher after 6 months of treatment $(\mathrm{OR}=6.0,95 \% \mathrm{CI}$ 2.8-12.9) and women were more likely not to adhere to their treatment regimen under oestrogen therapy $(\mathrm{OR}=6.8,95 \% \mathrm{CI}$ 3.4-14.0). No cases of endometrial carcinoma were reported in the one small study that evaluated this outcome.

\section{(2) OESTROGEN VERSUS OESTROGEN + PROGESTO- GEN (continuous)}

Rates of endometrial hyperplasia were significantly higher under unopposed oestrogen treatment when compared with $\mathrm{O}+\mathrm{P}$ treatment although these rates did not appear to increase with longer duration of follow up: at 6 months (OR=14.2, 95\% CI 6.431.7), at 12 months ( $\mathrm{OR}=15.0,95 \% \mathrm{CI} 9.7-23.2)$, at 24 months $(\mathrm{OR}=14.5,95 \% \mathrm{CI} 8.5-24.8)$ and at 36 months $(\mathrm{OR}=17.1,95 \%$ CI 9.9-29.4). However, the odds ratios reported were pooled estimates and varied according to the dosage of $\mathrm{O}$ and $\mathrm{O}+\mathrm{P}$, causing significant heterogeneity at 24 months follow up. Unscheduled biopsies or D \& C were also more likely under unopposed oestrogen treatment $(\mathrm{OR}=20.8,95 \% \mathrm{CI} 12.5-34.5)$. Cycles of irregular bleeding or spotting were significantly less likely during the 12 months of treatment with unopposed oestrogen $(\mathrm{OR}=0.8,95 \%$ CI 0.73-0.9 and OR=0.6, 95\% CI 0.56-0.7) but it is unclear exactly when during the year of treatment that these occurred. However, women were significantly more likely to adhere to their $\mathrm{O}$ $+\mathrm{P}$ treatment than the unopposed oestrogen treatment $(\mathrm{OR}=6.0$, $95 \%$ CI 3.6-10.2). No rates of endometrial carcinoma were reported.

\section{(3) OESTROGEN VS OESTROGEN + PROGESTOGEN (se- quential)}

Endometrial hyperplasia was significantly more likely under unopposed oestrogen treatment when compared with sequential $\mathrm{O}$ $+\mathrm{P}$ treatment and this appeared to increase with longer duration of treatment and follow up; at 6 months $(\mathrm{OR}=11.6,95 \% \mathrm{CI}$ 5.5-24.5), 12 months (OR=15.2, 95\% CI 10.0-22.9), 24 months $(\mathrm{OR}=19.8,95 \% \mathrm{CI} 11.1-35.6)$ and 36 months $(\mathrm{OR}=22.6,95 \%$ CI 13.5-37.7). Unscheduled biopsies or D \& C were also more likely $(\mathrm{OR}=20.5,95 \% \mathrm{CI}$ 13.0-32.3) and irregular bleeding was more common under treatment with oestrogen alone $(\mathrm{OR}=5.9$, 95\% CI 2.5-13.7 and OR=2.0, 95\% CI 1.8-2.3). There was a significant difference between treatment groups in rates of adherence to therapy (OR=3.4, 95\% CI 2.2-5.1) but there was significant heterogeneity in the pooled estimate with women taking higher dose oestrogen more likely to adhere to treatment and women taking lower dose oestrogen showing a trend towards less adherence in one study. There were no differences between treatment groups in the number of cycles of irregular bleeding and no cases of endometrial carcinoma.

(4) OESTROGEN + PROGESTOGEN (continuous) VS PLACEBO 
No significant differences were found in the rates of endometrial hyperplasia or carcinoma, unscheduled biopsies or D \& C and adherence to therapy between treatment groups. Irregular bleeding, both within six months of starting treatment and at longer durations of treatment, was however more likely under combined oestrogen-progestogen therapy $((\mathrm{OR}=6.4,95 \% \mathrm{CI} 2.7-15.1)$ and (OR=6.1, 95\% CI 2.7-13.7) respectively).

(5) OESTROGEN + PROGESTOGEN (sequential) VS PLACEBO

Hyperplasia rates did not significantly differ between treatment groups at 12 and 36 months after starting therapy but hyperplasia was more likely under sequential therapy after 24 months $(\mathrm{OR}=4$, 95\% CI 1.2-14.0). When sensitivity analysis was performed excluding the small trial where hyperplasia was an incidental outcome, this difference was no longer significant. Nevertheless, there is a strong although non significant trend in favour of lower rates in the placebo group at all durations of treatment and in most cases results are from only one trial. There were no differences in rates of endometrial cancer or irregular bleeding rates. However, women in the placebo group were more likely to adhere to their treatment than women in the combined sequential $\mathrm{O}+\mathrm{P}$ group $(\mathrm{OR}=3.5,95 \%$ CI 1.5-8.1).

(6) OESTROGEN + PROGESTOGEN (continuous) VS OESTROGEN + PROGESTOGEN (sequential)

The rates of endometrial hyperplasia were not significantly different between the two types of combined treatment at six, 12 and 24 months although there was an increasing trend over time in favour of the continuous therapy group. At 36 months, the frequency of hyperplasia was significantly lower under sequential treatment (OR=0.3, 95\% CI 0.09-0.97). There were no significant differences between groups in the rates of carcinoma and adherence to therapy. There were also no significant differences between groups in the proportion of women with irregular bleeding both within 6six and after six months of treatment although results were heterogeneous and the pooled OR was misleading. In the large MSG trial, there were higher rates of cycles with irregular bleeding and spotting in the continuous $\mathrm{O}+\mathrm{P}$ treatment group $((\mathrm{OR}=2.3,95 \%$ CI 2.1-2.5) and (OR=1.6, 95\% CI 1.5-1.8) respectively).

(7) OESTROGEN + PROGESTOGEN (sequential, 1 month cycle) VS OESTROGEN + PROGESTOGEN (sequential, 3 month cycle)

Rates of endometrial hyperplasia were significantly increased in the long cycle treatment group after 12 and 36 months of treatment in one multi centre study in Scandinavia which was discontinued as a result $(\mathrm{OR}=0.11,95 \% \mathrm{CI} 0.03-0.52$ and $\mathrm{OR}=0.18,95 \% \mathrm{CI}$ 0.06-0.49 respectively). This finding was not found in one other multi centre after 24 months of treatment. Adherence to therapy and rates of endometrial cancer did not differ between treatment groups.

\section{SENSITIVITY ANALYSES}

For many of the comparisons, the outcomes were recorded by only one or two trials and sensitivity analysis could not be performed. Where more trials were included, the exclusion of poorer quality trials usually did not alter the results markedly. However, where moderate dose oestrogen was compared with placebo, the OR for endometrial hyperplasia at 24 months increased from 9.5 (5.9$15.4)$ to $11.6(6.9-19.4)$ with the exclusion of the poorer quality trials and there were also increases in the odds ratios for endometrial hyperplasia at 6 and 12 months when unopposed oestrogen was compared with oestrogen-progestogen therapy. However, irregular bleeding after 6 months of treatment was not significantly different between women taking moderate dose oestrogen and placebo after the exclusion of the poorer quality trials (Ettinger 1992; Harris 1991) (previously, OR=1.9 (1.05-3.46)). This result is likely to be caused by lower power; there was little heterogeneity in the initial results and the odds ratio was almost identical with and without the excluded trials. Sensitivity analysis also compared the results found according to any type of hyperplasia with the results where diagnosis of hyperplasia excluded the simple form but the direction of the results was not altered. No other differences were found in the sensitivity analyses.

\section{HETEROGENEITY}

There was significant heterogeneity in the pooled results for non adherence to therapy when unopposed oestrogen was compared with oestrogen-progestogen sequential therapy but different doses of oestrogen were pooled for the estimate. If the doses of oestrogen are examined separately, women were significantly more likely to not adhere to their treatment when taking unopposed oestrogen (CEE $0.625 \mathrm{mg}$ ) when compared to women taking the combined $\mathrm{O}+\mathrm{P}$ regimens (CEE $0.625 \mathrm{mg}+\mathrm{MPA} 5 \mathrm{mg}$ or MPA $10 \mathrm{mg}$ or MP 200mg) but significantly more women did not adhere to their treatment in the $\mathrm{O}+\mathrm{P}$ group compared to the $\mathrm{O}$ group where the dose of oestrogen was increased to CEE $1.25 \mathrm{mg}$ in both comparison groups. The reason for this discrepancy is not clear but sensitivity analysis with the exclusion of the Gelfand trial (with a high proportion of withdrawals) suggests that women are more likely to adhere to the combined regimen compared with the unopposed oestrogen regimen.

Significant heterogeneity was also found in the pooled estimate for incidence of irregular bleeding both within 6 months and after 6 months of treatment when continuous $\mathrm{O}+\mathrm{P}$ was compared with sequential $\mathrm{O}+\mathrm{P}$ therapy. All of the included trials for these outcomes were regarded as poorer quality trials because of either unspecified concealment, lack of double blinding or analyses not by intention to treat and so the pooled estimates must be regarded with caution. The large MSG trial, however, reported significantly more cycles with irregular bleeding and spotting in the group of women who took continuous as opposed to sequential $\mathrm{O}+\mathrm{P}$ therapy and this result is likely to be a more valid indication of the frequency of irregular bleeding.

Hormone replacement therapy in postmenopausal women: endometrial hyperplasia and irregular bleeding

Copyright ( 2004 The Cochrane Collaboration. Published by John Wiley \& Sons, Ltd 


\section{DISCUSSION}

Most of the RCTs included in this review have studied recently postmenopausal women (within five years of the menopause) and thus the findings are more applicable to this group than older postmenopausal women.

The assessment of endometrial hyperplasia in this review is clinically important because it is associated with an overall increased risk of endometrial cancer, although this risk differs according to the type of hyperplasia diagnosed. There is evidence that untreated simple hyperplasia without atypia progresses infrequently over a 13 year period to carcinoma while this risk is greater in women with complex hyperplasia (Kurman 1985). Untreated hyperplasia with atypia is more likely to progress to cancer (Kurman 1985; Terakawa 1997). Most of the trials included in this review have distinguished 'hyperplastic' endometrium of any type from other types of endometrium but sensitivity analysis has also been performed with the inclusion of only those trials that identified the type of hyperplasia. When the simple type is excluded from the definition of hyperplasia, the direction of the results has not differed but in some cases the strength of the increased risk has been reduced.

The results confirm that the main adverse effect of unopposed oestrogen replacement therapy was an increased risk of endometrial hyperplasia (of any type), although no excess risk was demonstrated with low dose oestrogen. There were still too little data, however, for declaring low-dose oestrogen as safe. There appeared to be a dose-response relationship and a duration of treatmentresponse relationship between unopposed oestrogen and risk of hyperplasia, a result which has been well documented elsewhere (Ziel 1975; Mack 1976; Grady 1995). This review, however, has been able to group a number of different oestrogenic preparations together with approximately similar therapeutic efficiency, which gives added weight to the results of individual trials. Unscheduled biopsies were also more likely under unopposed oestrogen therapy since these are likely to be performed where there is concern about endometrial stimulation and consequent hyperplasia.

The incidence of irregular bleeding after six months of treatment with unopposed moderate or high dose oestrogen therapy was higher than when compared with placebo treatment and women were more likely not to adhere to their treatment regimen. The distinction between regular and irregular bleeding is difficult since scheduled bleeding is expected under sequential $\mathrm{O}+\mathrm{P}$ therapy. Further, women are likely to withdraw from a trial before completion if they are unhappy with unscheduled and unpredicted bleeding, which may lead to an underestimation of the rate. The distinction in the review between unscheduled bleeding occurring within 6 months and after six months of treatment was arbitrary and assessment in the latter group may have been measured at different times during treatment, for example, at seven months, 12 months or 24 months. Nevertheless, the included trials carefully distinguished between scheduled and unscheduled bleeding where these outcomes were measured. Sensitivity analysis also permitted a more robust assessment when a high proportion of the group withdrew from treatment. Bleeding at different time intervals after the initiation of treatment will be more precisely measured in the coming review on comparative dosage trials of oestrogen and progestogen.

The addition of progestogen to oestrogen replacement therapy in women with intact uteri significantly prevented the development of endometrial hyperplasia. The prevention of endometrial hyperplasia seemed to be related to type, duration and dose of progestogen administered. Sequential O + P therapy, with the progestogen administered for 12 days or more appeared to be more effective than shorter courses of progestogen although these regimens were not directly compared. The duration of progestogen in the included studies in this review ranged from 11 to 14 days and in one study the progestogen was given in the first 12 days of the oestrogen regimen rather than during the latter part of the oestrogen regimen (imitating the second half of the menstrual cycle). The requirement that doses of progestogen in sequential therapy need to be given for at least 10 days is confirmed by a large case-control study (Pike 1997).

Irregular bleeding occurred more frequently with continuous combined $\mathrm{O}+\mathrm{P}$ therapy when compared with unopposed oestrogen therapy but was less likely under sequential $\mathrm{O}+\mathrm{P}$ therapy when compared with unopposed oestrogen therapy. There is good evidence that this occurrence of irregular bleeding and spotting under continuous combined therapy persists and gradually decreases only within the first year after initiation of treatment and most women have achieved amenorrhoea by 12 months (MacLennan 1993). Further investigation for irregular bleeding such as hysteroscopy and endometrial biopsy should be considered if irregular bleeding persists beyond 12 months of treatment. Concern about bleeding on HRT is a major focus of women considering treatment (MacLennan 1992; Whitehead 1990; Rozenberg 1996) and counseling is required to elicit good compliance.

Unscheduled biopsies were performed more frequently in women with unopposed oestrogen treatment regardless of type of $\mathrm{O}+\mathrm{P}$ treatment probably because of concern about endometrial stimulation. Women were less likely to adhere to their unopposed $\mathrm{O}$ treatment regimen when compared with $\mathrm{O}+\mathrm{P}$ therapy either continuous or sequential.

Risk of endometrial hyperplasia or cancer was not significantly increased by $\mathrm{O}+\mathrm{P}$ regimens when compared with placebo although endometrial cancer is a rare event and an adequate assessment of this risk is unlikely to be made within the context of the limited time frame of the trials included in this review (maximum three years). Higher rates of endometrial hyperplasia after 24 months of treatment in the sequential $\mathrm{O}+\mathrm{P}$ group did not persist under sensitivity analysis after the exclusion of poorer quality studies. This finding clarifies the contradictory results of a recent meta- 
analysis of case control and cohort studies (Grady 1995). This meta-analysis reported that in three cohort studies and one RCT there was a decreased risk of endometrial cancer in users of oestrogen plus progestogen compared to non users but each of three case control studies reported a non-significant small increase in endometrial cancer risk associated with combination hormone use.

Irregular bleeding, however, was more likely under continuous combined $\mathrm{O}+\mathrm{P}$ therapy but not sequential $\mathrm{O}+\mathrm{P}$ therapy when compared with placebo although adherence to therapy did not differ between continuous combined $\mathrm{O}+\mathrm{P}$ therapy and placebo treatment groups. Nevertheless, women were more likely not to adhere to therapy when under sequential $\mathrm{O}+\mathrm{P}$ treatment than under placebo treatment.

Comparison of the type of progestogen regimen, continuous combined versus sequential, suggested that after 36 months of treatment endometrial hyperplasia was more likely under sequential treatment. There appeared to be an increasing duration of treatment-response effect. Although this result was based on only one study and should be treated with caution, two nonrandomised studies suggested that there may be a higher rate of hyperplasia with sequential therapy (Sturdee 1994; Beresford 1997). In most cases, the dose of progestogen used in the sequential regimens is higher than the dose used in combined continuous treatment. The daily exposure to any progestogen is obviously important in preventing endometrial hyperplasia over a long period. This evidence is critical given the long periods of time over which women may take hormone replacement therapy.

Comparison of the long cycle sequential therapy (progestogen given once every three months) with short cycle sequential therapy (progestogen given once a month) was mostly based on one study which was discontinued because of increased rates of hyperplasia in the long cycle treatment group. Their finding was not confirmed by one small study (Heikkinen 1997) and results from a prospective but non-randomised trial (Hirvonen 1995) show that further research is urgently needed in this area.

This review has compared oestrogen only regimens and both combined continuous and sequential oestrogen plus progestogen regimens but has not been able to adequately determine the best dose, duration and regimen of progestogen required to minimise the proliferative effect of unopposed oestrogen on the endometrium and prevent non adherence to treatment by keeping irregular bleeding to a minimum.

\section{REVIEWERS' CONCLUSIONS}

\section{Implications for practice}

The evidence that unopposed oestrogen therapy increases the risk of endometrial hyperplasia is consistently associated with the du- ration and strength of dose. Irregular bleeding and consequent treatment adherence problems may also result.

The addition of oral progestogens administered either cyclically or continuously for endometrial protection should be considered in women with an intact uterus. Endometrial hyperplasia may be less likely under a continuous combined regimen than a sequential regimen, in particular with long durations of therapy. Regular withdrawal bleeding is expected with a sequential regimen of $O$ $+\mathrm{P}$ but women appear to experience less irregular bleeding than with a continuous $\mathrm{O}+\mathrm{P}$ regimen. Irregular or unscheduled bleeding in the first year of continuous $\mathrm{O}+\mathrm{P}$ therapy does not need investigation but endometrial biopsy and hysteroscopy could be considered after this time.

In current practice, sequential regimens are often recommended as initial HRT for perimenopausal women, while women who have not menstruated for more than 1 year are recommended to commence on continuous regimens. These results should also be applied in the context of improvement of menopausal symptoms and also long term benefits of various regimens of hormone replacement therapy together with other adverse effects such as breast tenderness, abdominal cramps, weight gain and mood swings.

In women who cannot tolerate or use progestogens, unopposed oestrogen therapy can be considered, but follow up should include long term annual endometrial assessment.

\section{Implications for research}

Although this review has compared unopposed oestrogen, combined continuous and sequential regimens of $\mathrm{O}+\mathrm{P}$ with each other and placebo, it was not within the scope of the review to determine the exact type, dose and duration of progestogen therapy necessary to prevent endometrial stimulation without causing the unwanted adverse effect of irregular bleeding. Another Cochrane systematic review is planned to assess the effect that type, dose and duration of progestogen use has on endometrial stimulation and measure relative adherence to treatment and frequency of irregular bleeding. This review will be more useful if treatment is assessed over a prolonged period, for example, ten to twenty years.

The suggestion that combined continuous oestrogen-progestogen therapy is more protective in the prevention of endometrial stimulation than the sequential regimens should also be investigated further.

The suggestion that short cycle sequential oestrogen-progestogen therapy is more protective of the endometrium than long cycle sequential oestrogen-progestogen therapy (progestogen administered once every three months) should also be investigated further.

Progestogens administered via other routes, for example, as a nasal spray or cream, by intramuscular injection and via an intrauterine device are not in widespread use but should be evaluated thoroughly for efficacy, safety and acceptability as alternative methods 
of progestogen administration to be used in combination with oestrogen.

\section{POTENTIALCONFLICTOF I N T ER ES T}

There was no conflict of interest.

\section{ACKNOWLEDGEMENTS}

The authors acknowledge the helpful comments of those who refereed previous versions of progestogen and we are especially grateful to those authors of included trials who provided additional data for this review. We also thank Professor John France and Professor Alastair MacLennan for their assistance in grouping oestrogens according to approximate equivalence. Special thanks are due to Ms Sarah Hetrick, Review Group Coordinator, for her professionalism and help with the inevitable problems that arise, to Mrs Sue Furness, Trials Search Coordinator, for her assistance with identifying trials and to Mrs Sue Hall, Secretary of the Review Group, for her secretarial help.

\section{SOURCESOFSUPPORT}

\section{External sources of support}

- Health Research Council NEW ZEALAND

Internal sources of support

- Dept of Obstetrics and Gynaecology, University of Auckland NEW ZEALAND

\section{RE F E R E N C E S}

\section{References to studies included in this review}

Blumel 1994 \{published data only\}

Blumel JE, Roncagliolo ME, Gramegna G, Vasquez R, Estartus A, Tacla X, Brandt A. Double-blind study of the effect of continuous therapy with estradiol valerate and medroxyprogesterone acetate on menopausal symptoms, lipid profile and endometrial thickness [Estudio doble ciego del efecto sobre la sintomatologia menopausica, el perfil lipidico y el grosor endometrial de una terapia continua de valerato de estradiol mas acetato de medroxiprogesterona]. Revista Chilena de Obstetricia y Ginecologia 1994;59(5):354-60.

Byrjalsen 1992 \{published data only\}

Byrjalsen I, Thormann L, Riis BJ, Christiansen. Secretory endometrial protein PP14 in serum from post-menopausal women receiving continuous combined oestradio-cyproterone acetate: Correlation with serum hormone concentrations and bleeding patterns. Maturitas 1992;15:39-46.
CHART 1996 \{published data only\}

Speroff L, Rowan J, Symons J, Genant H, Wilborn W. The comparative effect on bone density, endometrium and lipids of continuous hormones as replacement therapy (CHART study). A randomized controlled trial. JAMA: Journal of the American Medical Association 1996;276(7):1397-403.

Ettinger 1992 \{published data only\} Ettinger B, Genant HK, Steiger P, Madvig P. Low-dosage micronized $17 \mathrm{~B}$-estradiol prevents bone loss in postmenopausal women. American Journal of Obstetrics \& Gynecology 1992;166:479-88.

Gelfand 1989 \{published data only\} Gelfand MM, Ferenczy A. A prospective 1-year study of estrogen and progestin in postmenopausal women: effects on the endometrium. Obstetrics \& Gynecology 1989;74:398-402.

Hagen 1982 \{published data only\} Hagen C, Christensen MS, Christiansen C, Stocklund K-E, Transbol 
I. Effects of two years' estrogen-gestagen replacement on climacteric symptoms and gonadotropins in the early postmenopausal period. Acta Obstetricia et Gynecologica Scandinavica 1982;61:237-41.

Harris 1991 \{published data only\}

Harris ST, Genant HK, Baylink DJ, Gallagher C, Karp SK, McConnell MA, Green EM, Stoll RW. The effects of estrone (ogen) on spinal bone density of postmenopausal women. Archives of Internal Medicine 1991;151:1980-4.

Heikkinen 1997 \{published data only\}

*Heikkinen J, Kyllonen E, Kurttila-Matero E, Wilen-Rosenqvist G, Lankinen KS, Rita H, Vaananen HK. HRT and exercise: effects on bone density, muscle strength and lipid metabolism. A placebo controlled 2-year prospective trial on two estrogen-progestin regimens in healthy postmenopausal women. Maturitas 1997;26:139-49.

Heikkinen JE, Finney JS, Lankinen KS, Wilen-Rosenqvist GH. Comparison of bleeding patterns and endometrial histology between a three monthly and monthly cycle HRT (abstract). Acta Obstetricia et Gynecologica Scandinavica Supplement Supplement 76(167 (4)), 82. 97. Acta Obstetricia et Gynecologica Scandinavica - Supplement 76(167 (4)), 82. 97. Acta Obstetricia et Gynecologica Scandinavica-Supplement 76(167 (4)), 82. 97. 1997;76(167 Suppl 4):83.

Luciano 1993 \{published data only\}

Luciano AA, De Souza MJ, Roy MP, Schoenfeld MJ, Nulsen JC, Halvorson CV. Evaluation of low-dose estrogen and progestin therapy in postmenopausal women. Journal of Reproductive Medicine 1993;38(3):207-14.

Marslew 1991 \{published data only\}

Marslew U, Riis BJ, Christiansen C. Desorgestrel in hormone replacement therapy: long-term effects on bone, calcium and lipid metabolism, climacteric symptoms, and bleeding. European Journal of Clinical Investigation 1991;21:601-7.

Marslew 1992 \{published data only\}

Marslew U, Overgaard K, Riis BJ, Christiansen C. Two new combinations of estrogen and progestogen for prevention of postmenopausal bone loss: long-term effects on bone, calcium and lipid metabolism, climacteric symptoms, and bleeding. Obstetrics \& Gynecology 1992; 79:202-10.

Mizunuma 1997 \{published data only\}

Mizunuma H, Okano H, Soda M, Kagami I, Miyamoto S, Tokizawa T, Honjo S, Ibuki Y. Prevention of postmenopausal bone loss with minimal uterine bleeding using low dose continuous estrogen/progestin therapy: a 2-year prospective study. Maturitas 1997; 27:69-76.

MSG 1994 \{published data only\}

Archer DF, Picker JH, Bottiglioni F for the Menopause Study Group. Bleeding patterns in postmenopausal women taking continuous combined or sequential regimens of conjugated estrogens with medroxyprogesterone acetate. Obstetrics \& Gynecology 1994;83(5):686-92.

Pickar JH, Archer DF. Is bleeding a predictor of endometrial hyperplasia in postmenopausal women receiving hormone replacement therapy. American Journal of Obstetrics \& Gynecology 1997;177:117883.

*Woodruff JD, Pickar JH for the Menopause Study Group. Incidence of endometrial hyperplasia in postmenopausal women taking conjugated estrogens (Premarin) with medroxyprogesterone acetate or conjugated estrogens alone. American Journal of Obstetrics \& Gynecology 1994;170(5):1213-23.

Notelovitz 1996 \{published data only\}

Genant HK, Lucas J, Weiss S, Akin M, Emkey R, McNaney-Flint H, Downs R, Mortola J, Watts N, Yang HM, Banav N, Brennan JJ, Nolan JC for the Estratab/Osteoporosis Group. Low-dose esterified estrogen therapy. Effects on bone, plasma estradiol concentrations, endometrium and lipid levels. Archives of Internal Medicine 1997; 157:2609-15

*Notelovitz M, Varner RE, Rebar RW, Fleischmann R, McIlwain HH, Schwartz SL, Sperling M, Wilborn W, Yang H-M, Silfen SL. Minimal endometrial proliferation over a two-year period in postmenopausal women taking $0.3 \mathrm{mg}$ of unopposed esterified estrogens. Menopause 1997;4(2):80-8.

Trabal JF, Lenihan JP, Melchione TE, Stoltz RR, Khairi S, Yang HM, van der Hoop RG. Low-dose unopposed estrogens: preliminary findings on the frequency and duration of vaginal bleeding in postmenopausal women receiving esterified estrogens over a two-year period. Menopause 1997;4(3):130-8.

Obel 1993 \{published data only\}

Obel EB, Munk-Jensen N, Svenstrup B, Bennett P, Micic S, HenrikNielsen R, Pors Nielsen S, Gydesen H, Jensen BM. A two-year double-blind controlled study of the clinical effect of combined and sequential postmenopausal replacement therapy and steroid metabolism during treatment. Maturitas 1993;16:13-21.

PEPI 1995 \{published data only\}

Bush TL, Espeland MA, Mebane-Sims I. The Postmenopausal Estrogen/Progestin Interventions (PEPI) Trial. Overview. Controlled Clinical Trials 1995;16:1S-2S.

Espeland MA, Bush TL, Mebane-Sims I, Stefanick ML, Johnson S, Sherwin R, Waclawiw M. Rationale, design, and conduct of the PEPI Trial. Controlled Clinical Trials 1995;16:3S-19S.

Johnson S, Mebane-Sims I, Hogan PE, Stoy DB. Recruitment of postmenopausal women in the PEPI Trial. Controlled Clinical Trials 1995;16:20S-35S.

Miller VT, Byington RL, Espeland MA, Langer R, Marcus R, Shumaker S, Stern MP. Baseline characteristics of the PEPI participants. Controlled Clinical Trials 1995;16:54S-65S.

Wood PD, Kessler G, Lippel K, Stefanick ML, Wasilauskas CH, Wells HB. Physical and laboratory measurements in the PEPI Trial. Controlled Clinical Trials 1995;16:36S-53S.

*Writing Group for the Pepi trial. Effects of hormone replacement therapy on endometrial histology in postmenopausal women. The Postmenopausal Estrogen/Progestin Interventions (PEPI) Trial. JAMA: Journal of the American Medical Association 1996;275(5):3705

Scandinavia 1996 \{published and unpublished data\} Cerin A, Heldaas K, Moeller B for the Scandinavian Long Cycle Study Group. Adverse endometrial effects of long-cycle estrogen and progestogen replacement therapy (letter). New England of Jourmal of Medicine 1996;334(10):668-9.

Williams 1990 \{published data only\} Williams SR, Frenchek B, Speroff T, Speroff L. A study of combined continuous ethinyl estradiol and norethindrone acetate for 
postmenopausal hormone replacement. American Journal of Obstetrics \& Gynecology 1990;162:438-46.

\section{References to studies excluded from this review \\ Aoki 1990}

Aoki T, Asai T. Assessment of oestrogen replacement therapy with conjugated oestrogens by histological evaluation of the endometrium in 205 women (abstract). 6th International Congress on the Menopause, Bangkok, Thailand. 1990:151.

\section{Campbell 1977}

Campbell S, Whitehead M. Oestrogen therapy and the menopausal syndrome. Clinics in Obstetrics \& Gynaecology 1977;4(1):31-47.

\section{Heytmanek 1990}

Heytmanek G. Continuous hormone replacement therapy with oestradiol valerate alone and in combination with cyproterone acetate: clinical and endometrial findings (abstract). 6th International Congress on the Menopause, Bangkok, Thailand. 1990:086.

\section{Nachtigall 1979}

Nachtigall LE, Nachtigall RH, Nachtigall RD, Beckman EM. Estrogen replacement therapy II: A prospective study in the relationship to carcinoma and cardiovascular and metabolic problems. Obstetrics and Gynecology 1979;54(1):74-9.

\section{Volpe 1986}

Volpe A, Facchinetti F, Grasso A, Petraglia F, Campanini D, Genazzani AR. Benefits and risks of different hormonal replacement therapies in post-menopausal women. Maturitas 1986;6:327-34.

\section{Additional references}

\section{Ansbacher 1993}

Ansbacher R. Bioequivalence of conjugated estrogen products. Clinical Pharmacokinetics 1993;24(4):271-4.

\section{Ansbacher 1994}

Ansbacher R. Estrogens: conjugated and esterified therapeutic substitution. Female Patient 1994;19:14-20.

\section{Antunes 1979}

Antunes CM, Strolley PD, Rosenshein NB, Davies JL, Tonascia JA, Brown C, Burnett L, Rutledge A, Pokempner M, Garcia R. Endometrial cancer and estrogen use. Report of a large case-control study. New England Journal of Medicine 1979;300(1):9-13.

\section{Beresford 1997}

Beresford SA, Weiss NS, Voight LF, McKnight B. Risk of endometrial cancer in relation to use of oestrogen combined with cyclic progestogen therapy in postmenopausal women. Lancet 197;349:458-61.

\section{Cust 1990}

Cust MP, Gangar KF, Hillard TC, Whitehead MI. A risk benefit assessment of oestrogen therapy in post menopausal women. Drug Safety 1990;5:345-58.

\section{Ellerington 1992}

Ellerington MC, Whitecroft SIV, Whitehead MI. HRT: Developments in therapy. British Medical Bulletin 1992;48:401-25.

France 1998

France J. Personal communication July 1998.

\section{Gardan 1977}

Gardan J, Reagan JW, Finkle WD. Oestrogen and endometrial carcinoma: An independent pathology review supporting original size estimate. New England Journal of Medicine 1977;297:570.

\section{Grady 1995}

Grady D, Gebretsadik T, Kerlikowske K, Ernster V, Petitti D. Hormone replacement therapy and endometrial cancer risk: a metaanalysis. Obstetrics \& Gynecology 1995;85:304-13.

\section{Hirvonen 1995}

Hirvonen E, Salmi T, Puolakka J, Heikkinen J, et al. Can progestin be limited to every third month only in postmenopausal women taking estrogen?. Maturitas 1995;21:39-44.

\section{Kurman 1985}

Kurman RJ, Kaminshi PF, Norm HJ. The behaviour of endometrial hyperplasia. A long term study of 'untreated' hyperplasia in $170 \mathrm{pa}-$ tients. Cancer 1985;56:403-12.

\section{Mack 1976}

Mack TM, Pike MC, Henderson BE, Pfeffer RI, Gerkins VR, Arthur M, Brown SE. Estrogens and endometrial cancer in a retirement community. New England Journal of Medicine 1976;294:1262-7.

\section{MacLennan 1992}

MacLennan AH, MacLennan A, O’Neill S, Kirkgard Y, Wenzel $S$, Chambers HM. Oestrogen and cyclical progestogen in postmenopausal hormone replacement therapy. Medical Journal of Australia 1992;157(3):167-70.

\section{MacLennan 1993}

MacLennan AH, MacLennan A, Wenzel S, Chambers HM, Eckert K. Continuous low-dose oestrogen and progestogen hormone replacement therapy: a randomised trial. Medical Journal of Australia 1993;159:102-6.

\section{MacLennan 1998}

MacLennan AH. Personal communication 16 March 1998; 13 August 1998.

\section{O'Connell 1998}

O'Connell D, Robertson J, Henry D, Gillespie W. A systematic review of the skeletal effects of estrogen therapy in postmenopausal women. II An assessment of treatment effects. Climacteric 1998;1: $112-23$.

Pike 1997

Pike MC, Peters RK, Cozen W, Probst-Hensch NM, Felix JC, Wan PC, Mack TM. Estrogen-progestin replacement therapy and endometrial cancer. Journal of the National Cancer Institute 1997;89: 1110-6.

\section{Rozenberg 1996}

Rozenberg S, Kroll M, Vandromme J. Decision factors influencing hormone replacement therapy. British Journal of Obstetrics \& Gynaecology 1996;103:92-8.

\section{Smith 1977}

Smith DC, Prentice R, Thompson DJ, Herrmann WL. Association of exogenous oestrogen and endometrial carcinoma. New England Journal of Medicine 1977;293:1164-7.

\section{Sturdee 1994}

Sturdee DW, Barlow DH, Ulrich LG, Wells M, Gydesen H, Campbell M, O'Brien K, Vessey M. Is the timing of withdrawal bleeding a 
guide to endometrial safety during sequential oestrogen-progestogen replacement therapy?. Lancet 1994;344(8928):979-82.

Terakawa 1997

Terakawa N, Kigawa J, Taketani Y, Yoshikawa H, Yajima A, Noda $\mathrm{K}$. The behaviour of endometrial hyperplasia: a prospective study. Journal of Obstetrics \& Gynaecology Research 1997;28:223-30.

\section{Udoff 1995}

Udoff L, Langenberg P, Adashi E. Combined continuous hormone replacement therapy: a clinical review. Obstetrics \& Gynecology 1995; 86:306-16.

\section{Whitehead 1977}

Whitehead MI, Queen J, Beard RN, Minardi J, Campbell S. The effects of cyclical oestrogen therapy and sequential oestrogen therapy on the endometrium of postmenopausal women. Acta Obstetricia et Gynecologica Scandinavica Supplement 1977;65:91-101.

\section{Whitehead 1981}

Whitehead MI, Townsend PT, Pryse-Davies J, Ryder TA, King RJB. Effects of estrogens and progestins on the biochemistry and morphology of the postmenopausal endometrium. New England Journal of Medicine 1981;305:1599-605.

\section{Whitehead 1987}

Whitehead MI, Fraser D. Controversies concerning the safety of estrogen replacement therapy. American Journal of Obstetrics \& Gynecology 1987;156(5):1313-22.

\section{Whitehead 1990}

Whitehead MI, Hillard TC, Crook D. The role and use of progestogens. Obstetrics \& Gynecology 1990;75(Suppl 4):59S-76S.

\section{Ziel 1975}

Ziel HK, Finkle WD. Increased risk of endometrial carcinoma amongst users of conjugated oestrogens. New England Journal of Medicine 1975;293:1167-70.

* Indicates the major publication for the study

T A B LE S

\section{Characteristics of included studies}

\section{Study}

Methods

\section{Blumel 1994}

Randomisation method not stated.

Single centre, parallel group design with double blinding.

Number of patients randomised: $\mathrm{n}=50$.

Number of withdrawals: $\mathrm{n}=2$ (lost to follow up from the placebo group).

No power calculation given and analysis not by intention to treat.

Source of funding not reported.
Patients with menopausal symptoms, mean ages 51 and 53.5 years, recruited from climacteric clinic at the Barros Luco-Trudeau Hospital in Chile.

Inclusion criteria: amenorrhoea for 6 months, $\mathrm{FSH}>40 \mathrm{mUI} / \mathrm{ml}$ and plasma estradiol $<50 \mathrm{pg} / \mathrm{ml}$. 


\section{Characteristics of included studies (Continued)}

Exclusion criteria: chronic illness, hormone dependant malignancies, use of oestrogen, progesterone or medications that could modify the lipid profile within the last 6 months.

\begin{tabular}{ll}
\hline Interventions & $\begin{array}{l}\text { Treatment: Oestradiol valerate (EV) 2mg + medroxyprogesterone acetate (MPA) 2.5mg (continuous) } \\
\text { Control: Placebo } \\
\\
\text { Duration: } 6 \text { months }\end{array}$ \\
\hline Outcomes & Bleeding patterns at 6 months follow up \\
\hline Notes & Publication (in Spanish) translated by Christine Aguilar, San Antonio Cochrane Centre. \\
\hline Allocation concealment & B \\
\hline
\end{tabular}

\section{Study Byrjalsen 1992}

Methods

Randomisation method by sealed, opaque, sequentially numbered identical envelopes.

Single centre, parallel group design with double blinding.

Number of patients randomised: $\mathrm{n}=50$.

Number of withdrawals: $n=7$ ( 1 from the placebo group because of illness unrelated to treatment and 6 from the treatment group, 3 because of bleeding, 1 oedema and 2 because of lack of time).

No power calculation reported and analysis not by intention to treat.

Source of funding: antiserum supplied by Schering AG, Germany.

Participants $\quad$ Postmenopausal patients from Denmark (clinic not stated), aged 45 to 57 years, who had undergone a natural menopause 6 months to 3 years previously.

Exclusion criteria: past or present diseases or use of medication known to influence the lipid metabolism or body composition, clinical or laboratory evidence of conditions that could influence the parameters to be studied or contraindicate the trial medication.

\begin{tabular}{ll}
\hline Interventions & Treatment: EV 2mg + Cyproterone acetate (CPA) 1mg 1 tablet daily \\
& Control: Placebo 1 tablet daily \\
& Duration: 2 years \\
\hline Outcomes & Frequency of hyperplasia \\
& Irregular bleeding within the first three months \\
& Irregular bleeding at 18 months after starting treatment \\
& Non adherence to treatment \\
\hline Notes & Author contacted with queries about data and reply received. \\
\hline Allocation concealment & A \\
\hline
\end{tabular}

Study

Methods

\section{CHART 1996}

Randomised, double blind, placebo controlled, multicentre study.

Method of randomisation and allocation concealment: randomisation code prepared by Biometrics Department in blocks of 9 with computer generated random numbers.

Number of patients randomised: $\mathrm{n}=1265$

Number of withdrawals: $\mathrm{n}=570$ (at 2 years) based on losses to follow up and stopping rule. Excluding the $10 \mathrm{mcg}$ EE2 group (treatment terminated due to high incidence of endometrial hyperplasia), $73 \%$ of subjects completed the study.

Power calculation for sample size reported but analysis not by intention to treat.

Source of funding: Parke-Davis Pharmaceutical Research.

Participants Country: USA (65 study centres participated).

Participants: women aged 40 years or older who had undergone spontaneous menopause within the last five years and who had an intact uterus.

Inclusion criteria: Healthy volunteers; FSH greater or equal to $40 \mathrm{IU} / \mathrm{L}$; estradiol less than or equal to 73 $\mathrm{pmol} / \mathrm{L}$; atrophic endometrium; no major illnesses. 


\section{Characteristics of included studies (Continued)}

Exclusion criteria: Baseline vaginal bleeding; baseline mammography suggestive of malignant disease; chronic use of medications that affect bone calcium metabolism or significant vasomotor symptoms that required medical treatment.

No participant was to have taken oral or transdermal oestrogen replacement therapy for 6 months prior to randomisation.

\begin{tabular}{ll}
\hline Interventions & Interventions: \\
1) $1 \mathrm{mcg}$ daily of oral ethinyl estradiol (EE2) plus $0.2 \mathrm{mg}$ of oral norethindrone acetate (NA) continuously \\
2) $2.5 \mathrm{mcg}$ daily of oral ethinyl estradiol (EE2) plus $0.5 \mathrm{mg}$ of oral norethindrone acetate (NA) continuously \\
3) $5 \mathrm{mcg}$ daily of oral ethinyl estradiol (EE2) plus $1 \mathrm{mg}$ of oral norethindrone acetate (NA) continuously \\
4) $10 \mathrm{mcg}$ daily of oral ethinyl estradiol (EE2) plus $1 \mathrm{mg}$ of oral norethindrone acetate (NA) \\
continuously \\
5) $1 \mathrm{mcg}$ daily of oral ethinyl estradiol (EE2) continuously \\
6) $2.5 \mathrm{mcg}$ daily of oral ethinyl estradiol (EE2) continuously \\
7) $5 \mathrm{mcg}$ daily of oral ethinyl estradiol (EE2) continuously \\
8) $10 \mathrm{mcg}$ daily of oral ethinyl estradiol (EE2) continuously \\
Control group: placebo \\
Duration: 2 years \\
Eutcomes \\
Endometrial biopsy at baseline and after 6,12,18 and 24 months of therapy. \\
Botes & were terminated from the study early owing to a high rate of hyperplasia for that treatment group. \\
\hline Allocation concealment & A
\end{tabular}

Study $\quad$ Ettinger 1992

Methods Randomisation method not stated.

Single centre, parallel group dose-ranging design with double blinding.

Number of patients randomised: not clear.

Number of patients analysed: $n=63$ ( $n=52$ with intact uterus).

No power calculation reported and analysis not by intention to treat.

Source of funding: Mead Johnson Laboratories, Division of Bristol Myers.

Participants Country: USA.

Postmenopausal mostly white women, aged 40 to 58 years, recruited from advertisements and physician referrals.

Inclusion criteria: Within 5 years of menopause (confirmed by bilateral oophorectomy or no menses for $>=$ 6 months; oestrogen deficiency (confirmed by FSH>40 u/L); body weight within $20 \%$ of ideal for height (Metropolitan Life Company Tables).

Exclusion criteria: Presence of diseases/conditions known to affect skeletal health such as thyroid/parathyroid disorders or other disorders of calcium homeostasis; use of anticonvulsants or glucocorticoids; evidence of renal, hepatic, cardiac or malignant diseases.

\begin{tabular}{ll}
\hline Interventions & Treatment: (1) $0.5 \mathrm{mg}$ micronised 17B-oestradiol + calcium carbonate supplements daily on 23 of 28 days. \\
& (2) $1.0 \mathrm{mg}$ micronised 17B-oestradiol + calcium carbonate supplements daily on 23 of 28 days \\
& (3) $2.0 \mathrm{mg}$ micronised 17B-oestradiol + calcium carbonate supplements daily on 23 of 28 days \\
& Control: Placebo + calcium carbonate supplements daily on 23 of 28 days \\
& Duration: 18 months \\
\hline Outcomes & Frequency of hyperplasia (from endometrial biopsy) \\
& Frequency of unexpected bleeding \\
\hline Notes & Eleven women (17.5\%) had previous hysterectomy so above outcomes analysed in a subgroup of 52 women. \\
& Primary objective of the study was to evaluate bone loss. \\
\hline Allocation concealment & B \\
\hline $\begin{array}{l}\text { Hormone replacement therapy in postmenopausal women: endometrial hyperplasia and irregular bleeding } \\
\text { Copyright @ } 2004 \text { The Cochrane Collaboration. Published by John Wiley \& Sons, Ltd }\end{array}$
\end{tabular}




\section{Characteristics of included studies (Continued) \\ Study \\ Gelfand 1989}

Methods
Computerised random assignment controlled by pharmacist.

Single centre, parallel group design, double blinding.

Number of women randomised: $\mathrm{n}=173$

Number of withdrawals: $n=78$ ( $n=24: 1$ year of treatment not complete when study terminated and not included in analysis; $\mathrm{n}=54$ : withdrew during the study for medical reasons but withdrawals not comparable between treatment groups $(9.5 \%, 9 \%, 2 \%$ and $28 \%$ respectively))

No power calculation reported and no analysis by intention to treat

Source of funding: Ayerst, McKenna and Harrison
Postmenopausal women aged 47 to 57 years recruited from Menopause Clinic in Montreal Canada.

Other inclusion criteria: No contraindication for HRT; moderate vasomotor menopausal symptoms; no bleeding for a minimum of 6 months; normotensive, normolipidemic; within $20 \%$ of their accepted weight for height.

Exclusion criteria: diabetes; thromboembolic disease; history of carcinoma, alcohol or drug abuse; other chronic illness or treatment with chronic medication; ERT $<6$ months prior to study.

Interventions

Treatment: 1) $0.625 \mathrm{mg}$ daily of oral conjugated equine estrogen (CEE) for 25 days of a 30 day cycle, plus placebo

2) $0.625 \mathrm{mg}$ daily of oral conjugated equine estrogen (CEE) for 25 days of a 30 day cycle, plus $5 \mathrm{mg}$ oral medroxyprogesterone acetate added to the last 11 days of the CEE cycle

3) $1.25 \mathrm{mg}$ daily of oral conjugated equine estrogen (CEE) for 25 days of a 30 day cycle, plus placebo

4) $1.25 \mathrm{mg}$ daily of oral conjugated equine estrogen (CEE) for 25 days of a 30 day cycle, plus $5 \mathrm{mg}$ oral medroxyprogesterone added to the last 11 days of the CEE cycle

Control: no control

Duration: 1 year

Outcomes Frequency of hyperplasia (endometrial biopsy at baseline, six and twelve months).

Irregular bleeding patterns at six and twelve months.

Non-adherence to therapy.

Notes

Allocation concealment A

Study

Methods

\section{Hagen 1982}

Randomisation by random sampling numbers but concealment of allocation not reported.

Single centre, parallel group design, placebo controlled with double blinding.

Number of patients randomised: $\mathrm{n}=119$ ( 4 arms from of a much larger study).

Number of withdrawals: $n=22$ ( 5 excluded post randomisation for intercurrent disease ( 3 placebo and 2 treatment) and 17 losses to follow up: 14 for personal reasons ( 5 placebo and 9 treatment) and 3 moved from the area).

No power calculation reported and analysis not by intention to treat.

Source of funding: Leo Pharmaceuticals, Medical Research Council, Direktor Jacob Madsens og hustru Olga Madsens Fund; Danish Hospital Foundation for Medical Research; Novo Foundation; CC Klestrup og hustru Henriette Klestrups Mindelegat; P Carl Petersens Fund; Nordisk Gjenforsikrings Selskabs Jubilaeumsfond; Fabrikant Einar Willumsens Mindelegat; Grosserer AV Lykfeldt or hustrus Legat.

Participants

Country: Denmark.

Women, aged 44 to 54 years, whose menstrual bleeding had stopped spontaneously within the last $1 / 2$ to 3 years and who were not receiving treatment with gonadal hormones, thiazides or other drugs known to influence calcium metabolism after the menopause.

Exclusion criteria: gynecological operation; elevated blood pressure (systolic above 170, diastolic above $105 \mathrm{mmHg}$ ); abnormal blood chemistry; pathological cervical smear or any disease which contraindicated the medications used in the trial. 


\section{Characteristics of included studies (Continued)}

Interventions Treatment: Trisequens forte (17B-oestradiol $4 \mathrm{mg}+$ estriol $2 \mathrm{mg}$ days $1-12,17 \mathrm{~B}$-oestradiol $4 \mathrm{mg}+$ estriol $2 \mathrm{mg}$ + NETA $1 \mathrm{mg}$ days $13-22$ and 17B-oestradiol $1 \mathrm{mg}+$ estriol $0.5 \mathrm{mg}$ days 23-28) (half of this group also took bendroflumethiazide $5 \mathrm{mg}$ /day).

Control: Placebo (half of this group also took bendroflumethiazide).

Duration: 2 years

\begin{tabular}{ll}
\hline Outcomes & Irregular bleeding patterns during treatment. \\
\hline Notes & All patients took 1 Sandoz calcium $(500 \mathrm{mg})$ tablet daily. The publication originally included 4 groups: \\
& Trisequens + thiazide, Trisequens + placebo, Placebo + thiazide, Placebo + placebo. Since the mean changes \\
& during the 2 years of treatment were almost identical in the 2 Trisequens groups and the 2 placebo groups, \\
& these groups were combined for other evaluations. The study was part of a larger study with 315 women and \\
& 10 groups assessing bone loss. \\
\hline Allocation concealment & B
\end{tabular}

Allocation concealment $\mathrm{B}$

\begin{tabular}{|c|c|}
\hline Study & Harris 1991 \\
\hline Methods & $\begin{array}{l}\text { Randomisation method not reported but study medication concealed in identical bottles. } \\
\text { Multicentre ( } 3 \text { study sites), parallel group design, placebo controlled with double blinding. } \\
\text { Number of patients randomised: } n=156 \text {. } \\
\text { Number of withdrawals: } n=36 \text { ( } 28 \text { lacked TBD values, } 2 \text { did not comply and } 6 \text { had baseline measurements } \\
\text { outside the time limits specified). } \\
\text { Power calculation for sample size performed and analysis by intention to treat for the outcomes reported in } \\
\text { this review. } \\
\text { Source of funding: Not reported. }\end{array}$ \\
\hline Participants & $\begin{array}{l}\text { Country: USA } \\
\text { Postmenopausal patients with mean age } 51 \text { years recruited from } 3 \text { study sites. } \\
\text { Inclusion criteria: no use of sex hormones for previous } 3 \text { months; last normal period or bilateral oophorec- } \\
\text { tomy for benign conditions }>2 \text { months previously; FSH levels within the postmenopausal range; no con- } \\
\text { traindications to oestrogen therapy; no drug treatment (except sex steroids or calcium) for osteoporosis }<1 \\
\text { year before entry into the study; resting supine } \mathrm{BP}<=160 / 90 \mathrm{~mm} \mathrm{Hg} \text { at first visit; weight within } 125 \% \text { of } \\
\text { upper limit of Metropolitan Insurance Company reference weights; spinal bone mineral content measured } \\
\text { by tomography >=80mg/cm } 3 \text { at first study visit. } \\
\text { Exclusion criteria: diseases or conditions that might affect bone or calcium metabolism or gastrointestinal } \\
\text { absorption; requirement for medication that might interfere with oestrogen metabolism or efficacy or calcium } \\
\text { or bone metabolism; treatment with hypolipidemic agents or ketoconazole; use of fluoride for osteoporosis } \\
\text { at any time. }\end{array}$ \\
\hline
\end{tabular}

Interventions $\quad$ Treatment: (1) Oestrone sulphate $0.3 \mathrm{mg}+2.5 \mathrm{~g}$ calcium carbonate daily for 25 days, followed by 6 days without treatment

(2) Oestrone sulphate $0.625 \mathrm{mg}+2.5 \mathrm{~g}$ calcium carbonate daily for 25 days +6 days with no treatment

(3) Oestrone sulphate $1.25 \mathrm{mg}+2.5 \mathrm{~g}$ calcium carbonate daily for 25 days +6 days with no treatment

Control: Placebo with same regimen

Duration: 2 years

\begin{tabular}{ll}
\hline Outcomes & $\begin{array}{l}\text { Frequency of hyperplasia at } 2 \text { years follow up } \\
\text { Frequency of irregular bleeding } \\
\text { Non adherence to therapy }\end{array}$ \\
\hline Notes & $\begin{array}{l}\text { Author contacted for clarification of data relating to adherence to therapy and reviewer was referred to Abbott } \\
\text { Laboratories. Abbott Laboratories have not replied so adherence to therapy is not included in the review. }\end{array}$ \\
\hline Allocation concealment & B \\
\hline
\end{tabular}

Study

Heikkinen 1997

Methods Randomisation method not stated.

Hormone replacement therapy in postmenopausal women: endometrial hyperplasia and irregular bleeding

Copyright ( 2004 The Cochrane Collaboration. Published by John Wiley \& Sons, Ltd 


\section{Characteristics of included studies (Continued)}

Single centre, parallel group, blinding unclear.

Number of women randomised: $\mathrm{n}=78$.

Number of women excluded: $\mathrm{n}=2$.

No power calculation or intention to treat analysis.

Source of funding: Orion Corporation.

\begin{tabular}{ll}
\hline Participants & Country: Finland \\
& 78 healthy women, aged 49 to 55 , in early menopause recruited from the city of Oulu in Finland. \\
& Inclusion criteria: $0.5-3$ years postmenopausal (confirmed by FSH), without previous HRT,without con- \\
& traindications for HRT. \\
& Exclusion criteria: specified diseases. \\
\hline Interventions & Treatment: \\
& (1) EV 2mg (day 1-21) + MPA 10mg (day 12-21) \\
& (2) EV 2mg (day 1-84) + MPA 20mg (day 71-84) \\
& Control: Placebo \\
& Duration: 2 years \\
\hline Outcomes & Hyperplasia at 2 years \\
& Irregular bleeding (data not published) \\
& Adherence to treatment \\
& Published trial supplied by drug company, Orion Corporation, which manufactures Tridestra, a long cycle \\
& sequential O + P treatment. \\
Nhe primary outcomes of this study were effects of HRT and exercise on bone density, muscle strength and & lipid metabolism. Hyperplasia and adherence to treatment were secondary outcomes. \\
\hline Allocation concealment & B \\
\hline
\end{tabular}

\section{Study}

Methods

\section{Luciano 1993}

Randomisation method not stated.

Single centre, parallel group design with double blinding.

No of women randomised: $\mathrm{n}=36$.

Number of withdrawals: $\mathrm{n}=7$.

No power calculation performed and no intention to treat analysis

Source of funding: Upjohn (in part)

\begin{tabular}{ll}
\hline Participants & Postmenopausal women were recruited from newspaper advertisements and letters to GPs in Farmington, \\
& Connecticut. \\
& Inclusion criteria: intact uterus, no contradindication to HRT, last menses at least one year prior, no HRT \\
& for at least 6 months prior, oestradiol $<35 \mathrm{pg} / \mathrm{mL}$ and FSH $<50 \mathrm{mIU} / \mathrm{mL}$. \\
& No exclusion criteria stated. \\
\hline Interventions & Treatment 1: Continuous $\mathrm{O}+\mathrm{P}(0.625 \mathrm{mg} \mathrm{CEE}+2.5 \mathrm{mg} \mathrm{MPA})$ \\
& Treatment 2: Continuous $\mathrm{O}+\mathrm{P}(0.625 \mathrm{mg} \mathrm{CEE}+5.0 \mathrm{mg} \mathrm{MPA})$ \\
& Treatment 3: Sequential O $+\mathrm{P}(0.625 \mathrm{mg}$ CEE days $1-25+5.0 \mathrm{mg}$ MPA days $14-25)$ \\
& Duration: 1 year \\
\hline Outcomes & Frequency of irregular bleeding \\
\hline Notes & \\
\hline Allocation concealment & B \\
\hline
\end{tabular}

Study MSG 1994

Methods

Methods of randomisation and allocation: computer generated schedule with packaged coded medication. Multicentre (99 sites), double-blind with parallel group design, placebo controlled.

Number of patients randomised: $\mathrm{n}=1724$.

Number of withdrawals: $n=255$ after 1 year of follow up; $n=339$ after 2 years of follow up.

Hormone replacement therapy in postmenopausal women: endometrial hyperplasia and irregular bleeding

Copyright ( 2004 The Cochrane Collaboration. Published by John Wiley \& Sons, Ltd 


\section{Characteristics of included studies (Continued)}

Power calculation for sample size performed but analysis not by intention to treat.

Source of funding: Wyeth-Ayerst Research.

Participants

Countries: USA and Europe

Healthy women aged 45-65 years with an intact uterus were recruited from 99 sites.

Inclusion criteria: Last natural menstrual cycle at least 12 months before the baseline screening; FSH higher than the lower limit for postmenopausal women for the given laboratory; no use of oestrogen- or progestogencontaining medication for at least 2 weeks before the pre study screening.

Exclusion criteria: Any contraindication for oestrogen or progstagen use, or if they had used any oestrogen containing medication within three months of entry; major medical illness, liver, kidney or diabetes; hypertension, systolic blood pressure greater than $160 \mathrm{mmHg}$ or diastolic pressure greater than $90 \mathrm{mmHg}$; abnormal cervical cytology or endometrial hyperplasia at baseline biopsy.

\begin{tabular}{ll}
\hline Interventions & Interventions: \\
& 1) $0.625 \mathrm{mg}$ per day of conjugated equine estrogen (CEE), plus placebo \\
2) $0.625 \mathrm{mg}$ per day of CEE plus $2.5 \mathrm{mg}$ per day of medroxyprogesterone acetate (MPA) continuous \\
3) $0.625 \mathrm{mg}$ per day of CEE plus $5 \mathrm{mg}$ per day of medroxyprogesterone acetate (MPA) continuous \\
4) $0.625 \mathrm{mg}$ per day of CEE plus $5 \mathrm{mg}$ per day of (MPA) last 14 days of the cycle (days 15-28), plus placebo \\
(days $1-14)$ \\
5) $0.625 \mathrm{mg}$ per day of CEE plus $10 \mathrm{mg}$ per day of (MPA) last 14 days of the cycle (days 15-28), plus placebo \\
(days 1-14) \\
Control: No placebo group - Oestrogen only was compared with different regimens of oestrogen plus \\
progestagen. \\
Duration: one year (13 cycles) \\
\hline Futcomes \\
end of cycles 6 and 13). \\
Frequency of irregular bleeding or spotting (number of cycles). \\
\hline If hyperplasia was confirmed, the patient was withdrawn from the study and given appropriate treatment. \\
\hline Allocation concealment & A
\end{tabular}

\begin{tabular}{|c|c|}
\hline Study & Marslew 1991 \\
\hline Methods & $\begin{array}{l}\text { Boxes of medication randomly numbered by independent person and distributed to participants successively. } \\
\text { Single centre, parallel group design, placebo controlled and blinding for measurements and calculations (not } \\
\text { participants). } \\
\text { Number of patients randomised: } n=73 \text {. } \\
\text { Number of withdrawals: } n=16 \text { ( } 5 \text { from } 1 \text { st treatment group: } 3 \text { because of adverse events, } 1 \text { because of lack } \\
\text { of time, } 1 \text { from illness unrelated to treatment; } 7 \text { from } 2 \text { nd treatment group: } 6 \text { because of adverse events, } 1 \\
\text { for personal reasons; } 4 \text { from placebo group: } 1 \text { for menopausal symptoms, } 1 \text { for personal reasons, } 1 \text { because } \\
\text { of lack of time and } 1 \text { moved). } \\
\text { No power calculation reported and analysis not by intention to treat. } \\
\text { Source of funding: Danish Medical Research Council; Organon. }\end{array}$ \\
\hline Participants & $\begin{array}{l}\text { Country: Denmark } \\
\text { Healthy postmenopausal women, aged } 45-54 \text { years, with a menopausal duration of } 6 \text { months to } 3 \text { years and } \\
\text { no history of any disease or medication known to influence the variables studied, were recruited from the } \\
\text { Glostrup hospital area. } \\
\text { Exclusion criteria not reported. }\end{array}$ \\
\hline Interventions & $\begin{array}{l}\text { Treatment: (1) } 17 \mathrm{~B} \text {-oestradiol } 1.5 \mathrm{mg} \text { on days } 1-12 \text { and } 17 \mathrm{~B} \text {-oestradiol } 1.5 \mathrm{mg}+\text { desogestrel } 150 \mathrm{ug} \text { on days } \\
13-24 \\
\text { (2) EV } 2 \mathrm{mg} \text { on days } 1-11 \text { and EV } 2 \mathrm{mg}+\text { MPA } 10 \mathrm{mg} \text { on days } 12-21 \\
\text { Control: Placebo }\end{array}$ \\
\hline
\end{tabular}

Hormone replacement therapy in postmenopausal women: endometrial hyperplasia and irregular bleeding

Copyright $\odot 2004$ The Cochrane Collaboration. Published by John Wiley \& Sons, Ltd 


\section{Characteristics of included studies (Continued)}

\begin{tabular}{ll} 
& Duration: 2 years \\
\hline Outcomes & $\begin{array}{l}\text { Frequency of irregular bleeding } \\
\text { Non-adherence to therapy }\end{array}$ \\
\hline Notes & $\begin{array}{l}\text { This is Study B of } 2 \text { consecutive studies conducted in the same population in accordance with similar } \\
\text { protocols. }\end{array}$ \\
\hline Allocation concealment & A \\
\hline
\end{tabular}

\begin{tabular}{|c|c|}
\hline Study & Marslew 1992 \\
\hline Methods & $\begin{array}{l}\text { Randomisation and concealment of allocation identical to Marslew } 1991 \text { study. } \\
\text { Single centre, parallel group and placebo controlled design with single blinding (assessor, not participants). } \\
\text { Number of patients randomised: } n=75 \text {. } \\
\text { Number of withdrawals: } n=13 \text { ( } 6 \text { from treatment } 1 \text { group: } 3 \text { because of persistent bleeding, } 2 \text { because of lack } \\
\text { of time and } 1 \text { because of oedema of the legs; } 6 \text { from treatment } 2 \text { group: } 2 \text { because of bleeding, } 2 \text { because of } \\
\text { headache, } 1 \text { from anxiety and } 1 \text { from unrelated illness; } 1 \text { from the placebo group because of thyrotoxicosis). } \\
\text { No power calculation reported and analysis not by intention to treat. } \\
\text { Source of funding: Danish Medical Council and Schering A/S. }\end{array}$ \\
\hline Participants & $\begin{array}{l}\text { Country: Denmark } \\
\text { Healthy postmenopausal women, aged } 45-54 \text { years, with a menopausal duration of } 6 \text { months to } 3 \text { years and } \\
\text { no history of any disease or medication known to influence the variables studied, were recruited from the } \\
\text { Glostrup hospital area. } \\
\text { Exclusion criteria not reported. }\end{array}$ \\
\hline Interventions & $\begin{array}{l}\text { Treatment: (1) Continuous EV 2mg + CPA 1mg } \\
\text { (2) Continuous EV 2mg + sequential levonorgestrel (LNG) 75ug (days 17-28) } \\
\text { Control: Continuous placebo } \\
\text { Duration: } 2 \text { years }\end{array}$ \\
\hline Outcomes & $\begin{array}{l}\text { Frequency of irregular bleeding } \\
\text { Non-adherence to therapy }\end{array}$ \\
\hline Notes & $\begin{array}{l}\text { This study is Study A of two consecutive studies conducted in the same population in accordance with similar } \\
\text { protocols. }\end{array}$ \\
\hline nent & \\
\hline
\end{tabular}

\begin{tabular}{ll} 
Study & Mizunuma $\mathbf{1 9 9 7}$ \\
\hline Methods & Randomisation method not stated. \\
& Single centre, parallel group design with no blinding. \\
& Number of women randomised: $\mathrm{n}=52$ \\
& Number of withdrawals: $\mathrm{n}=16$ \\
& Power calculation for sample size performed but samples inadequate. Analysis not by intention to treat. \\
& Source of funding: not stated. \\
\hline Participants & Country: Japan \\
& 52 women either with natural menopause or bilateral oophorectomy at least 1 year prior to study recruited \\
& and the study conducted in the Department of Obstetrics and Gynaecology of a university hospital. \\
& Inclusion criteria: regular menses, no hormonal treatment since menopause, no regular exercise, free of \\
& hepatic, renal or other diseases with an effect on bone. \\
& Exclusion criteria: not stated. \\
Treatment: \\
(1) CEE $0.625 \mathrm{mg} /$ day \\
(2) CEE $0.625 \mathrm{mg}+$ MPA $2.5 \mathrm{mg} /$ day \\
(3) CEE $0.3 \mathrm{mg}+$ MPA $2.5 \mathrm{mg} / \mathrm{day}$ \\
Control: no treatment (data not given)
\end{tabular}




\section{Characteristics of included studies (Continued)}

\begin{tabular}{ll} 
& Duration: 2 years \\
\hline Outcomes & Irregular bleeding \\
\hline Notes & $\begin{array}{l}\text { The primary outcome of this study was effect of treatment on bone loss and irregular bleeding was a secondary } \\
\text { outcome. The data for irregular bleeding were read off the graphs. }\end{array}$ \\
\hline Allocation concealment & B \\
\hline
\end{tabular}

\section{Study}

Methods

\section{Notelovitz 1996}

A single randomisation schedule was generated by the Department of Biometrics, Solvay Pharmaceuticals, with 4-patient randomisation blocks of treatment distributed to each centre.

Multicentre, parallel group and placebo controlled design with double-blinding.

Number of patients randomised: $\mathrm{n}=280$ (with intact uterus) of a total of 406 .

Number of withdrawals: $\mathrm{n}=42$ (before follow up endometrial biopsy).

Number of patients analysed: $\mathrm{n}=238$ ( $54 \%$ of this group completed the study).

No power calculation reported but analysis by intention to treat.

Source of funding: Solvay Pharmaceuticals.

\section{Country: USA.}

Healthy postmenopausal women with a uterus, aged 40-62, were recruited from 29 centres.

Inclusion criteria: natural or surgical menopause (final menstrual period or oophorectomy between 6 months and 4 years prior to start of study; FSH>=50IU/L; non smokers; $45-54$ years of age ( $>21$ years if documented bilateral oophorectomy; within 25\% of ideal body weight (Metropolitan Height and Weight Tables).

Exclusion criteria: bone mineral density $>=2$ SD below normal peak for young adult women or evidence of vertebral compression fracture on screening radiography; treatment with oestrogens or progestins within 8 weeks of enrolment; endometrial histology indicating either insufficient tissue in the presence of transvaginal ultrasound endometrial thickness of $>4 \mathrm{~mm}$ or proliferative, hyperplastic or secretory endometrium; previous endometrial ablation; undiagnosed vaginal bleeding; oestrogen dependent cancers; abnormalities of Pap smear or mammogram.

Interventions $\quad$ Treatment: (1) Esterified oestrogen (ESE) $0.3 \mathrm{mg}$ daily

(2) ESE $0.625 \mathrm{mg}$ daily

(3) ESE $1.25 \mathrm{mg}$ daily

Control: Placebo daily

Outcomes

Frequency of endometrial hyperplasia at 6 and 12 months follow up.

Non-adherence to treatment.

Frequency of irregular bleeding.

Frequency of unscheduled endometrial biopsies (data not suitable for entry in the review)

Notes

The outcomes reported in this review are only for the women with an intact uterus $n=280$ out of a total $\mathrm{n}=406$ in the study.

Allocation concealment A

Study

Methods

\section{Obel 1993}

Randomisation method and concealment of allocation not reported.

Single centre, parallel group and placebo controlled design with double blinding.

Number of patients randomised: $\mathrm{n}=151$.

Number of withdrawals: $\mathrm{n}=22$ (11 from treatment 1: 5 because of adverse events, 1 because of breast cancer, 5 for reasons unrelated to treatment; 5 from treatment 2: 3 because of adverse events, 2 because of carcinoma; 6 from placebo group: 1 because of adverse events, 1 because of anxiety, 1 for reasons unrelated to treatment). No power calculation reported and analysis not by intention to treat. Source of funding: Not reported.

Participants Country: Denmark 


\section{Characteristics of included studies (Continued)}

Volunteers with early menopause (last spontaneous vaginal bleeding $>6$ and $<24$ months earlier) and with no use of HRT during preceding 24 months recruited from Frederiksborg County.

Exclusion criteria: previous or current oestrogen-dependent neoplasia; thromboembolic disease, liver or pancreatic disease, diabetes mellitus, severe obesity, diseases with high or low bone turnover and medication known to influence bone metabolism or provoke induction of liver enzymes.

\begin{tabular}{ll}
\hline Interventions & Treatment: (1) Continuous E2 2mg + NETA 1mg (Kliogest) daily \\
& (2) Sequential: Oestradiol (E2) 2mg (days 1-12), E2 2mg + norethisterone acetate (NETA) 1mg (days 13-22), \\
& E2 1 mg (days 23-28) \\
& Control: Placebo \\
& Duration: 2 years \\
\hline Outcomes & Frequency of endometrial hyperplasia and/or carcinoma at 2 years \\
& Frequency of irregular bleeding \\
& Non-adherence to therapy \\
\hline Notes & Some of the data was read off the graphs. \\
\hline Allocation concealment & B \\
\hline
\end{tabular}

\begin{tabular}{|c|c|}
\hline Study & PEPI 1995 \\
\hline Methods & $\begin{array}{l}\text { Methods of randomisation and allocation: computer generated. } \\
\text { Treatment group assignment was stratified by clinical center and uterine status (hysterectomy status). } \\
\text { Multicentre ( } 7 \text { clinical centres), parallel group, placebo controlled design with double blinding. } \\
\text { Number of patients randomised: } \mathrm{n}=596 \\
\text { Number of patients analysed: } \mathrm{n}=596 \text { (no exclusions post randomisation). } \\
\text { Power calculation for sample size performed and analysis by intention to treat. } \\
\text { Source of funding: Wyeth-Ayerst Laboratories. }\end{array}$ \\
\hline Participants & $\begin{array}{l}\text { Country: USA } \\
875 \text { healthy postmenopausal volunteers ( } 596 \text { with a uterus, } 279 \text { without a uterus), aged } 45-65 \text { years (average } \\
56.2 \text { years) were recruited via a national mass media campaign. } \\
\text { Inclusion criteria: good health; willing to accept random assignment to a hormone therapy or placebo; } \\
\text { cessation of menses for at least one year, but not more than } 10 \text { years prior to enrolment; surgically menopausal } \\
\text { at least } 2 \text { months after hysterectomy; FSH levels >= } 40 \mathrm{IU} / \mathrm{L} \text {; normal atrophic endometrial biopsy and } \\
\text { mammography results at baseline. } \\
\text { Exclusion criteria : breast or endometrial cancer; any other cancer except non-melanomatous skin cancer di- } \\
\text { agnosed < } 5 \text { years before baseline; serious medical illness (myocardial infarction within six months, congestive } \\
\text { heart failure, stroke, transient ischaemic attack); severe menopausal symptoms; use of HRT within previous } \\
2 \text { months; hyper- or hypothyroidism; normal pelvic examination, papanicolaou test and endometrial biopsy. }\end{array}$ \\
\hline Interventions & $\begin{array}{l}\text { Treatment: Participants randomised to equal numbers to one of the following oral treatments in } 28 \text { day } \\
\text { cycles: } \\
\text { 1) } 0.625 \mathrm{mg} \text { per day of conjugated equine estrogen (CEE) } \\
\text { 2) } 0.625 \mathrm{mg} \text { per day CEE }+10 \mathrm{mg} \text { per day of Medroxyprogesterone acetate (MPA) for the first } 12 \text { days per } \\
\text { month (sequential) } \\
\text { 3) } 0.625 \mathrm{mg} \text { per day CEE }+2.5 \mathrm{mg} \text { per day of MPA (continuous) } \\
\text { 4) } 0.625 \mathrm{mg} \text { per day CEE }+200 \mathrm{mg} \text { per day of cyclic micronized progesterone for the first } 12 \text { days per month } \\
\text { (sequential) } \\
\text { Control: Placebo } \\
\text { Duration: } 3 \text { years }\end{array}$ \\
\hline
\end{tabular}

Outcomes $\quad$ Frequency of hyperplasia or carcinoma (confirmed by endometrial biopsy) annuallly (at 12, 24 and 36 months)

Frequency of unscheduled biopsies or dilatation and curettage

Non-adherence to therapy

b) Diary of symptoms, reports of vaginal bleeding, medication use and interim illnesses was reviewed. 


\section{Characteristics of included studies (Continued)}

Visits at three, six and twelve months first year, six months thereafter for a total of three years.

Notes 39 women were unblinded because of endometrial biopsy results classified as complex hyperplasia, atypia or carcinoma. 32 of these were from the unopposed oestrogen group (group 1) , 3 were receiving placebo, and 4 were receiving one of the $\mathrm{O}+\mathrm{P}$ regimens.

Allocation concealment A

\begin{tabular}{ll} 
Study & Scandinavia 1996 \\
\hline Methods & Randomisation method not given. \\
& Multi-centre, parallel group design, blinding not clear. \\
& Number of women randomised: $\mathrm{n}=240$. \\
& Number of exclusions: not given. \\
& No indication given of power calculation or intention to treat analysis. \\
& Source of funding: not given. \\
\hline Participants & Countries: Denmark, Norway and Sweden. \\
& 240 women recruited aged 45-65 years (mean 52 +/- 4 years) who had been postmenopausal for at least 1 \\
& year. \\
& No other inclusion or exclusion criteria given. \\
\hline Interventions & Treatment 1: Oestradiol 2mg (day 1-78), oestradiol 1mg (day 79-84) + NET 1mg (day 69-78) (long cycle) \\
& Treatment 2: Oestradiol 2mg (day 1-22), oestradiol 1mg (day 23-28) + NET 1mg (day 13-22) (short cycle) \\
& Duration: 5 years (but study terminated early because of unsatisfactory safety profile. \\
\hline Outcomes & Endometrial hyperplasia or carcinoma. \\
\hline Notes & The details of this study are contained in published correspondence and authors contacted for additional \\
& information but no reply received to date. \\
& The study was discontinued because of the unsatisfactory safety profile of the long-cycle hormone replacement \\
& regimen. \\
\hline Allocation concealment & B \\
\hline
\end{tabular}

\begin{tabular}{|c|c|}
\hline Study & Williams 1990 \\
\hline Methods & $\begin{array}{l}\text { Randomisation method not stated. } \\
\text { Single centre, parallel group design with single blinding (assessors only). } \\
\text { No. of women randomised: } n=77 \\
\text { No. of withdrawals: } n=13 \\
\text { No power calculation performed and analysis not by intention to treat. } \\
\text { Source of funding not stated. }\end{array}$ \\
\hline Participants & $\begin{array}{l}\text { Postmenopausal women, aged } 37 \text { to } 59 \text {, were recruited from advertisements in a Cleveland newspaper. } \\
\text { Inclusion criteria: natural menopause (last menses between } 12 \text { and } 60 \text { months prior to the study), white or } \\
\text { oriental ethnic group, within } 10 \% \text { of ideal body weight, no hormonal therapy within the last } 3 \text { months, } \\
\text { nonsmoking. } \\
\text { Exclusion criteria: cancer, hypertension, diabetes, disease of liver, gall bladder disease, heart/vascular system } \\
\text { disease, alcoholism, corticosteroid therapy. }\end{array}$ \\
\hline Interventions & $\begin{array}{l}\text { Treatment 1: Continuous } \mathrm{O}+\mathrm{P}(20 \mathrm{ug} \mathrm{EE}+1.0 \mathrm{mg} \text { NETA }) \\
\text { Treatment 2: Continuous } \mathrm{O}+\mathrm{P}(10 \mathrm{ug} \mathrm{EE}+1.0 \mathrm{mg} \text { NETA }) \\
\text { Treatment 3: Continuous } \mathrm{O}+\mathrm{P}(10 \mathrm{ug} \mathrm{EE}+0.5 \mathrm{mg} \text { NETA }) \\
\text { Treatment 4: Continuous } \mathrm{O}+\mathrm{P}(5 \mathrm{ug} \mathrm{EE}+1.0 \mathrm{mg} \text { NETA }) \\
\text { Treatment 5: Continuous } \mathrm{O}+\mathrm{P}(5 \mathrm{ug} \mathrm{EE}+0.5 \mathrm{mg} \text { NETA }) \\
\text { Treatment 6: Sequential O + P }(0.625 \mathrm{mg} \text { CEE days } 1-25+10 \mathrm{mg} \text { MPA days } 16-25)\end{array}$ \\
\hline Outcomes & $\begin{array}{l}\text { Frequency of vaginal spotting at } 3,6 \text {, and } 12 \text { months } \\
\text { Non adherence to therapy }\end{array}$ \\
\hline
\end{tabular}




\title{
Characteristics of excluded studies
}

\author{
Study \\ Reason for exclusion
}

Aoki 1990

This trial has published in abstract form and located by handsearching. No indication was given whether women were randomised to treatment groups and attempts were made to contact the author for clarification but no reply was received.

Campbell 1977 This trial is excluded because endometrial hyperplasia at baseline is not an exclusion criterion for entry into the trial (exclusion criterion for this review is any contraindication to HRT).

Heytmanek 1990 This trial was published in abstract form and was located by handsearching. No indication was given whether women were randomised to treatment groups and attempts were made to contact the author for clarification but no reply was received.

Nachtigall 1979 Trial was based on 84 matched pairs that were randomised to treatment or placebo. However, participants were hospitalised with long term chronic disease which is an exclusion criterion for this review.

Volpe 1986

This trial is excluded because endometrial hyperplasia at baseline is not an exclusion criterion for entry into the trial (exclusion criterion for this review is any contraindication to HRT). The numbers in each arm of the trial are small and the effects of treatment on the endometrium are evaluated by assessing the improvement in the endometrium from baseline as a result of treatment.

\section{G R A P H S}

\section{Comparison 01. LOW DOSE OESTROGEN VERSUS PLACEBO}

\begin{tabular}{|c|c|c|c|c|}
\hline Outcome title & $\begin{array}{l}\text { No. of } \\
\text { studies }\end{array}$ & $\begin{array}{c}\text { No. of } \\
\text { participants }\end{array}$ & Statistical method & Effect size \\
\hline $\begin{array}{l}\text { Endometrial hyperplasia at } 6 \\
\text { months }\end{array}$ & 2 & 609 & Peto Odds Ratio 95\% CI & $1.56[0.22,10.97]$ \\
\hline $\begin{array}{l}\text { Endometrial hyperplasia at } 12 \\
\text { months }\end{array}$ & 2 & 522 & Peto Odds Ratio 95\% CI & $2.68[0.69,10.40]$ \\
\hline $\begin{array}{l}\text { Endometrial hyperplasia at } 18-24 \\
\text { months }\end{array}$ & 4 & 526 & Peto Odds Ratio 95\% CI & $1.73[0.66,4.55]$ \\
\hline $\begin{array}{l}\text { Endometrial hyperplasia at } 36 \\
\text { months }\end{array}$ & 0 & 0 & Peto Odds Ratio 95\% CI & Not estimable \\
\hline Unscheduled biopsy or D \& C & 0 & 0 & Peto Odds Ratio 95\% CI & Not estimable \\
\hline Endometrial cancer & 0 & 0 & Peto Odds Ratio 95\% CI & Not estimable \\
\hline $\begin{array}{l}\text { Irregular bleeding patterns < } \\
\quad 6 \mathrm{mth} \text { from treatment }\end{array}$ & 0 & 0 & Peto Odds Ratio 95\% CI & Not estimable \\
\hline $\begin{array}{l}\text { Irregular bleeding patterns }>= \\
\quad 6 \mathrm{mths} \text { from treatment }\end{array}$ & 3 & 237 & Peto Odds Ratio 95\% CI & $0.87[0.46,1.64]$ \\
\hline Non adherence to therapy & 1 & 119 & Peto Odds Ratio 95\% CI & $0.59[0.25,1.36]$ \\
\hline
\end{tabular}




\section{Comparison 02. MODERATE DOSE OESTROGEN VS PLACEBO}

\begin{tabular}{|c|c|c|c|c|}
\hline Outcome title & $\begin{array}{l}\text { No. of } \\
\text { studies }\end{array}$ & $\begin{array}{c}\text { No. of } \\
\text { participants }\end{array}$ & Statistical method & Effect size \\
\hline $\begin{array}{l}\text { Endometrial hyperplasia at } 6 \\
\text { months }\end{array}$ & 1 & 119 & Peto Odds Ratio 95\% CI & $5.40[1.40,20.91]$ \\
\hline $\begin{array}{l}\text { Endometrial hyperplasia at } 12 \\
\text { months }\end{array}$ & 2 & 357 & Peto Odds Ratio 95\% CI & $8.29[4.24,16.21]$ \\
\hline $\begin{array}{l}\text { Endometrial hyperplasia at } 18-24 \\
\text { months }\end{array}$ & 4 & 445 & Peto Odds Ratio 95\% CI & $9.58[5.93,15.46]$ \\
\hline $\begin{array}{l}\text { Endometrial hyperplasia at } 36 \\
\text { months }\end{array}$ & 1 & 238 & Peto Odds Ratio 95\% CI & $15.99[9.28,27.54]$ \\
\hline Unscheduled biopsy or D \& C & 1 & 238 & Peto Odds Ratio 95\% CI & $19.94[11.99,33.14]$ \\
\hline Endometrial cancer & 1 & 238 & Peto Odds Ratio 95\% CI & $0.14[0.00,6.82]$ \\
\hline $\begin{array}{l}\text { Irregular bleeding patterns }< \\
\quad 6 \mathrm{mths} \text { from treatment }\end{array}$ & 0 & 0 & Peto Odds Ratio 95\% CI & Not estimable \\
\hline $\begin{array}{l}\text { Irregular bleeding patterns }>= \\
6 \mathrm{mths} \text { from treatment }\end{array}$ & 3 & 216 & Peto Odds Ratio 95\% CI & $1.90[1.05,3.46]$ \\
\hline Non adherence to therapy & 2 & 357 & Peto Odds Ratio 95\% CI & $3.57[2.33,5.47]$ \\
\hline
\end{tabular}

\section{Comparison 03. HIGH DOSE OESTROGEN VS PLACEBO}

\begin{tabular}{|c|c|c|c|c|}
\hline Outcome title & $\begin{array}{l}\text { No. of } \\
\text { studies }\end{array}$ & $\begin{array}{c}\text { No. of } \\
\text { participants }\end{array}$ & Statistical method & Effect size \\
\hline $\begin{array}{l}\text { Endometrial hyperplasia at } 6 \\
\text { months }\end{array}$ & 1 & 120 & Peto Odds Ratio 95\% CI & $9.10[3.62,22.85]$ \\
\hline $\begin{array}{l}\text { Endometrial hyperplasia at } 12 \\
\text { months }\end{array}$ & 1 & 120 & Peto Odds Ratio 95\% CI & $10.69[4.55,25.10]$ \\
\hline $\begin{array}{l}\text { Endometrial hyperplasia at } 24 \\
\text { months }\end{array}$ & 1 & 120 & Peto Odds Ratio 95\% CI & $13.06[5.88,29.02]$ \\
\hline $\begin{array}{l}\text { Endometrial hyperplasia at } 36 \\
\text { months }\end{array}$ & 0 & 0 & Peto Odds Ratio 95\% CI & Not estimable \\
\hline Unscheduled biopsy or D \& C & 0 & 0 & Peto Odds Ratio 95\% CI & Not estimable \\
\hline Endometrial cancer & 1 & 120 & Peto Odds Ratio 95\% CI & Not estimable \\
\hline $\begin{array}{l}\text { Irregular bleeding patterns < } \\
\quad 6 \mathrm{mth} \text { from treatment }\end{array}$ & 0 & 0 & Peto Odds Ratio 95\% CI & Not estimable \\
\hline $\begin{array}{l}\text { Irregular bleeding patterns }>= \\
\quad 6 \mathrm{mth} \text { from treatment }\end{array}$ & 1 & 106 & Peto Odds Ratio 95\% CI & $6.01[2.81,12.86]$ \\
\hline Non adherence to therapy & 1 & 120 & Peto Odds Ratio 95\% CI & $6.83[3.35,13.95]$ \\
\hline
\end{tabular}

\section{Comparison 04. OESTROGEN VS OESTROGEN/PROGESTAGEN (continuous)}

\begin{tabular}{lcccc} 
Outcome title & $\begin{array}{c}\text { No. of } \\
\text { studies }\end{array}$ & $\begin{array}{c}\text { No. of } \\
\text { participants }\end{array}$ & Statistical method & Effect size \\
\hline $\begin{array}{l}\text { Endometrial hyperplasia at } 6 \\
\quad \text { months }\end{array}$ & 5 & 1660 & Peto Odds Ratio 95\% CI & $14.24[6.41,31.65]$ \\
$\begin{array}{l}\text { Endometrial hyperplasia at 12 } \\
\text { months }\end{array}$ & 6 & 1680 & Peto Odds Ratio 95\% CI & $14.98[9.69,23.16]$ \\
$\begin{array}{l}\text { Endometrial hyperplasia at 24 } \\
\text { months }\end{array}$ & 5 & 734 & Peto Odds Ratio 95\% CI & $14.53[8.50,24.84]$ \\
$\begin{array}{l}\text { Endometrial hyperplasia at 36 } \\
\text { months }\end{array}$ & 1 & 239 & Peto Odds Ratio 95\% CI & 17.07 [9.89, 29.44] \\
\hline
\end{tabular}

Hormone replacement therapy in postmenopausal women: endometrial hyperplasia and irregular bleeding 


\begin{tabular}{|c|c|c|c|c|}
\hline Unscheduled biopsy or D \& C & 1 & 239 & Peto Odds Ratio 95\% CI & $20.79[12.51,34.54]$ \\
\hline Endometrial cancer & 1 & 239 & Peto Odds Ratio 95\% CI & Not estimable \\
\hline $\begin{array}{l}\text { Irregular bleeding patterns }<=6 \\
\text { months after treatment }\end{array}$ & 1 & 35 & Peto Odds Ratio 95\% CI & $0.81[0.19,3.39]$ \\
\hline $\begin{array}{l}\text { Irregular bleeding patterns }>6 \\
\text { months after treatment }\end{array}$ & 1 & 35 & Peto Odds Ratio 95\% CI & Not estimable \\
\hline $\begin{array}{l}\text { Number of cycles with irregular } \\
\text { bleeding at } 12 \text { months }\end{array}$ & 1 & 11147 & Peto Odds Ratio 95\% CI & $0.81[0.73,0.90]$ \\
\hline $\begin{array}{l}\text { Number of cycles with irregular } \\
\text { spotting at } 12 \text { months }\end{array}$ & 1 & 11147 & Peto Odds Ratio 95\% CI & $0.63[0.56,0.70]$ \\
\hline Non adherence to therapy & 1 & 239 & Peto Odds Ratio 95\% CI & $6.02[3.55,10.21]$ \\
\hline \multicolumn{5}{|c|}{ Comparison 05. OESTROGEN VS OESTROGEN + PROGESTAGEN (sequential) } \\
\hline Outcome title & $\begin{array}{l}\text { No. of } \\
\text { studies }\end{array}$ & $\begin{array}{c}\text { No. of } \\
\text { participants }\end{array}$ & Statistical method & Effect size \\
\hline $\begin{array}{l}\text { Endometrial hyperplasia at } 6 \\
\text { months }\end{array}$ & 3 & 978 & Peto Odds Ratio 95\% CI & $11.58[5.48,24.45]$ \\
\hline $\begin{array}{l}\text { Endometrial hyperplasia at } 12 \\
\text { months }\end{array}$ & 4 & 1284 & Peto Odds Ratio 95\% CI & $15.15[10.02,22.91]$ \\
\hline $\begin{array}{l}\text { Endometrial hyperplasia at } 24 \\
\text { months }\end{array}$ & 1 & 357 & Peto Odds Ratio 95\% CI & $19.83[11.06,35.55]$ \\
\hline $\begin{array}{l}\text { Endometrial hyperplasia at } 36 \\
\text { months }\end{array}$ & 1 & 357 & Peto Odds Ratio 95\% CI & $22.56[13.49,37.71]$ \\
\hline Unscheduled biopsy or D \& C & 1 & 357 & Peto Odds Ratio 95\% CI & $20.50[13.01,32.32]$ \\
\hline Endometrial cancer & 2 & 1189 & Peto Odds Ratio 95\% CI & $2.04[0.11,38.10]$ \\
\hline $\begin{array}{l}\text { Irregular bleeding patterns }<6 \\
\text { months after } \mathrm{Rx}\end{array}$ & 0 & 0 & Peto Odds Ratio 95\% CI & Not estimable \\
\hline $\begin{array}{l}\text { Irregular bleeding patterns }>6 \\
\text { months after } \mathrm{Rx}\end{array}$ & 1 & 95 & Peto Odds Ratio 95\% CI & $5.90[2.54,13.69]$ \\
\hline $\begin{array}{l}\text { Number of cycles of irregular } \\
\text { bleeding }\end{array}$ & 1 & 11143 & Peto Odds Ratio 95\% CI & $1.99[1.75,2.27]$ \\
\hline $\begin{array}{l}\text { Number of cycles of irregular } \\
\text { spotting }\end{array}$ & 1 & 11143 & Peto Odds Ratio 95\% CI & $1.00[0.87,1.14]$ \\
\hline Non adherence to therapy & 3 & 530 & Peto Odds Ratio 95\% CI & $3.36[2.21,5.10]$ \\
\hline
\end{tabular}

Comparison 07. OESTROGEN + PROGESTOGEN (continuous) VS PLACEBO

\begin{tabular}{|c|c|c|c|c|}
\hline Outcome title & $\begin{array}{l}\text { No. of } \\
\text { studies }\end{array}$ & $\begin{array}{c}\text { No. of } \\
\text { participants }\end{array}$ & Statistical method & Effect size \\
\hline $\begin{array}{l}\text { Endometrial hyperplasia at } 6 \\
\text { months }\end{array}$ & 1 & 436 & Peto Odds Ratio 95\% CI & Not estimable \\
\hline $\begin{array}{l}\text { Endometrial hyperplasia at } 12 \\
\text { months }\end{array}$ & 2 & 607 & Peto Odds Ratio 95\% CI & Not estimable \\
\hline $\begin{array}{l}\text { Endometrial hyperplasia at } 24 \\
\text { months }\end{array}$ & 4 & 681 & Peto Odds Ratio 95\% CI & $0.79[0.06,11.07]$ \\
\hline $\begin{array}{l}\text { Endometrial hyperplasia at } 36 \\
\text { months }\end{array}$ & 1 & 239 & Peto Odds Ratio 95\% CI & $0.51[0.05,4.91]$ \\
\hline Unscheduled biopsy or D \& C & 1 & 239 & Peto Odds Ratio 95\% CI & $0.89[0.37,2.18]$ \\
\hline Endometrial carcinoma & 1 & 239 & Peto Odds Ratio 95\% CI & $0.13[0.00,6.76]$ \\
\hline $\begin{array}{l}\text { Irregular bleeding patterns }<6 \\
\text { months after treatment }\end{array}$ & 2 & 139 & Peto Odds Ratio 95\% CI & $6.37[2.69,15.08]$ \\
\hline
\end{tabular}


Irregular bleeding patterns $>=6$

\section{Comparison 08. OESTROGEN + PROGESTOGEN (sequential) vs PLACEBO}

\begin{tabular}{|c|c|c|c|c|}
\hline Outcome title & $\begin{array}{l}\text { No. of } \\
\text { studies }\end{array}$ & $\begin{array}{c}\text { No. of } \\
\text { participants }\end{array}$ & Statistical method & Effect size \\
\hline $\begin{array}{l}\text { Endometrial hyperplasia at } 12 \\
\text { months }\end{array}$ & 2 & 406 & Peto Odds Ratio 95\% CI & $3.03[0.57,16.05]$ \\
\hline $\begin{array}{l}\text { Endometrial hyperplasia at } 24 \\
\text { months }\end{array}$ & 3 & 495 & Peto Odds Ratio 95\% CI & $4.00[1.15,13.95]$ \\
\hline $\begin{array}{l}\text { Endometrial hyperplasia at } 36 \\
\text { months }\end{array}$ & 1 & 357 & Peto Odds Ratio 95\% CI & $2.43[0.78,7.55]$ \\
\hline Unscheduled biopsy or D \& C & 1 & 357 & Peto Odds Ratio 95\% CI & $1.49[0.76,2.92]$ \\
\hline Endometrial cancer & 1 & 357 & Peto Odds Ratio 95\% CI & $0.05[0.00,3.18]$ \\
\hline $\begin{array}{l}\text { Irregular bleeding patterns }<6 \\
\text { months after treatment }\end{array}$ & 1 & 96 & Peto Odds Ratio 95\% CI & $0.66[0.11,3.95]$ \\
\hline $\begin{array}{l}\text { Irregular bleeding patterns }>=6 \\
\text { months after treatment }\end{array}$ & 4 & 287 & Peto Odds Ratio 95\% CI & $1.21[0.51,2.86]$ \\
\hline Non adherence to therapy & 4 & 276 & Peto Odds Ratio 95\% CI & $3.47[1.49,8.09]$ \\
\hline
\end{tabular}

\section{Comparison 10. OESTROGEN + PROGESTOGEN (continuous) VS OESTROGEN + PROGESTOGEN (sequen- tial)}

\begin{tabular}{|c|c|c|c|c|}
\hline Outcome title & $\begin{array}{l}\text { No. of } \\
\text { studies }\end{array}$ & $\begin{array}{c}\text { No. of } \\
\text { participants }\end{array}$ & Statistical method & Effect size \\
\hline $\begin{array}{l}\text { Endometrial hyperplasia at } 6 \\
\text { months }\end{array}$ & 1 & 1171 & Peto Odds Ratio 95\% CI & $1.00[0.06,15.98]$ \\
\hline $\begin{array}{l}\text { Endometrial hyperplasia at } 12 \\
\text { months }\end{array}$ & 2 & 1460 & Peto Odds Ratio 95\% CI & $0.45[0.11,1.87]$ \\
\hline $\begin{array}{l}\text { Endometrial hyperplasia at } 24 \\
\text { months }\end{array}$ & 2 & 442 & Peto Odds Ratio 95\% CI & $0.38[0.09,1.68]$ \\
\hline $\begin{array}{l}\text { Endometrial hyperplasia at } 36 \\
\text { months }\end{array}$ & 1 & 358 & Peto Odds Ratio 95\% CI & $0.30[0.09,0.97]$ \\
\hline Endometrial cancer & 2 & 1460 & Peto Odds Ratio 95\% CI & $0.13[0.00,6.77]$ \\
\hline $\begin{array}{l}\text { Irregular bleeding patterns }<6 \\
\text { months after treatment }\end{array}$ & 2 & 154 & Peto Odds Ratio 95\% CI & $1.46[0.41,5.26]$ \\
\hline $\begin{array}{l}\text { Irregular bleeding patterns }>=6 \\
\text { months after treatment }\end{array}$ & 4 & 215 & Peto Odds Ratio 95\% CI & $0.41[0.13,1.31]$ \\
\hline $\begin{array}{l}\text { Number of cycles of irregular } \\
\text { bleeding }\end{array}$ & 1 & 15012 & Peto Odds Ratio 95\% CI & $2.29[2.09,2.52]$ \\
\hline $\begin{array}{l}\text { Number of cycles of irregular } \\
\text { spotting }\end{array}$ & 1 & 15012 & Peto Odds Ratio 95\% CI & $1.64[1.49,1.81]$ \\
\hline Non adherence to therapy & 5 & 612 & Peto Odds Ratio 95\% CI & $0.70[0.44,1.09]$ \\
\hline
\end{tabular}

Hormone replacement therapy in postmenopausal women: endometrial hyperplasia and irregular bleeding 


\section{Comparison 11. SEQUENTIAL OESTROGEN + PROGESTOGEN (1 month) VS SEQUENTIAL OESTROGEN + PROGESTOGEN (3 months)}

\begin{tabular}{lcccc} 
Outcome title & $\begin{array}{c}\text { No. of } \\
\text { studies }\end{array}$ & $\begin{array}{c}\text { No. of } \\
\text { participants }\end{array}$ & Statistical method & Effect size \\
\hline $\begin{array}{l}\text { Endometrial hyperplasia at } 12 \\
\quad \text { months }\end{array}$ & 1 & 195 & Peto Odds Ratio 95\% CI & $0.11[0.03,0.52]$ \\
$\begin{array}{l}\text { Endometrial hyperplasia at } 24 \\
\quad \text { months }\end{array}$ & 2 & 239 & Peto Odds Ratio 95\% CI & $0.51[0.15,1.72]$ \\
$\begin{array}{l}\text { Endometrial hyperplasia at 36 } \\
\quad \text { months }\end{array}$ & 1 & 195 & Peto Odds Ratio 95\% CI & $0.18[0.06,0.49]$ \\
$\begin{array}{l}\text { Endometrial cancer } \\
\text { Non adherence to therapy }\end{array}$ & 1 & 195 & Peto Odds Ratio 95\% CI & $0.12[0.00,6.22]$ \\
\hline
\end{tabular}

\section{COVER SHEET}

Title

Authors

Contribution of author(s)

Issue protocol first published

Date of most recent amendment

Date of most recent

SUBSTANTIVE amendment

What's New

DOI

\section{Cochrane Library number}

Editorial group

Editorial group code
Hormone replacement therapy in postmenopausal women: endometrial hyperplasia and irregular bleeding

Lethaby A, Farquhar C, Sarkis A, Roberts H, Jepson R, Barlow D

Arpine Sarkis registered the title, prepared the protocol, selected trials for inclusion, assessed quality and performed data extraction.

Ruth Jepson reviewed the protocol, performed searches, selected trials for inclusion, assessed quality, and commented on the final draft of the review.

Cindy Farquhar reviewed the protocol, performed data extraction and commented on the final draft of the review.

David Barlow provided comment on the protocol and the final draft of the review.

Helen Roberts assessed included trials for quality, performed data extraction and commented on the final draft of the review.

Anne Lethaby modified the protocol, performed searches, selected trials for inclusion, assessed quality, performed data extraction, entered data, prepared the final review and incorporated suggested changes.

I

25 November 2003

24 February 1999

Information not supplied by author

10.1002/14651858.CD000402

CD000402

Cochrane Menstrual Disorders and Subfertility Group

HM-MENSTR

Hormone replacement therapy in postmenopausal women: endometrial hyperplasia and irregular bleeding

Copyright $\odot 2004$ The Cochrane Collaboration. Published by John Wiley \& Sons, Ltd 


\section{GRAPHS AND OTHER TABLES}

\section{Comparison II. Endometrial hyperplasia at 6 months}

Review: Hormone replacement therapy in postmenopausal women: endometrial hyperplasia and irregular bleeding Comparison: 01 LOW DOSE OESTROGEN VERSUS PLACEBO

Outcome: 0 I Endometrial hyperplasia at 6 months

\begin{tabular}{|c|c|c|c|c|c|}
\hline Study & $\begin{array}{c}\text { Low dose } O \\
n / N\end{array}$ & $\begin{array}{c}\text { Placebo } \\
\mathrm{n} / \mathrm{N}\end{array}$ & $\begin{array}{l}\text { Peto Odds Ratio } \\
\qquad 95 \% \mathrm{Cl}\end{array}$ & $\begin{array}{c}\text { Weight } \\
(\%)\end{array}$ & $\begin{array}{l}\text { Peto Odds Ratio } \\
\qquad 95 \% \mathrm{Cl}\end{array}$ \\
\hline \multicolumn{6}{|c|}{ 0। I- I0 mcg ethinyl oestradiol (EE) } \\
\hline CHART 1996 & $5 / 397$ & 0/93 & & 75.3 & $3.47[0.37,32.75]$ \\
\hline Subtotal $(95 \% \mathrm{Cl})$ & 397 & 93 & & 75.3 & $3.47[0.37,32.75]$ \\
\hline \multicolumn{6}{|c|}{ Total events: 5 (Low dose O), 0 (Placebo) } \\
\hline \multicolumn{6}{|c|}{ Test for heterogeneity: not applicable } \\
\hline \multicolumn{6}{|c|}{ Test for overall effect $z=1.09 \quad p=0.3$} \\
\hline \multicolumn{6}{|c|}{02 0.3mg esterified oestrogens (ESE) } \\
\hline Notelovitz 1996 & $0 / 59$ & $1 / 60$ & - & 24.7 & $0.14[0.00,6.94]$ \\
\hline Subtotal $(95 \% \mathrm{Cl})$ & 59 & 60 & & 24.7 & $0.14[0.00,6.94]$ \\
\hline \multicolumn{6}{|c|}{ Total events: 0 (Low dose O), I (Placebo) } \\
\hline \multicolumn{6}{|c|}{ Test for heterogeneity: not applicable } \\
\hline \multicolumn{6}{|c|}{ Test for overall effect $z=0.99 \quad p=0.3$} \\
\hline Total $(95 \% \mathrm{Cl})$ & 456 & 153 & & 100.0 & $1.56[0.22,10.97]$ \\
\hline \multicolumn{6}{|c|}{ Total events: 5 (Low dose O), I (Placebo) } \\
\hline \multicolumn{6}{|c|}{ Test for heterogeneity chi-square $=1.96 \mathrm{df}=\mid \mathrm{p}=0.16 \mathrm{|}=49.0 \%$} \\
\hline Test for overall effec & $p=0.7$ & & & & \\
\hline
\end{tabular}

$0.0010 .010 .1 \quad 1 \quad 10 \quad 100 \quad 1000$

Favours $O \quad$ Favours placebo 


\section{Comparison II. Endometrial hyperplasia at 12 months}

Review: Hormone replacement therapy in postmenopausal women: endometrial hyperplasia and irregular bleeding

Comparison: 01 LOW DOSE OESTROGEN VERSUS PLACEBO

Outcome: 02 Endometrial hyperplasia at 12 months

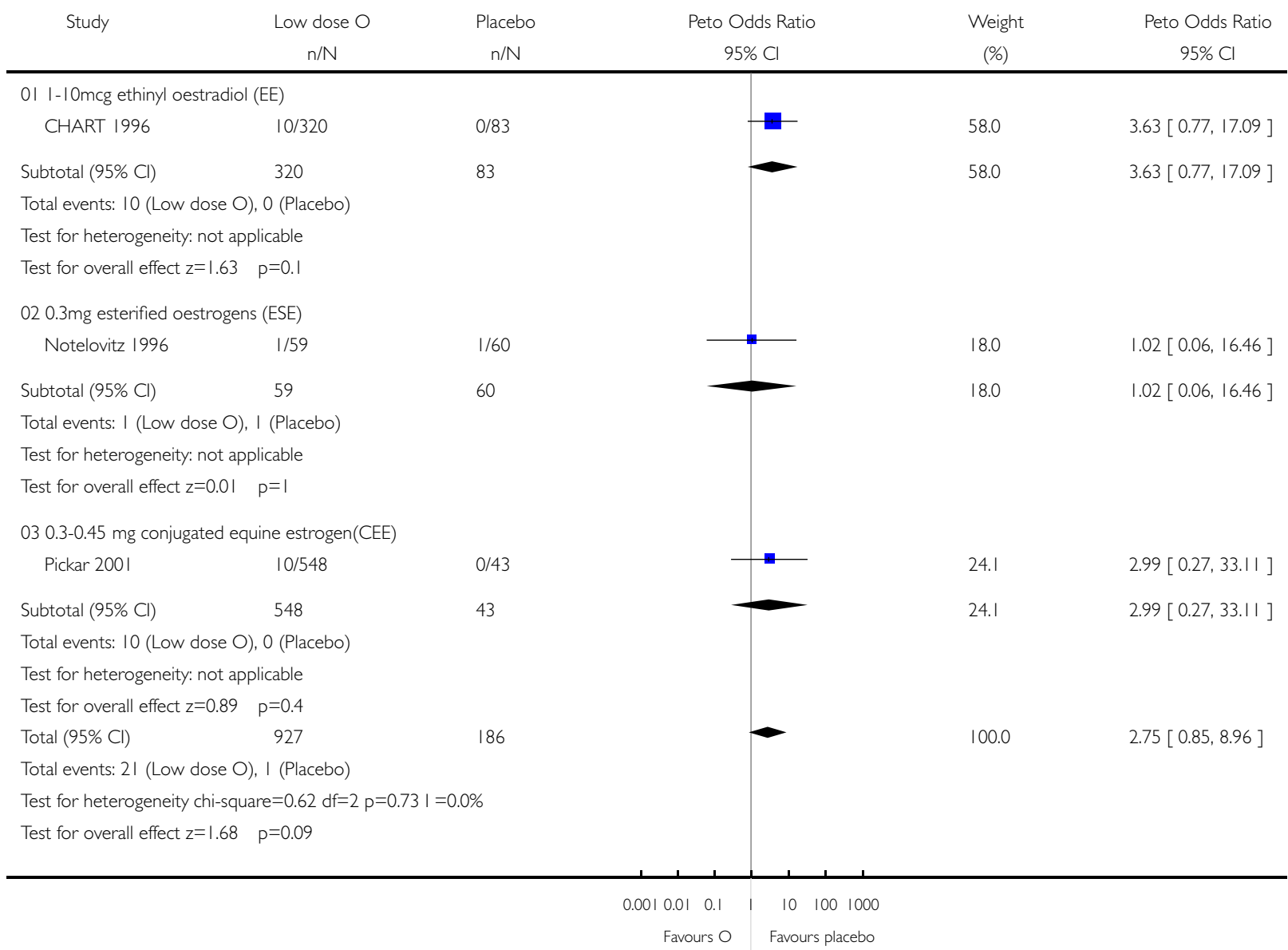




\section{Comparison II. Endometrial hyperplasia at 18-24 months}

Review: Hormone replacement therapy in postmenopausal women: endometrial hyperplasia and irregular bleeding

Comparison: OI LOW DOSE OESTROGEN VERSUS PLACEBO

Outcome: 03 Endometrial hyperplasia at 18-24 months

Study Low dose $0 \quad$ Placebo Peto Odds Ratio $\quad$ Weight

\begin{tabular}{|c|c|c|c|c|c|}
\hline (1) & $\mathrm{n} / \mathrm{N}$ & $\mathrm{n} / \mathrm{N}$ & $95 \% \mathrm{Cl}$ & $(\%)$ & $95 \% \mathrm{Cl}$ \\
\hline \multicolumn{6}{|c|}{ 0I I-IOmcg ethinyl oestradiol (EE) } \\
\hline CHART 1996 & $14 / 239$ & $1 / 59$ & & 55.0 & $2.38[0.65,8.75]$ \\
\hline Subtotal $(95 \%$ Cl) & 239 & 59 & & 55.0 & $2.38[0.65,8.75]$ \\
\hline \multicolumn{6}{|c|}{ Total events: I4 (Low dose O), I (Placebo) } \\
\hline \multicolumn{6}{|c|}{ Test for heterogeneity: not applicable } \\
\hline \multicolumn{6}{|c|}{ Test for overall effect $z=1.31 \quad p=0.2$} \\
\hline \multicolumn{6}{|c|}{$020.5 \mathrm{mg}$ micronised I 7B oestradiol (E2) } \\
\hline Ettinger 1992 & $1 / 8$ & $0 / 14$ & & 5.6 & $15.64[0.27,920.01]$ \\
\hline Subtotal $(95 \% \mathrm{Cl})$ & 8 & 14 & & 5.6 & $15.64[0.27,920.01]$ \\
\hline \multicolumn{6}{|c|}{ Total events: I (Low dose O), 0 (Placebo) } \\
\hline \multicolumn{6}{|c|}{ Test for heterogeneity: not applicable } \\
\hline \multicolumn{6}{|c|}{ Test for overall effect $z=1.32 \quad p=0.2$} \\
\hline \multicolumn{6}{|c|}{$030.3 \mathrm{mg}$ and $0.625 \mathrm{mg}$ oestrone sulphate } \\
\hline Harris 1991 & $4 / 63$ & $2 / 24$ & & 27.4 & $0.74[0.12,4.66]$ \\
\hline Subtotal $(95 \% \mathrm{Cl})$ & 63 & 24 & & 27.4 & $0.74[0.12,4.66]$ \\
\hline \multicolumn{6}{|c|}{ Total events: 4 (Low dose O), 2 (Placebo) } \\
\hline \multicolumn{6}{|c|}{ Test for heterogeneity: not applicable } \\
\hline \multicolumn{6}{|c|}{ Test for overall effect $z=0.32 \quad p=0.7$} \\
\hline \multicolumn{6}{|c|}{04 0.3mg esterified oestrogens (ESE) } \\
\hline Notelovitz 1996 & $1 / 59$ & $1 / 60$ & & 12.0 & $1.02[0.06,16.46]$ \\
\hline Subtotal $(95 \% \mathrm{Cl})$ & 59 & 60 & & 12.0 & $1.02[0.06,16.46]$ \\
\hline \multicolumn{6}{|c|}{ Total events: I (Low dose O), I (Placebo) } \\
\hline \multicolumn{6}{|c|}{ Test for heterogeneity: not applicable } \\
\hline \multicolumn{6}{|c|}{ Test for overall effect $z=0.01 \quad p=1$} \\
\hline Total $(95 \% \mathrm{Cl})$ & 369 & 157 & & 100.0 & $1.73[0.66,4.55]$ \\
\hline \multicolumn{6}{|c|}{ Total events: 20 (Low dose O), 4 (Placebo) } \\
\hline \multicolumn{6}{|c|}{ Test for heterogeneity chi-square $=2.32 \mathrm{df}=3 \mathrm{p}=0.5 \mathrm{I} \mid=0.0 \%$} \\
\hline Test for overall effec & $p=0.3$ & & & & \\
\hline
\end{tabular}

$0.0010 .010 .1 \quad 1 \quad 10 \quad 1001000$

Favours $\mathrm{O}$ Favours placebo 


\section{Comparison II. Endometrial hyperplasia at 36 months}

Review: Hormone replacement therapy in postmenopausal women: endometrial hyperplasia and irregular bleeding Comparison: OI LOW DOSE OESTROGEN VERSUS PLACEBO

Outcome: 04 Endometrial hyperplasia at 36 months

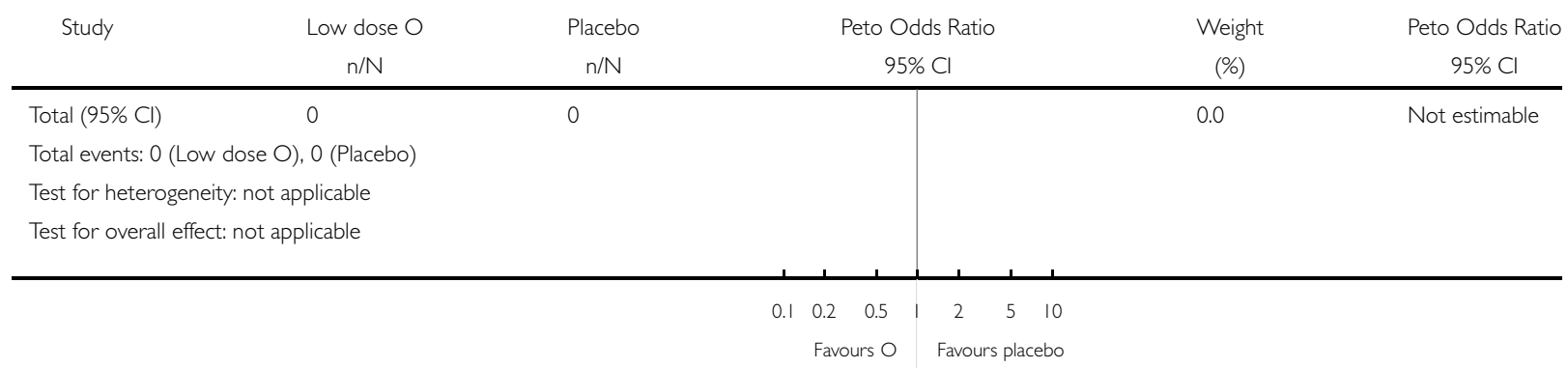

\section{Comparison II. Unscheduled biopsy or D \& C}

Review: Hormone replacement therapy in postmenopausal women: endometrial hyperplasia and irregular bleeding Comparison: OI LOW DOSE OESTROGEN VERSUS PLACEBO

Outcome: 05 Additional investigations (unscheduled biopsy)

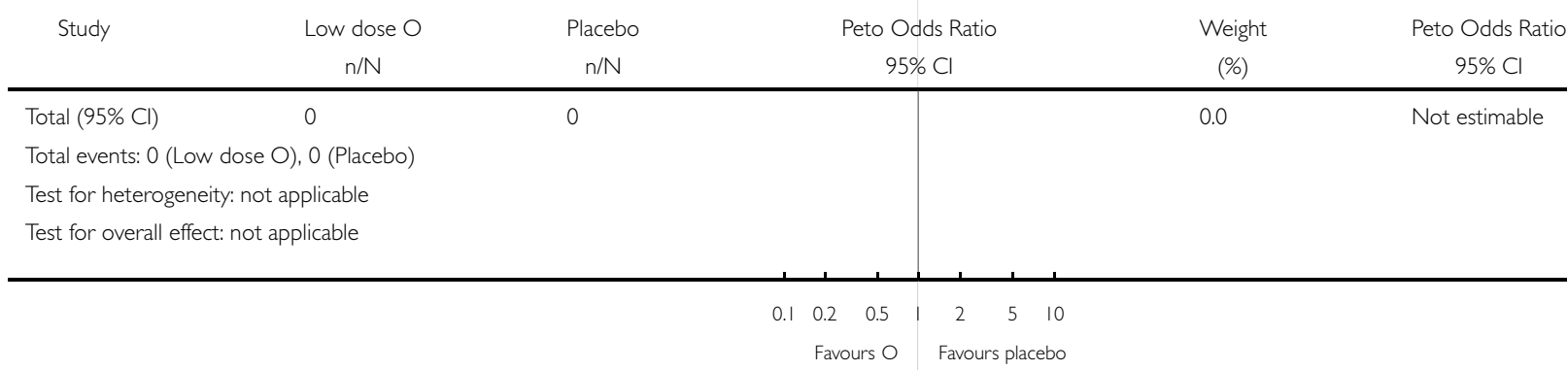

\section{Comparison II. Endometrial cancer}

Review: Hormone replacement therapy in postmenopausal women: endometrial hyperplasia and irregular bleeding Comparison: 0 I LOW DOSE OESTROGEN VERSUS PLACEBO

Outcome: 06 Endometrial cancer

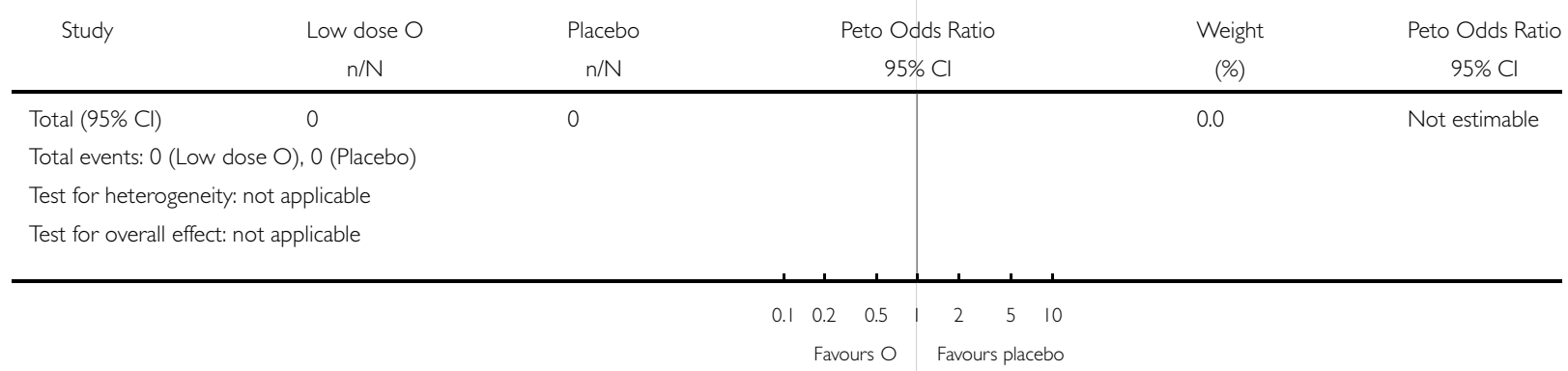




\section{Comparison II. Irregular bleeding patterns $<6 \mathrm{mths}$ from treatment}

Review: Hormone replacement therapy in postmenopausal women: endometrial hyperplasia and irregular bleeding Comparison: 01 LOW DOSE OESTROGEN VERSUS PLACEBO

Outcome: 07 Irregular bleeding patterns $<6$ mths from treatment

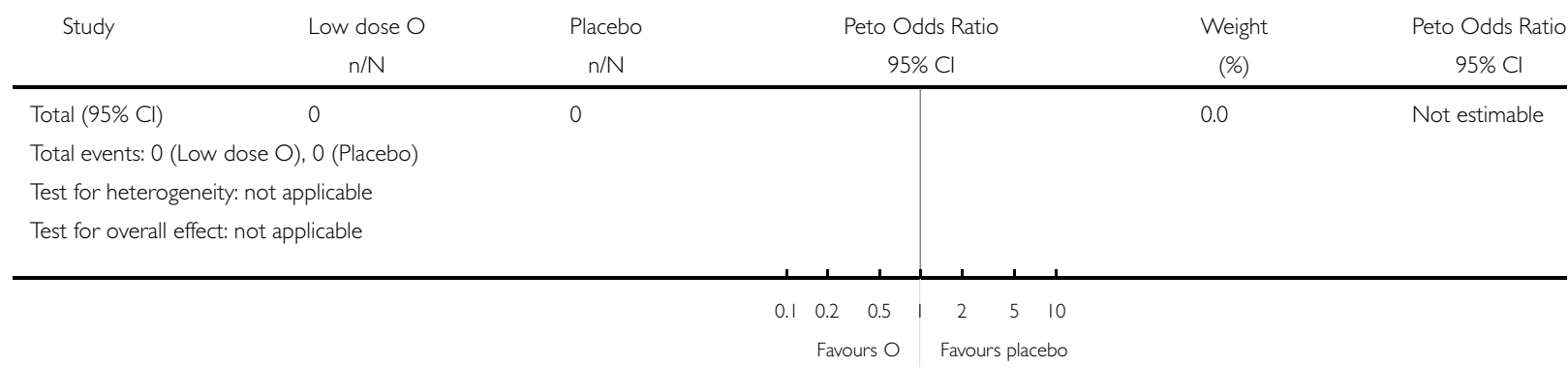

\section{Comparison II. Irregular bleeding patterns $>=6 \mathrm{mths}$ from treatment}

Review: Hormone replacement therapy in postmenopausal women: endometrial hyperplasia and irregular bleeding Comparison: 01 LOW DOSE OESTROGEN VERSUS PLACEBO

Outcome: 08 Irregular bleeding patterns $>=6$ mths from treatment

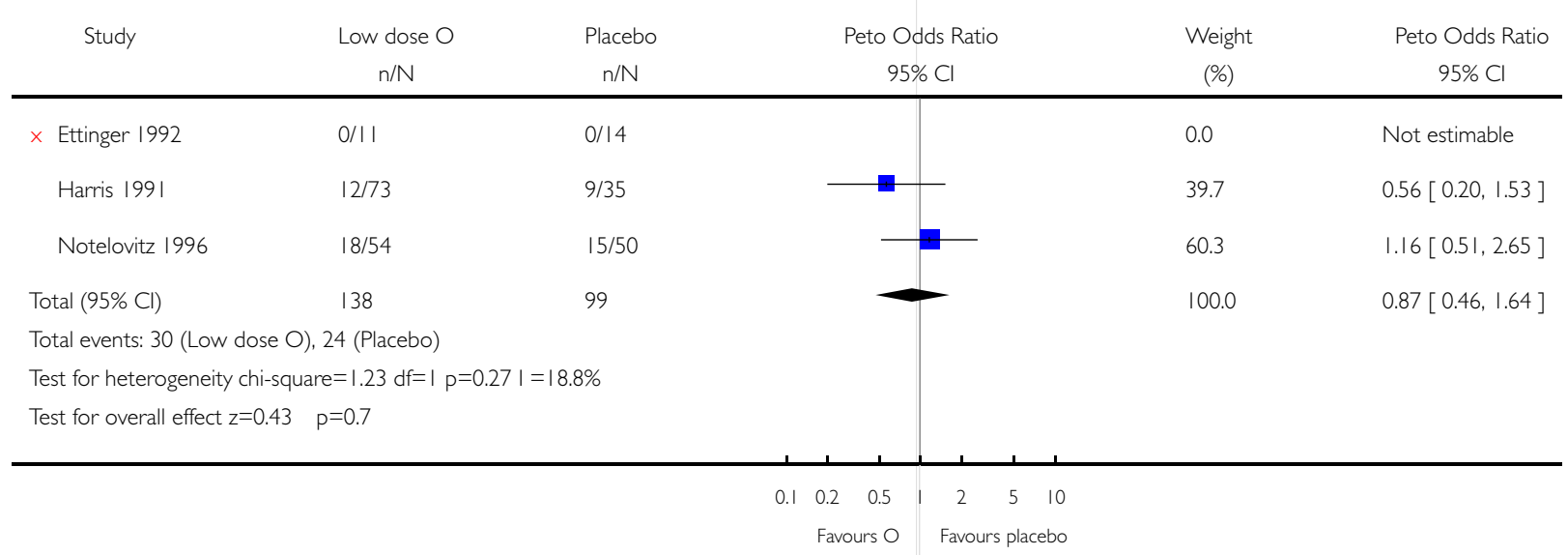




\section{Comparison II. Non adherence to therapy}

Review: Hormone replacement therapy in postmenopausal women: endometrial hyperplasia and irregular bleeding Comparison: OI LOW DOSE OESTROGEN VERSUS PLACEBO

Outcome: 09 Non adherence to therapy

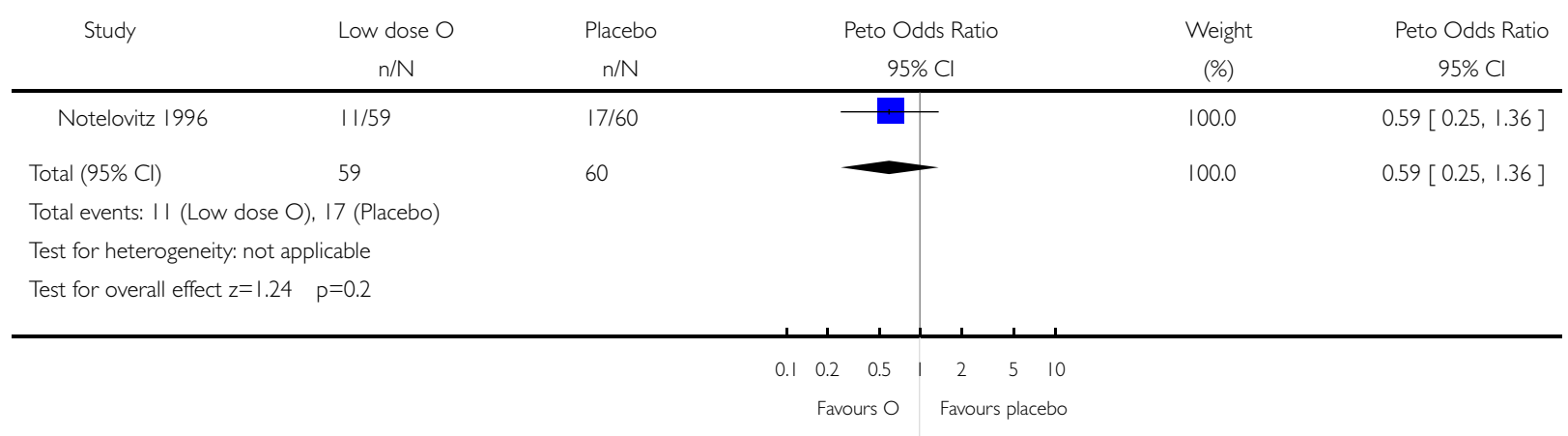

\section{Comparison II. Endometrial hyperplasia at 6 months}

Review: Hormone replacement therapy in postmenopausal women: endometrial hyperplasia and irregular bleeding

Comparison: 02 MODERATE DOSE OESTROGEN VS PLACEBO

Outcome: 0 I Endometrial hyperplasia at 6 months

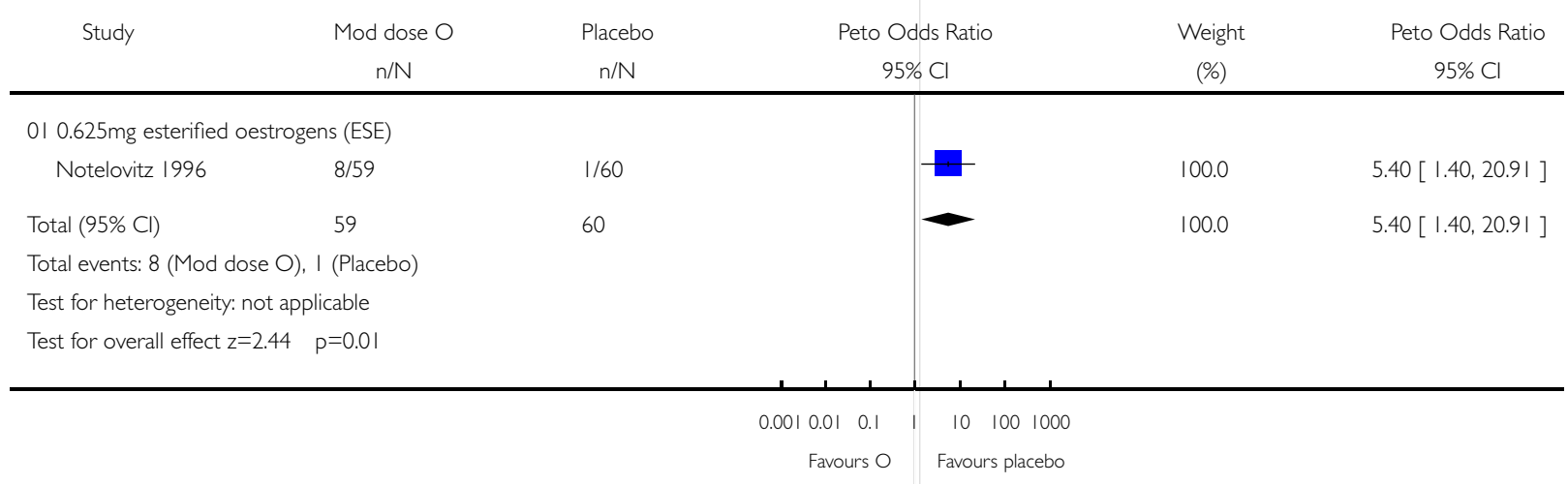




\section{Comparison II. Endometrial hyperplasia at 12 months}

Review: Hormone replacement therapy in postmenopausal women: endometrial hyperplasia and irregular bleeding Comparison: 02 MODERATE DOSE OESTROGEN VS PLACEBO

Outcome: 02 Endometrial hyperplasia at 12 months

Study

Mod dose $\mathrm{O}$

Placebo

Peto Odds Ratio

Weight

Peto Odds Ratio

$\mathrm{n} / \mathrm{N}$

$\mathrm{n} / \mathrm{N}$

$95 \% \mathrm{Cl}$

(\%)

$95 \% \mathrm{Cl}$

OI $0.625 \mathrm{mg}$ conjugated equine oestrogen (CEE)

PEPI $1995 \quad 25 / 119$

$\begin{array}{lll}\text { Pickar 200I 20/249 0/37 } & \text { 201 }\end{array}$

Subtotal $(95 \% \mathrm{Cl}) \quad 368 \quad 156$

Total events: 45 (Mod dose O), 0 (Placebo)

Test for heterogeneity chi-square $=1.5 \mathrm{Idf}=\mid \mathrm{p}=0.22 \mathrm{I}=33.9 \%$

Test for overall effect $z=5.43 \quad p<0.0000$ ।

$020.625 \mathrm{mg}$ esterified oestrogens (ESE)

Notelovitz $1996 \quad$ 12/59

Subtotal $(95 \% \mathrm{Cl})$

59

60

Total events: 12 (Mod dose O), I (Placebo)

Test for heterogeneity: not applicable

Test for overall effect $z=3.25 \quad p=0.00$ I

Total $(95 \% \mathrm{Cl})$

427

$0 / 119$

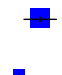

$+$

(1)

Total events: 57 (Mod dose O) । (Placebo)

Test for heterogeneity chi-square $=1.52 \mathrm{df}=2 \mathrm{p}=0.47 \mathrm{|}=0.0 \%$

Test for overall effect $z=6.33 \quad p<0.0000$ l

$\begin{array}{ll}52.8 & 9.26[4.05,21.16] \\ 19.8 & 3.42[0.89,13.23] \\ 72.6 & 7.06[3.49,14.29]\end{array}$




\section{Comparison II. Endometrial hyperplasia at 18-24 months}

Review: Hormone replacement therapy in postmenopausal women: endometrial hyperplasia and irregular bleeding

Comparison: 02 MODERATE DOSE OESTROGEN VS PLACEBO

Outcome: 03 Endometrial hyperplasia at 18-24 months

\begin{tabular}{|c|c|c|c|c|c|}
\hline Study & $n / N$ & $\mathrm{n} / \mathrm{N}$ & $95 \% \mathrm{Cl}$ & $\begin{array}{l}\text { Vveight } \\
(\%)\end{array}$ & $95 \% \mathrm{Cl}$ \\
\hline \multicolumn{6}{|c|}{ OI $0.625 \mathrm{mg}$ conjugated equine oestrogen (CEE) } \\
\hline PEPI 1995 & $54 / 119$ & $0 / 119$ & 畐 & 62.6 & $13.15[7.18,24.08]$ \\
\hline Subtotal $(95 \% \mathrm{Cl})$ & 119 & 119 & $\bullet$ & 62.6 & $13.15[7.18,24.08]$ \\
\hline \multicolumn{6}{|c|}{ Total events: 54 (Mod dose O), 0 (Placebo) } \\
\hline \multicolumn{6}{|c|}{ Test for heterogeneity: not applicable } \\
\hline \multicolumn{6}{|c|}{ Test for overall effect $z=8.34 \quad p<0.0000$ I } \\
\hline \multicolumn{6}{|c|}{$021.0 \mathrm{mg}$ and $2.0 \mathrm{mg}$ micronised I7B oestradiol (E2) } \\
\hline Ettinger 1992 & $4 / 20$ & $0 / 14$ & & 5.3 & $6.49[0.80,52.37]$ \\
\hline Subtotal $(95 \% \mathrm{Cl})$ & 20 & 14 & & 5.3 & $6.49[0.80,52.37]$ \\
\hline \multicolumn{6}{|c|}{ Total events: 4 (Mod dose O), 0 (Placebo) } \\
\hline \multicolumn{6}{|c|}{ Test for heterogeneity: not applicable } \\
\hline \multicolumn{6}{|c|}{ Test for overall effect $z=1.75 \quad p=0.08$} \\
\hline \multicolumn{6}{|c|}{$031.25 \mathrm{mg}$ oestrone sulphate } \\
\hline Harris 1991 & $5 / 30$ & $2 / 24$ & - & 9.2 & $2.06[0.42,10.05]$ \\
\hline Subtotal $(95 \% \mathrm{Cl})$ & 30 & 24 & & 9.2 & $2.06[0.42,10.05]$ \\
\hline \multicolumn{6}{|c|}{ Total events: 5 (Mod dose O), 2 (Placebo) } \\
\hline \multicolumn{6}{|c|}{ Test for heterogeneity: not applicable } \\
\hline \multicolumn{6}{|c|}{ Test for overall effect $z=0.90 \quad p=0.4$} \\
\hline \multicolumn{6}{|c|}{$040.625 \mathrm{mg}$ esterified oestrogens (ESE) } \\
\hline Notelovitz 1996 & $17 / 59$ & $1 / 60$ & $\rightarrow$ & 23.0 & $8.14[3.00,22.10]$ \\
\hline Subtotal $(95 \% \mathrm{Cl})$ & 59 & 60 & $<$ & 23.0 & $8.14[3.00,22.10]$ \\
\hline \multicolumn{6}{|c|}{ Total events: I7 (Mod dose O), I (Placebo) } \\
\hline \multicolumn{6}{|c|}{ Test for heterogeneity: not applicable } \\
\hline \multicolumn{6}{|c|}{ Test for overall effect $z=4.11 \quad p=0.00004$} \\
\hline Total $(95 \% \mathrm{Cl})$ & 228 & 217 & $\bullet$ & 100.0 & $9.58[5.93,15.46]$ \\
\hline \multicolumn{6}{|c|}{ Total events: 80 (Mod dose O), 3 (Placebo) } \\
\hline \multicolumn{6}{|c|}{ Test for heterogeneity chi-square $=4.90 \mathrm{df}=3 \mathrm{p}=0.18 \mathrm{I}=38.7 \%$} \\
\hline Test for overall effect & $p<0.0000$ । & & & & \\
\hline
\end{tabular}

$0.0010 .010 .1 \quad 1 \quad 10 \quad 1001000$

Favours $\bigcirc \quad$ Favours placebo 


\section{Comparison II. Endometrial hyperplasia at 36 months}

Review: Hormone replacement therapy in postmenopausal women: endometrial hyperplasia and irregular bleeding Comparison: 02 MODERATE DOSE OESTROGEN VS PLACEBO

Outcome: 04 Endometrial hyperplasia at 36 months

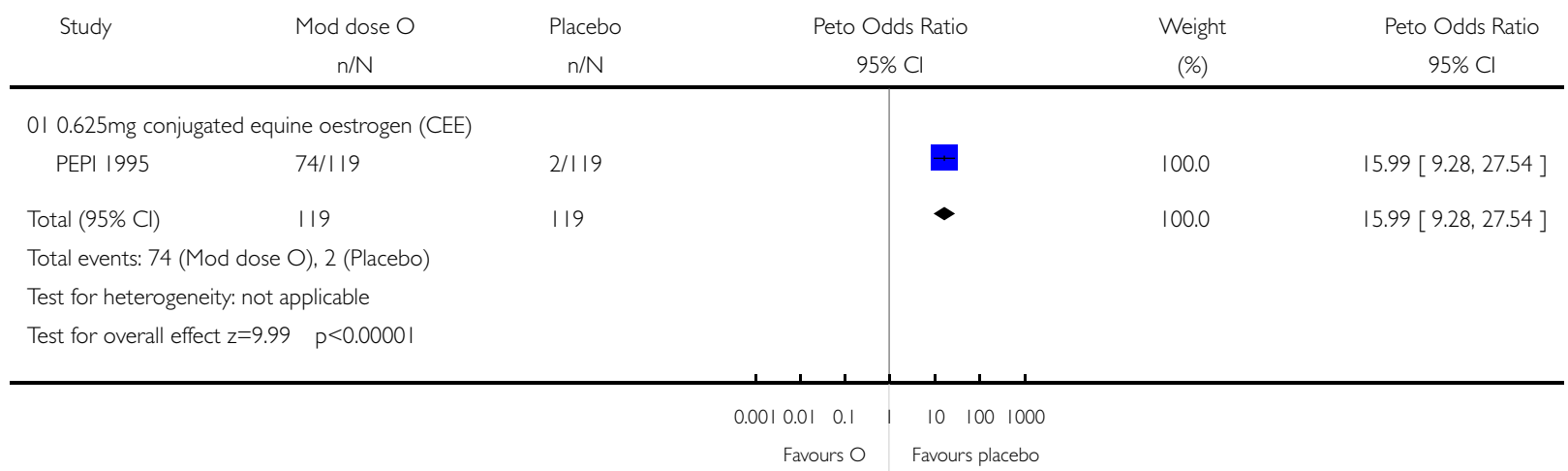

\section{Comparison II. Unscheduled biopsy or D \& C}

Review: Hormone replacement therapy in postmenopausal women: endometrial hyperplasia and irregular bleeding Comparison: 02 MODERATE DOSE OESTROGEN VS PLACEBO

Outcome: 05 Additional investigations (unscheduled biopsy)

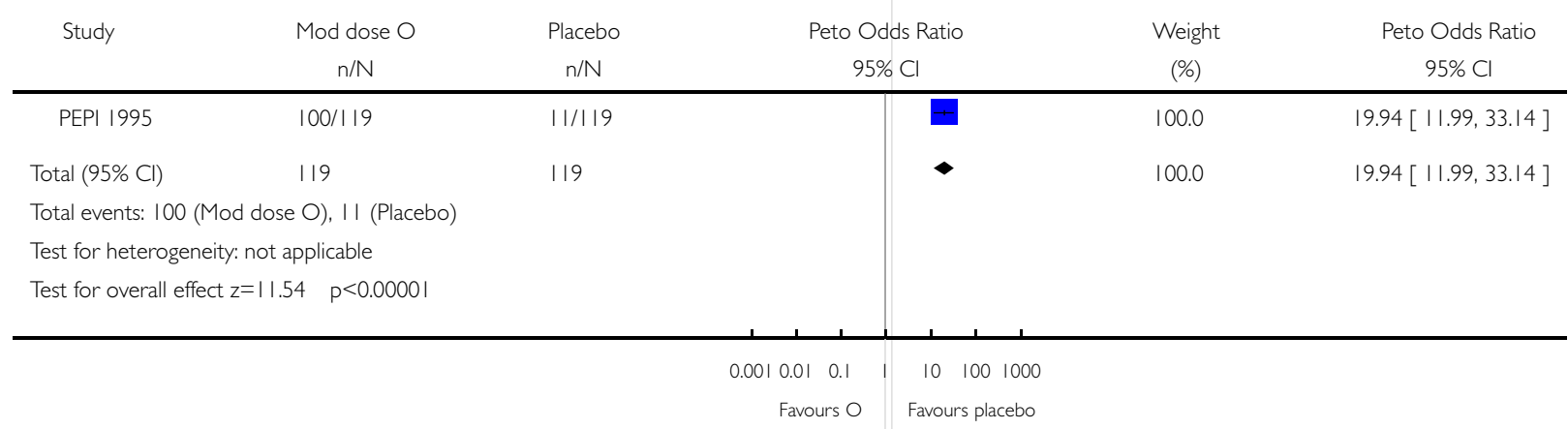




\section{Comparison II. Endometrial cancer}

Review: Hormone replacement therapy in postmenopausal women: endometrial hyperplasia and irregular bleeding Comparison: 02 MODERATE DOSE OESTROGEN VS PLACEBO

Outcome: 06 Endometrial cancer

\begin{tabular}{|c|c|c|c|c|c|}
\hline Study & $\begin{array}{c}\text { Mod dose } O \\
n / N\end{array}$ & $\begin{array}{c}\text { Placebo } \\
\mathrm{n} / \mathrm{N}\end{array}$ & $\begin{array}{c}\text { Peto Odds Ratio } \\
95 \% \mathrm{Cl}\end{array}$ & $\begin{array}{c}\text { Weight } \\
(\%)\end{array}$ & $\begin{array}{c}\text { Peto Odds Ratio } \\
95 \% \mathrm{Cl}\end{array}$ \\
\hline PEPI 1995 & $0 / 119$ & $1 / 119$ & \begin{tabular}{l|l}
+1 & \\
\end{tabular} & 100.0 & $0.14[0.00,6.82]$ \\
\hline Total $(95 \% \mathrm{Cl})$ & 119 & 119 & & 100.0 & $0.14[0.00,6.82]$ \\
\hline \multicolumn{6}{|c|}{ Total events: 0 (Mod dose O), I (Placebo) } \\
\hline \multicolumn{6}{|c|}{ Test for heterogeneity: not applicable } \\
\hline Test for overall & $00=0.3$ & & & & \\
\hline
\end{tabular}

$0.0010 .01 \quad 0.1 \quad 1 \quad 10 \quad 100 \quad 1000$

Favours $O \quad$ Favours placebo

\section{Comparison II. Irregular bleeding patterns $<6 \mathrm{mths}$ from treatment}

Review: Hormone replacement therapy in postmenopausal women: endometrial hyperplasia and irregular bleeding

Comparison: 02 MODERATE DOSE OESTROGEN VS PLACEBO

Outcome: 07 Irregular bleeding patterns $<6$ mths from treatment

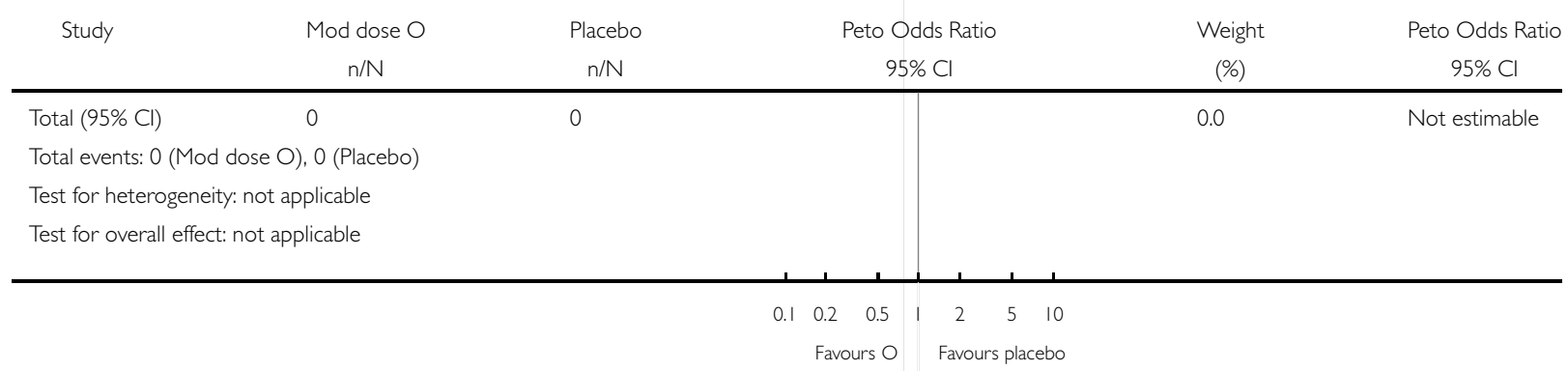




\section{Comparison II. Irregular bleeding patterns $>=6 \mathrm{mths}$ from treatment}

Review: Hormone replacement therapy in postmenopausal women: endometrial hyperplasia and irregular bleeding Comparison: 02 MODERATE DOSE OESTROGEN VS PLACEBO

Outcome: 08 Irregular bleeding patterns $>=6$ mths from treatment

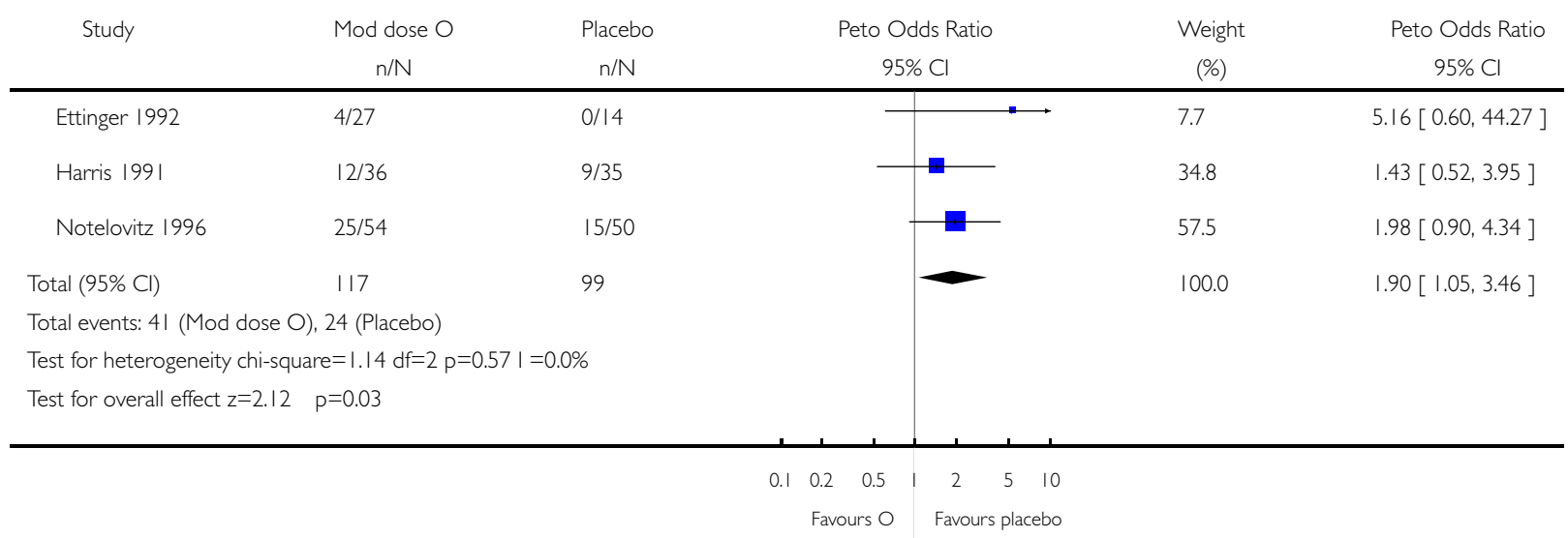

\section{Comparison II. Non adherence to therapy}

Review: Hormone replacement therapy in postmenopausal women: endometrial hyperplasia and irregular bleeding Comparison: 02 MODERATE DOSE OESTROGEN VS PLACEBO

Outcome: 09 Mean number of excess bleeding episodes(36 months)

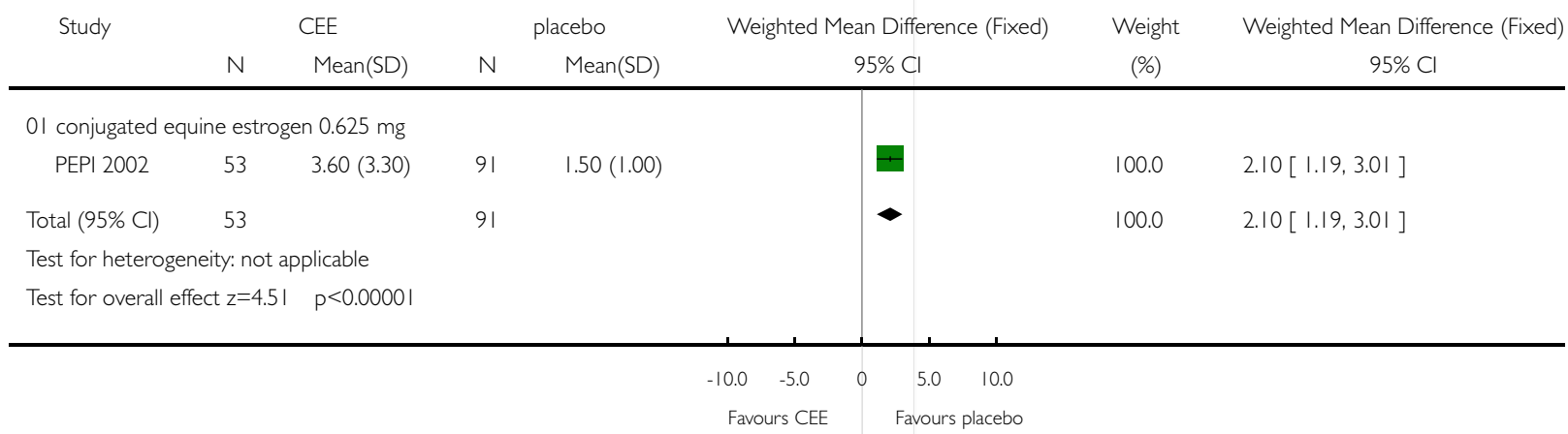




\section{Comparison II. Endometrial hyperplasia at 6 months}

Review: Hormone replacement therapy in postmenopausal women: endometrial hyperplasia and irregular bleeding Comparison: 03 HIGH DOSE OESTROGEN VS PLACEBO

Outcome: 0 I Endometrial hyperplasia at 6 months

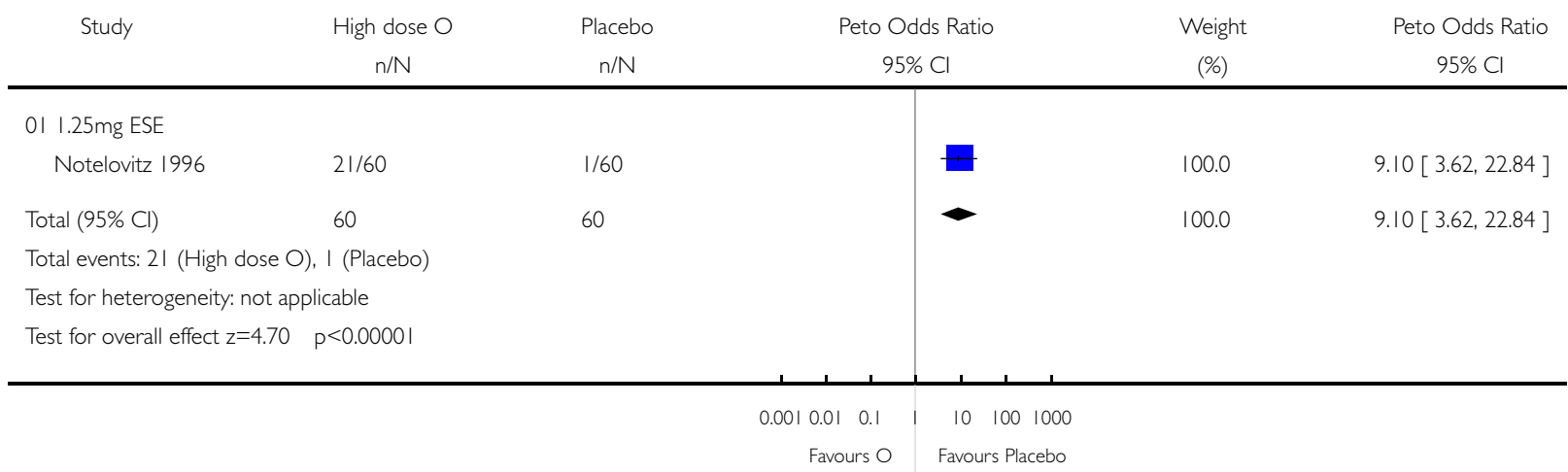

\section{Comparison II. Endometrial hyperplasia at 12 months}

Review: Hormone replacement therapy in postmenopausal women: endometrial hyperplasia and irregular bleeding

Comparison: 03 HIGH DOSE OESTROGEN VS PLACEBO

Outcome: 02 Endometrial hyperplasia at 12 months

$\mathrm{n} / \mathrm{N} \quad \mathrm{n} / \mathrm{N}$

95\% Cl

$011.25 \mathrm{mg}$ ESE

Notelovitz 1996

Total $(95 \% \mathrm{Cl})$

$26 / 60$

60

Total events: 26 (High dose O), I (Placebo)

Test for heterogeneity: not applicable

Test for overall effect $z=5.44 \quad p<0.0000$ I
$1 / 60$

60

60

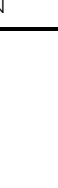

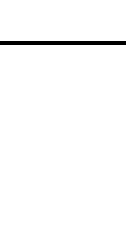

(n)

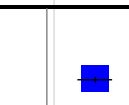

$\begin{array}{ll}100.0 & 10.69[4.55,25.10] \\ 100.0 & 10.69[4.55,25.10]\end{array}$

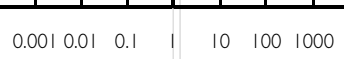

Favours $O \quad$ Favours Placebo 


\section{Comparison II. Endometrial hyperplasia at 24 months}

Review: Hormone replacement therapy in postmenopausal women: endometrial hyperplasia and irregular bleeding Comparison: 03 HIGH DOSE OESTROGEN VS PLACEBO

Outcome: 03 Endometrial hyperplasia at 24 months

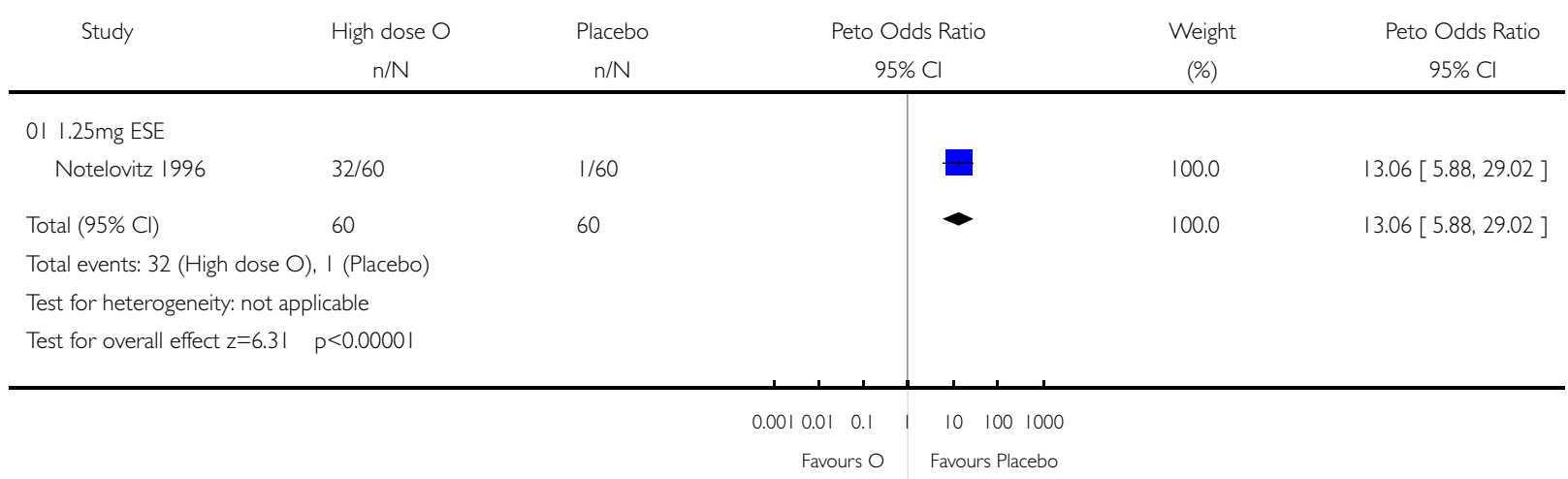

\section{Comparison II. Endometrial hyperplasia at 36 months}

Review: Hormone replacement therapy in postmenopausal women: endometrial hyperplasia and irregular bleeding

Comparison: 03 HIGH DOSE OESTROGEN VS PLACEBO

Outcome: 04 Endometrial hyperplasia at 36 months

\begin{tabular}{|c|c|c|c|c|c|c|}
\hline Study & $\begin{array}{c}\text { High dose } O \\
n / N\end{array}$ & $\begin{array}{c}\text { Placebo } \\
n / N\end{array}$ & \multicolumn{2}{|c|}{ Peto Odds Ratio } & $\begin{array}{c}\text { Weight } \\
(\%)\end{array}$ & $\begin{array}{c}\text { Peto Odds Ratio } \\
95 \% \mathrm{Cl}\end{array}$ \\
\hline \multicolumn{7}{|l|}{$011.25 \mathrm{mg}$ ESE } \\
\hline Total $(95 \% \mathrm{Cl})$ & 0 & 0 & & & 0.0 & Not estimable \\
\hline \multicolumn{7}{|c|}{ Total events: 0 (High dose O), 0 (Placebo) } \\
\hline \multicolumn{7}{|c|}{ Test for heterogeneity: not applicable } \\
\hline \multicolumn{7}{|c|}{ Test for overall effect: not applicable } \\
\hline & & & $0.0010 .01 \quad 0.1$ & $10 \quad 100 \quad 1000$ & & \\
\hline & & & Favours $\bigcirc$ & Favours Placebo & & \\
\hline
\end{tabular}

Hormone replacement therapy in postmenopausal women: endometrial hyperplasia and irregular bleeding

Copyright (c) 2004 The Cochrane Collaboration. Published by John Wiley \& Sons, Ltd 


\section{Comparison II. Unscheduled biopsy or D \& C}

Review: Hormone replacement therapy in postmenopausal women: endometrial hyperplasia and irregular bleeding Comparison: 03 HIGH DOSE OESTROGEN VS PLACEBO

Outcome: 05 Additional investigations (unscheduled biopsy)

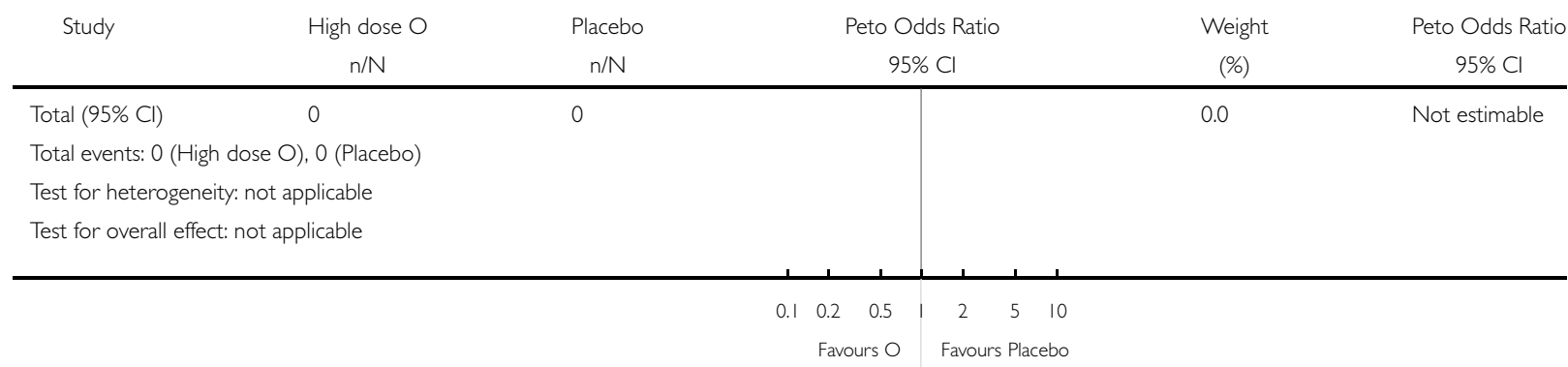

\section{Comparison II. Endometrial cancer}

Review: Hormone replacement therapy in postmenopausal women: endometrial hyperplasia and irregular bleeding Comparison: 03 HIGH DOSE OESTROGEN VS PLACEBO

Outcome: 06 Endometrial cancer

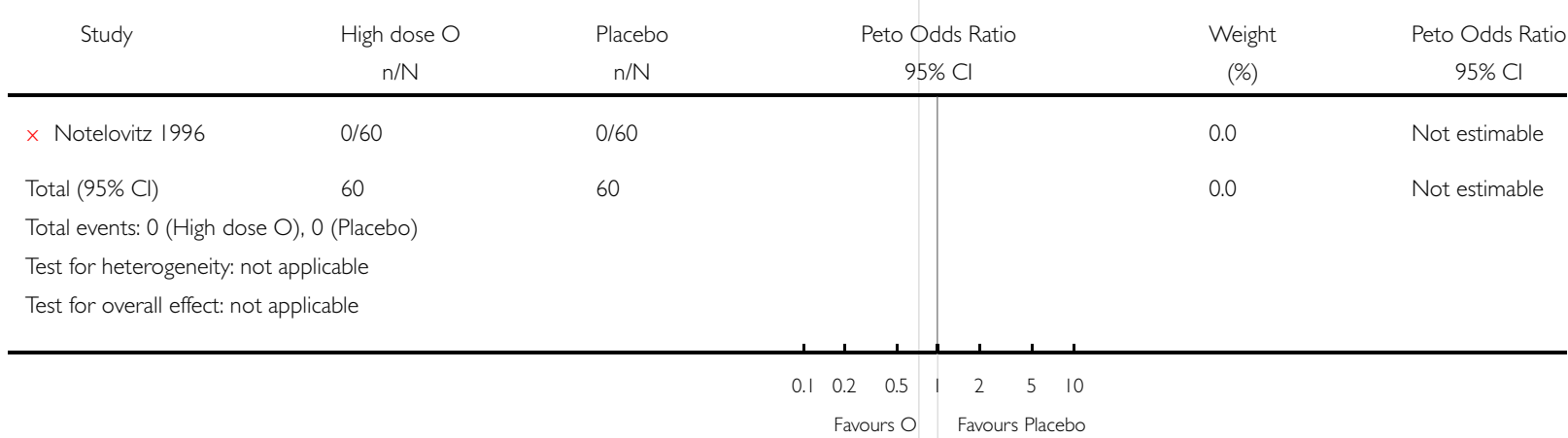

\section{Comparison II. Irregular bleeding patterns $<6 \mathrm{~m}$ ths from treatment}

Review: Hormone replacement therapy in postmenopausal women: endometrial hyperplasia and irregular bleeding Comparison: 03 HIGH DOSE OESTROGEN VS PLACEBO

Outcome: 07 Irregular bleeding patterns $<6$ mths from treatment

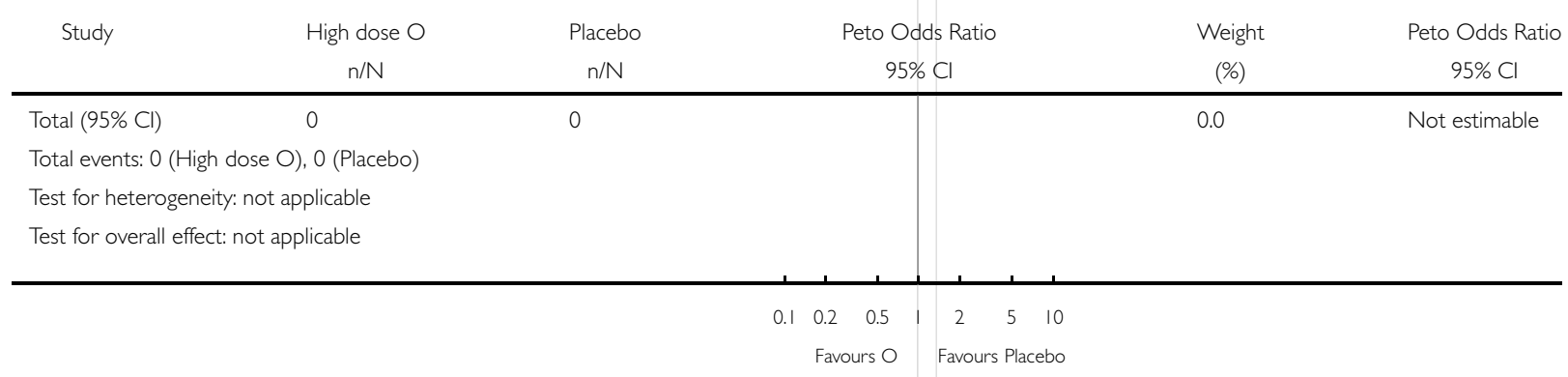

Hormone replacement therapy in postmenopausal women: endometrial hyperplasia and irregular bleeding 


\section{Comparison II. Irregular bleeding patterns $>=6 \mathrm{mths}$ from treatment}

Review: Hormone replacement therapy in postmenopausal women: endometrial hyperplasia and irregular bleeding Comparison: 03 HIGH DOSE OESTROGEN VS PLACEBO

Outcome: 08 Irregular bleeding patterns $>=6$ mths from treatment

\begin{tabular}{|c|c|c|c|c|c|}
\hline Study & $\begin{array}{c}\text { High dose } O \\
n / N\end{array}$ & $\begin{array}{c}\text { Placebo } \\
\mathrm{n} / \mathrm{N}\end{array}$ & $\begin{array}{c}\text { Peto Odds Ratio } \\
95 \% \mathrm{Cl}\end{array}$ & $\begin{array}{c}\text { Weight } \\
(\%)\end{array}$ & $\begin{array}{c}\text { Peto Odds Ratio } \\
95 \% \mathrm{Cl}\end{array}$ \\
\hline Notelovitz 1996 & $42 / 56$ & $15 / 50$ & & 100.0 & $6.01[2.81,12.86]$ \\
\hline Total $(95 \% \mathrm{Cl})$ & 56 & 50 & & 100.0 & $6.01[2.81,12.86]$ \\
\hline \multicolumn{6}{|c|}{ Total events: 42 (High dose O), I5 (Placebo) } \\
\hline \multicolumn{6}{|c|}{ Test for heterogeneity: not applicable } \\
\hline Test for overall effec & $p<0.0000$ & & & & \\
\hline
\end{tabular}

$\begin{array}{lllllll}0.1 & 0.2 & 0.5 & 1 & 2 & 5 & 10\end{array}$

Favours $\mathrm{O}$ Favours Placebo

\section{Comparison II. Non adherence to therapy}

Review: Hormone replacement therapy in postmenopausal women: endometrial hyperplasia and irregular bleeding Comparison: 03 HIGH DOSE OESTROGEN VS PLACEBO

Outcome: 09 Non adherence to therapy

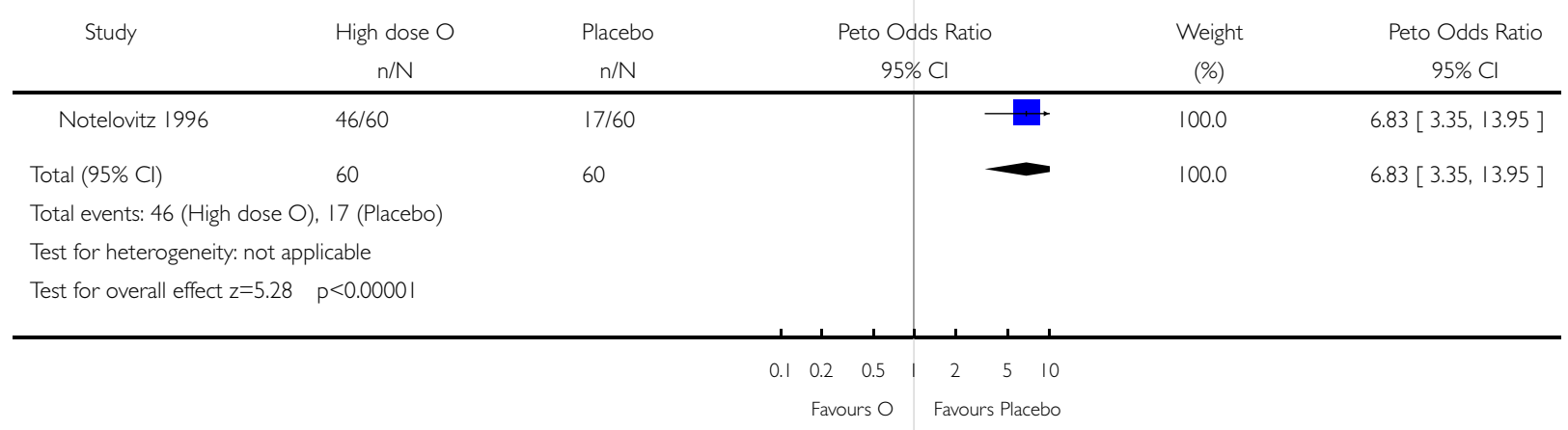




\section{Comparison II. Endometrial hyperplasia at 6 months}

Review: Hormone replacement therapy in postmenopausal women: endometrial hyperplasia and irregular bleeding Comparison: 04 OESTROGEN VS OESTROGEN/PROGESTAGEN (continuous)

Outcome: 0 I Endometrial hyperplasia at 6 months

\begin{tabular}{|c|c|c|c|c|c|}
\hline Study & Oestrogen & Oest + Prog (cont) & Peto Odds Ratio & Weight & Peto Odds Ratio \\
\hline
\end{tabular}

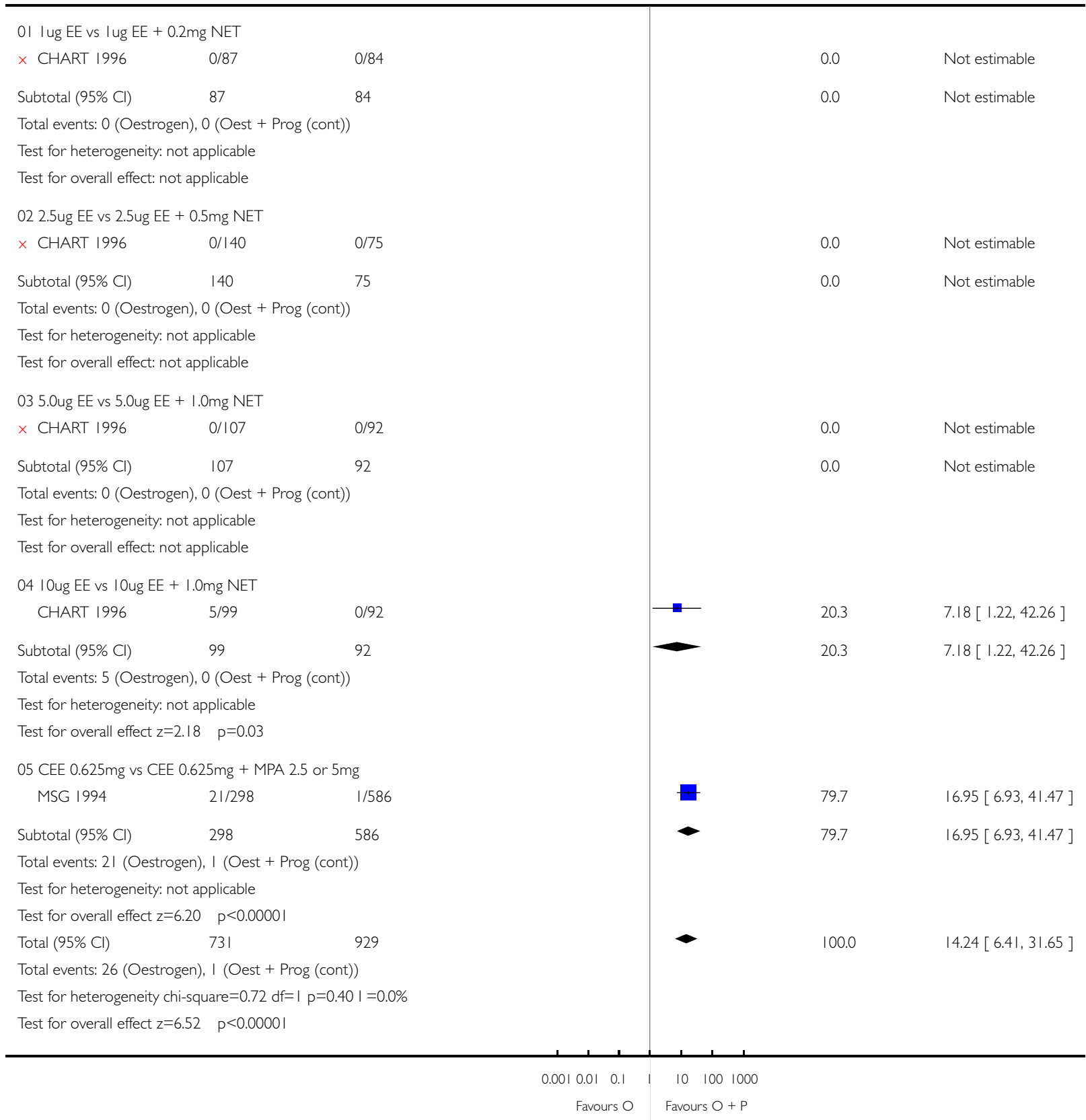

Hormone replacement therapy in postmenopausal women: endometrial hyperplasia and irregular bleeding 


\section{Comparison II. Endometrial hyperplasia at 12 months}

Review: Hormone replacement therapy in postmenopausal women: endometrial hyperplasia and irregular bleeding Comparison: 04 OESTROGEN VS OESTROGEN/PROGESTAGEN (continuous)

Outcome: 02 Endometrial hyperplasia at 12 months

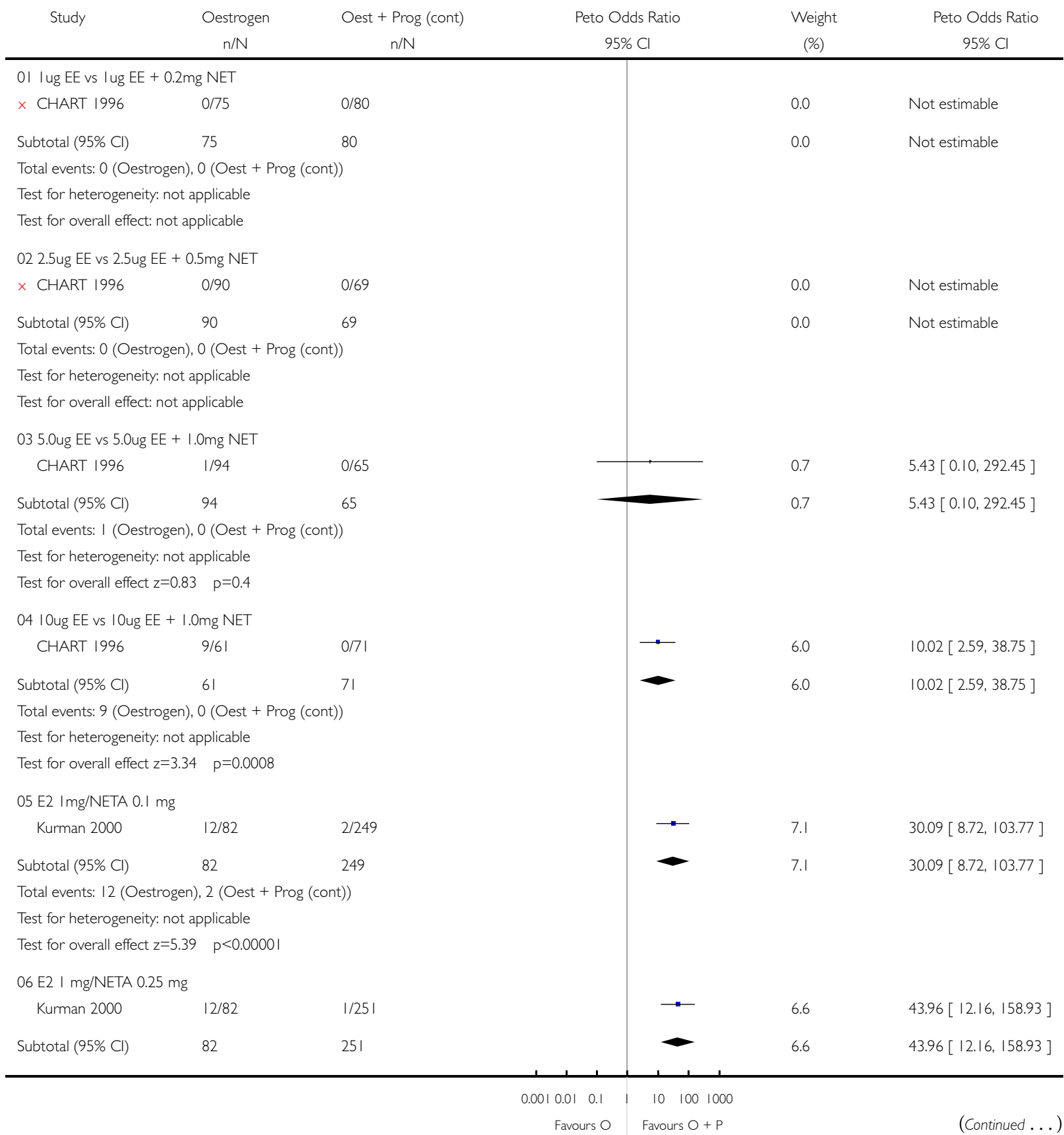



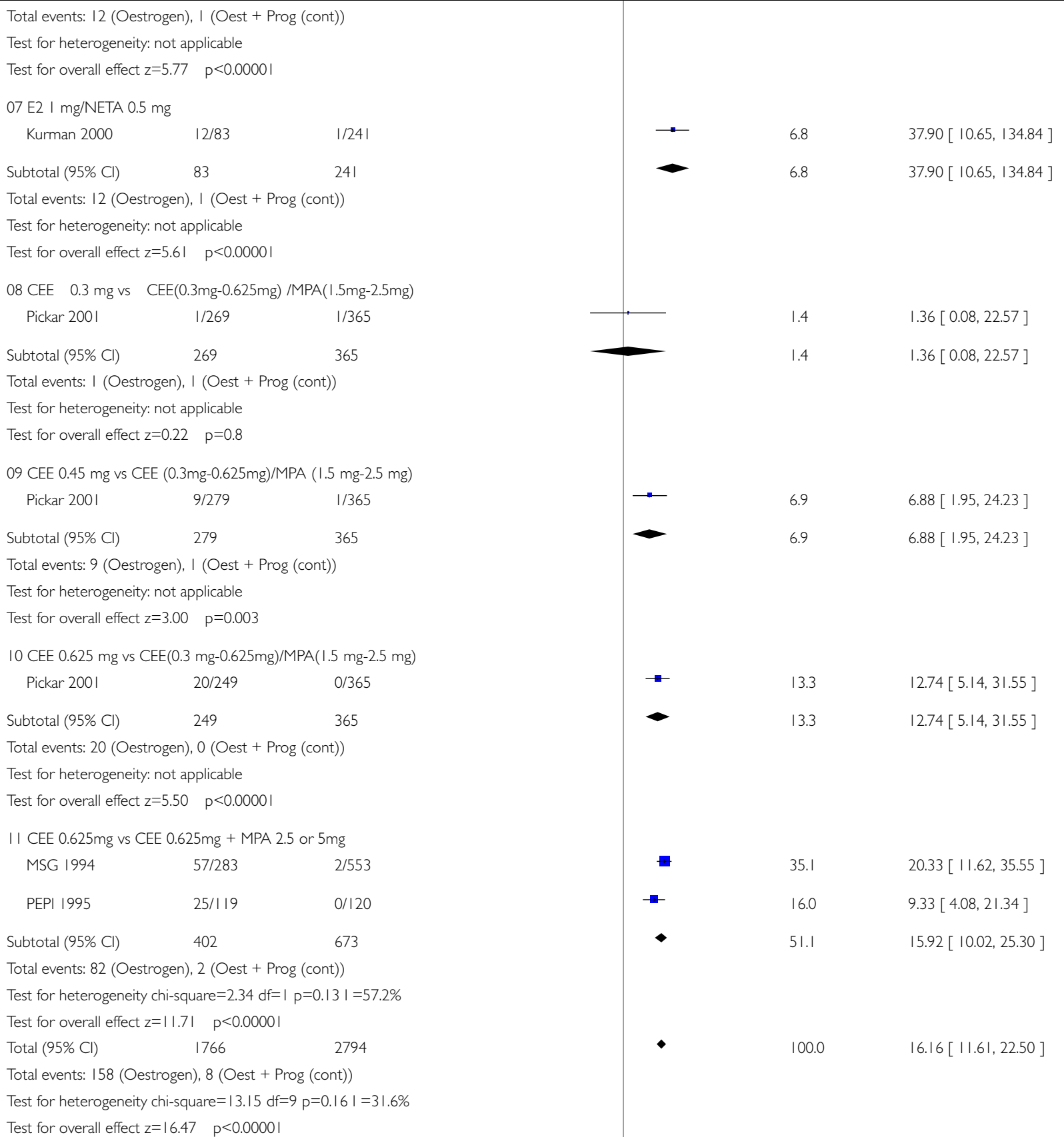

$\begin{array}{lllllll}0.001 & 0.01 & 0.1 & 1 & 10 & 100 & 1000\end{array}$

Favours $\mathrm{O} \quad$ Favours $\mathrm{O}+\mathrm{P}$ 


\section{Comparison II. Endometrial hyperplasia at 24 months}

Review: Hormone replacement therapy in postmenopausal women: endometrial hyperplasia and irregular bleeding Comparison: 04 OESTROGEN VS OESTROGEN/PROGESTAGEN (continuous)

Outcome: 03 Endometrial hyperplasia at 24 months

Study Oestrogen Oest + Prog (cont)

$\mathrm{n} / \mathrm{N}$

$\mathrm{n} / \mathrm{N}$

Peto Odds Ratio

Weight

Peto Odds Ratio

$95 \% \mathrm{Cl}$

OI Iug EE vs Iug EE + 0.2mg NET

CHART 1996

$1 / 69$

Subtotal $(95 \% \mathrm{Cl})$

64

69

Total events: I (Oestrogen), I (Oest + Prog (cont))

Test for heterogeneity: not applicable

Test for overall effect $z=0.05 \quad p=1$

02 2.5ug EE vs 2.5ug EE + 0.5mg NET

$\begin{array}{lll}\text { CHART } 1996 & 1 / 67 & 0 / 57\end{array}$

Subtotal $(95 \% \mathrm{Cl})$

67

$95 \% \mathrm{Cl}$

(\%)

Total events: I (Oestrogen), 0 (Oest + Prog (cont))

Test for heterogeneity: not applicable

Test for overall effect $z=0.92 \quad p=0.4$

03 5.0ug EE vs 5.0ug EE + I.0mg NET

$\begin{array}{lll}\text { CHART } 1996 & 2 / 90 & 0 / 65\end{array}$

Subtotal $(95 \% \mathrm{Cl}) \quad 90 \quad 65$

Total events: 2 (Oestrogen), 0 (Oest + Prog (cont))

Test for heterogeneity: not applicable

Test for overall effect $z=1.21 \quad p=0.2$

04 IOug EE vs IOug EE + 1.0mg NET

$\begin{array}{lll}\text { CHART } 1996 & 0 / 65\end{array}$

Subtotal $(95 \% \mathrm{Cl}) \quad 18 \quad 65$

Total events: 10 (Oestrogen), 0 (Oest + Prog (cont))

Test for heterogeneity: not applicable

Test for overall effect $z=6.37 \quad p<0.0000$ ।

05 CEE $0.625 \mathrm{mg}$ vs CEE $0.625 \mathrm{mg}+$ MPA 2.5 or $5 \mathrm{mg}$

PEPI $1995 \quad 54 / 119 \quad 1 / 120$

Subtotal $(95 \% \mathrm{Cl})$

119

120

Total events: 54 (Oestrogen), I (Oest + Prog (cont))

Test for heterogeneity: not applicable

Test for overall effect $z=8.16 \quad p<0.0000$ ।

Total $(95 \% \mathrm{Cl}) \quad 358 \quad 376$

Total events: 68 (Oestrogen), 2 (Oest + Prog (cont))

Test for heterogeneity chi-square $=13.74 \mathrm{df}=4 \mathrm{p}=0.008 \mathrm{|}=70.9 \%$

Test for overall effect $z=9.79 \quad p<0.0000$ ।

\begin{tabular}{lll}
$\square .7$ & 3.7 & $1.08[0.07,17.47]$ \\
\hline & 3.7 & $1.08[0.07,17.47]$
\end{tabular}

(2)




\section{Comparison II. Endometrial hyperplasia at 36 months}

Review: Hormone replacement therapy in postmenopausal women: endometrial hyperplasia and irregular bleeding Comparison: 04 OESTROGEN VS OESTROGEN/PROGESTAGEN (continuous)

Outcome: 04 Endometrial hyperplasia at 36 months

\begin{tabular}{|c|c|c|c|c|c|}
\hline Study & $\begin{array}{c}\text { Oestrogen } \\
n / N\end{array}$ & $\begin{array}{c}\text { Oest + Prog (cont) } \\
n / N\end{array}$ & $\begin{array}{c}\text { Peto Odds Ratio } \\
95 \% \mathrm{Cl}\end{array}$ & $\begin{array}{c}\text { Weight } \\
(\%)\end{array}$ & $\begin{array}{c}\text { Peto Odds Ratio } \\
95 \% \mathrm{Cl}\end{array}$ \\
\hline
\end{tabular}

OI CEE $0.625 \mathrm{mg}$ vs CEE $0.625 \mathrm{mg}+$ MPA 2.5 or $5 \mathrm{mg}$

PEPI $1995 \quad 74 / 119$

120

100.0

$100.0 \quad 17.07[9.89,29.44]$

Total $(95 \% \mathrm{Cl})$

119

$-\quad 100.0$

$17.07[9.89,29.44]$

Total events: 74 (Oestrogen), I (Oest + Prog (cont))

Test for heterogeneity: not applicable

Test for overall effect $z=10.20 \quad p<0.0000$

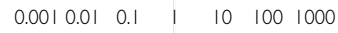

Favours $\mathrm{O} \quad$ Favours $\mathrm{O}+\mathrm{P}$

\section{Comparison II. Unscheduled biopsy or D \& C}

Review: Hormone replacement therapy in postmenopausal women: endometrial hyperplasia and irregular bleeding

Comparison: 04 OESTROGEN VS OESTROGEN/PROGESTAGEN (continuous)

Outcome: 05 Additional investigations (unscheduled biopsy)

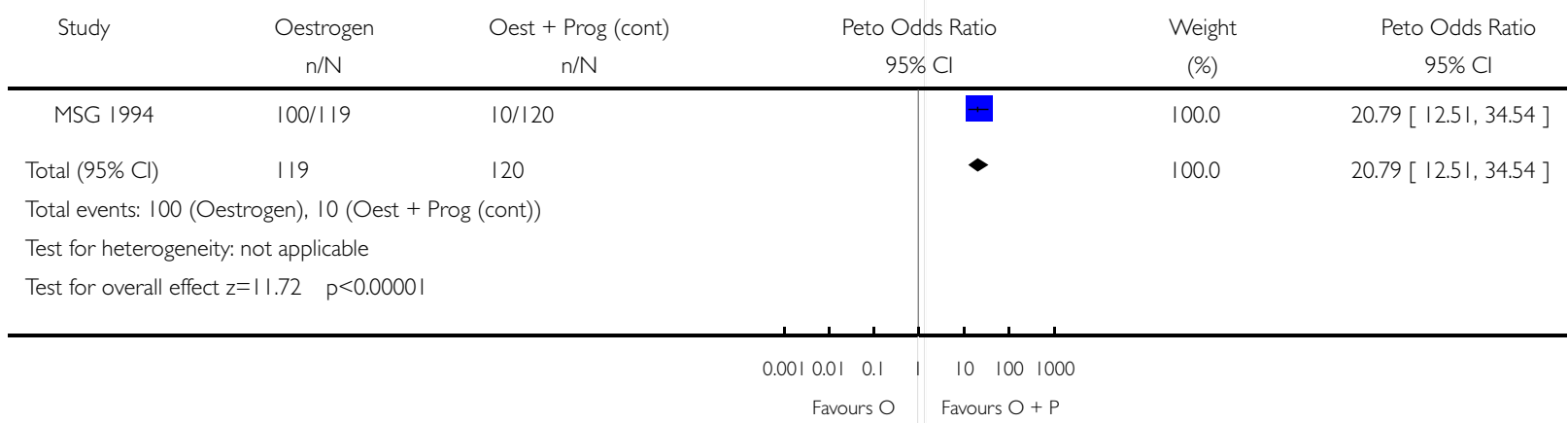




\section{Comparison II. Endometrial cancer}

Review: Hormone replacement therapy in postmenopausal women: endometrial hyperplasia and irregular bleeding Comparison: 04 OESTROGEN VS OESTROGEN/PROGESTAGEN (continuous)

Outcome: 06 Endometrial cancer

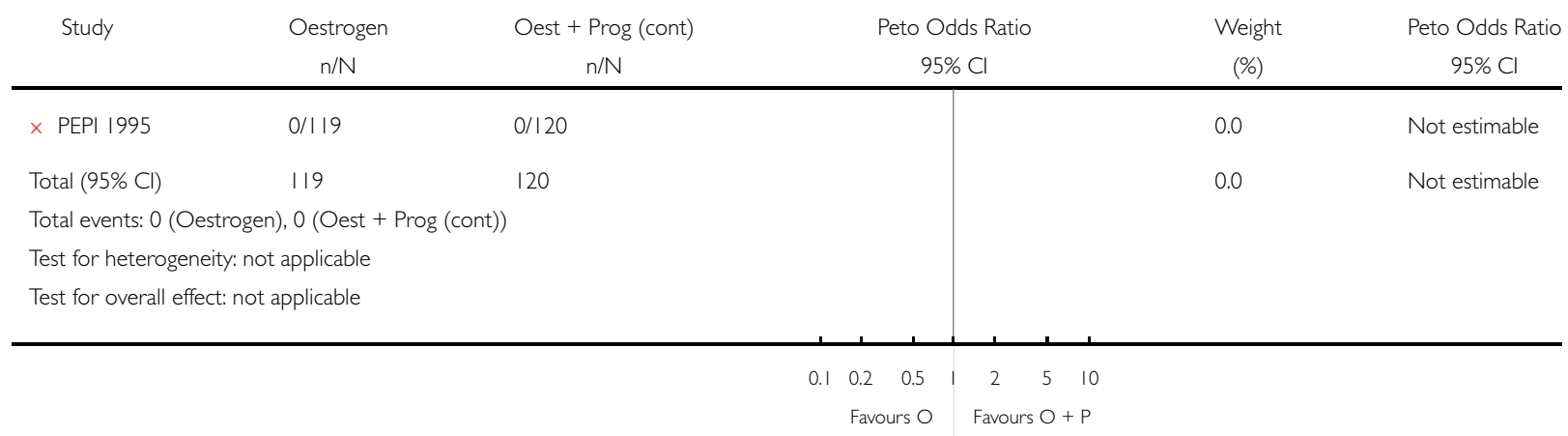

\section{Comparison II. Irregular bleeding patterns $<=6$ months after treatment}

Review: Hormone replacement therapy in postmenopausal women: endometrial hyperplasia and irregular bleeding Comparison: 04 OESTROGEN VS OESTROGEN/PROGESTAGEN (continuous)

Outcome: 07 Irregular bleeding patterns $<=6$ months after treatment

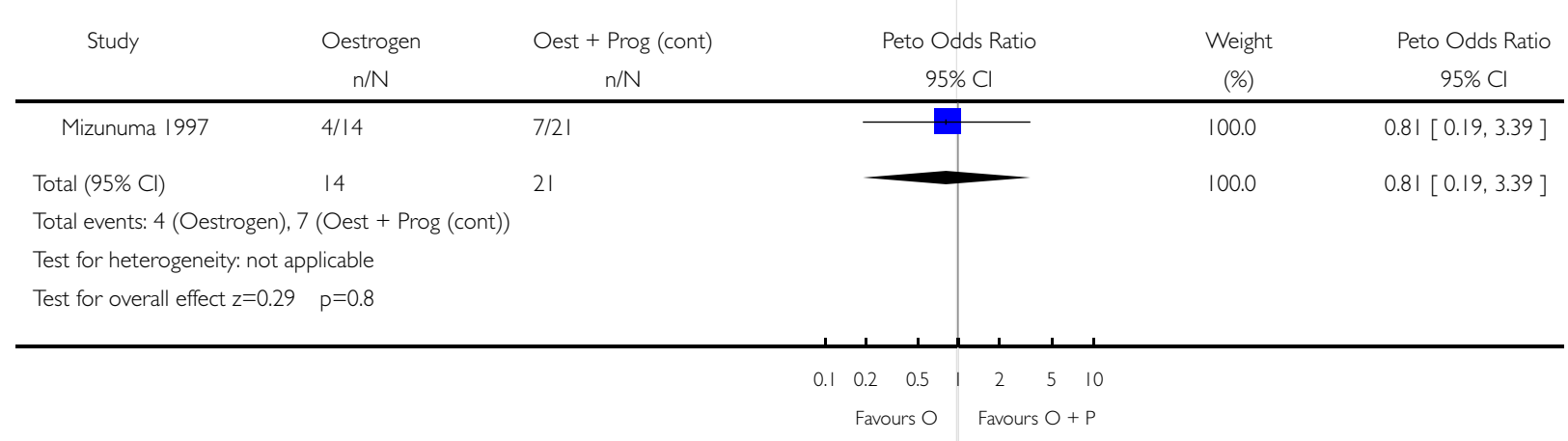




\section{Comparison II. Irregular bleeding patterns $>6$ months after treatment}

Review: Hormone replacement therapy in postmenopausal women: endometrial hyperplasia and irregular bleeding Comparison: 04 OESTROGEN VS OESTROGEN/PROGESTAGEN (continuous)

Outcome: 08 Irregular bleeding at month II

Study Oestrogen $\quad O+P$

$\mathrm{O}+$

$\mathrm{n} / \mathrm{N}$

$\mathrm{n} / \mathrm{N}$

Odds Ratio (Fixed)

Weight

$95 \% \mathrm{Cl}$

(\%)

Odds Ratio (Fixed) $95 \% \mathrm{Cl}$

OI E2 | mg vs E2 I mg/NET 0.1 mg Archer 1999

$61 / 292$

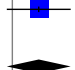

43.2

$1.54[0.91,2.59]$

Subtotal $(95 \% \mathrm{Cl})$

97

292

Total events: 28 (Oestrogen), $6 \mathrm{I}(\mathrm{O}+\mathrm{P})$

Test for heterogeneity: not applicable

Test for overall effect $z=\mid .61 \quad p=0.1$

02 E2 Img vs E2 Img/NET 0.25 mg

Archer $1999 \quad 28 / 98$

Subtotal $(95 \% \mathrm{Cl}) \quad 98$

$98 \quad 290$

290

Total events: 28 (Oestrogen), 49 (O + P)

Test for heterogeneity: not applicable

Test for overall effect $z=2.48 \quad p=0.0$ I

03 E2 I mg vs E2 Img/NET 0.5 mg Archer $1999 \quad 28 / 98$

98

$30 / 290$

Subtotal $(95 \% \mathrm{Cl})$

Total events: 28 (Oestrogen), $30(\mathrm{O}+\mathrm{P})$

Test for heterogeneity: not applicable

Test for overall effect $z=4.21 \quad p=0.00003$

Total $(95 \% \mathrm{Cl})$

293

Total events: 84 (Oestrogen), $140(\mathrm{O}+\mathrm{P})$

Test for heterogeneity chi-square $=4.31 \mathrm{df}=2 \mathrm{p}=0.12 \mathrm{I}=53.6 \%$

Test for overall effect $z=4.68 \quad p<0.0000$ ।

$\begin{array}{lllllll}0.1 & 0.2 & 0.5 & 1 & 2 & 5 & 10\end{array}$

Favours $\mathrm{O}$ Favours $\mathrm{O}+\mathrm{P}$ 


\section{Comparison II. Number of cycles with irregular bleeding at 12 months}

Review: Hormone replacement therapy in postmenopausal women: endometrial hyperplasia and irregular bleeding Comparison: 04 OESTROGEN VS OESTROGEN/PROGESTAGEN (continuous)

Outcome: 09 Number of cycles with irregular bleeding within 12 months

\begin{tabular}{|c|c|c|c|c|c|}
\hline Study & $\begin{array}{l}\text { Oestrogen } \\
n / N\end{array}$ & $\begin{array}{c}\text { Oest }+ \text { Prog (cont) } \\
n / N\end{array}$ & $\begin{array}{l}\text { Peto Odds Ratio } \\
\qquad 95 \% \mathrm{Cl}\end{array}$ & $\begin{array}{c}\text { Weight } \\
(\%)\end{array}$ & $\begin{array}{c}\text { Peto Odds Ratio } \\
95 \% \mathrm{Cl}\end{array}$ \\
\hline MSG 1994 & $532 / 3639$ & $1319 / 7508$ & & 100.0 & $0.81[0.73,0.90]$ \\
\hline Total $(95 \% \mathrm{Cl})$ & 3639 & 7508 & $\bullet$ & 100.0 & $0.81[0.73,0.90]$ \\
\hline \multicolumn{6}{|c|}{ Total events: 532 (Oestrogen), 1319 (Oest + Prog (cont)) } \\
\hline \multicolumn{6}{|c|}{ Test for heterogeneity: not applicable } \\
\hline Test for overall & $.92 p=0.000$ & & & & \\
\hline
\end{tabular}

$\begin{array}{lllllll}0.1 & 0.2 & 0.5 & 1 & 2 & 5 & 10\end{array}$

Favours $\mathrm{O}$ Favours $\mathrm{O}+\mathrm{P}$

\section{Comparison II. Number of cycles with irregular spotting at 12 months}

Review: Hormone replacement therapy in postmenopausal women: endometrial hyperplasia and irregular bleeding

Comparison: 04 OESTROGEN VS OESTROGEN/PROGESTAGEN (continuous)

Outcome: 10 Number of cycles with irregular spotting within 12 months

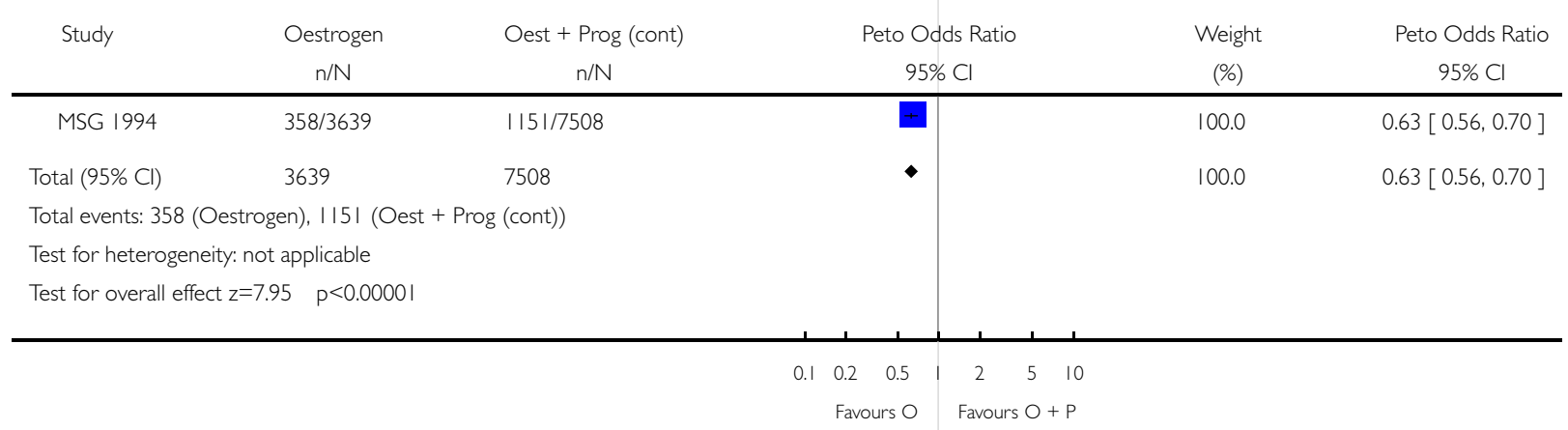




\section{Comparison II. Non adherence to therapy}

Review: Hormone replacement therapy in postmenopausal women: endometrial hyperplasia and irregular bleeding Comparison: 04 OESTROGEN VS OESTROGEN/PROGESTAGEN (continuous)

Outcome: II Non adherence to therapy

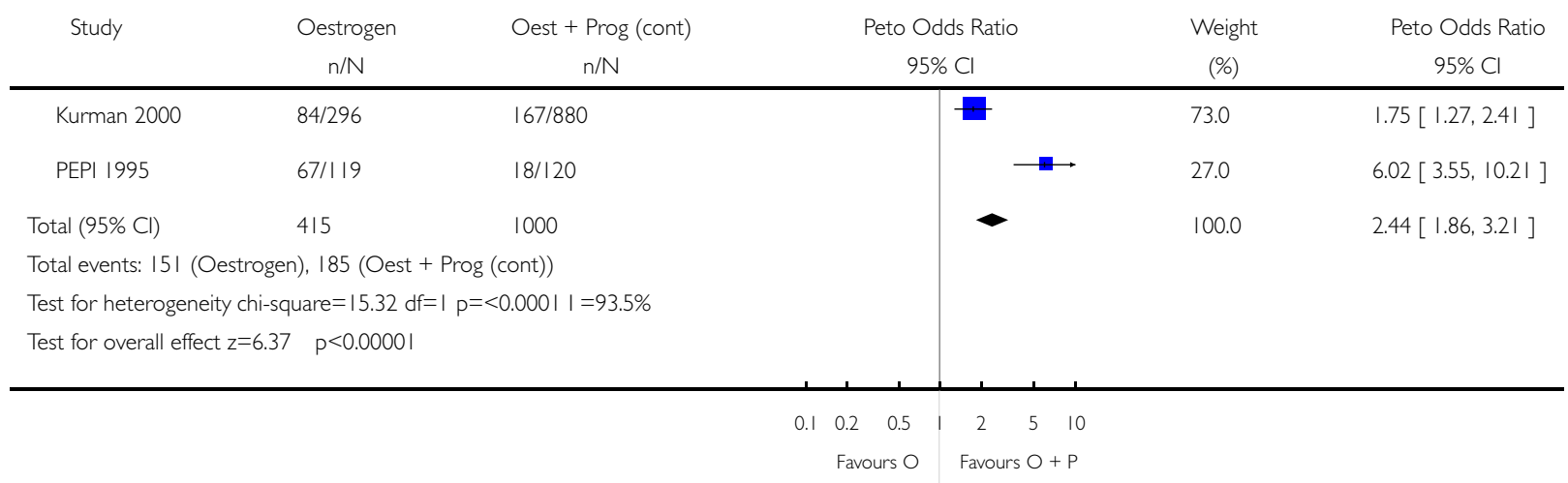

\section{Comparison II. Endometrial hyperplasia at 6 months}

Review: Hormone replacement therapy in postmenopausal women: endometrial hyperplasia and irregular bleeding

Comparison: 05 OESTROGEN VS OESTROGEN + PROGESTAGEN (sequential)

Outcome: 0 I Endometrial hyperplasia at 6 months

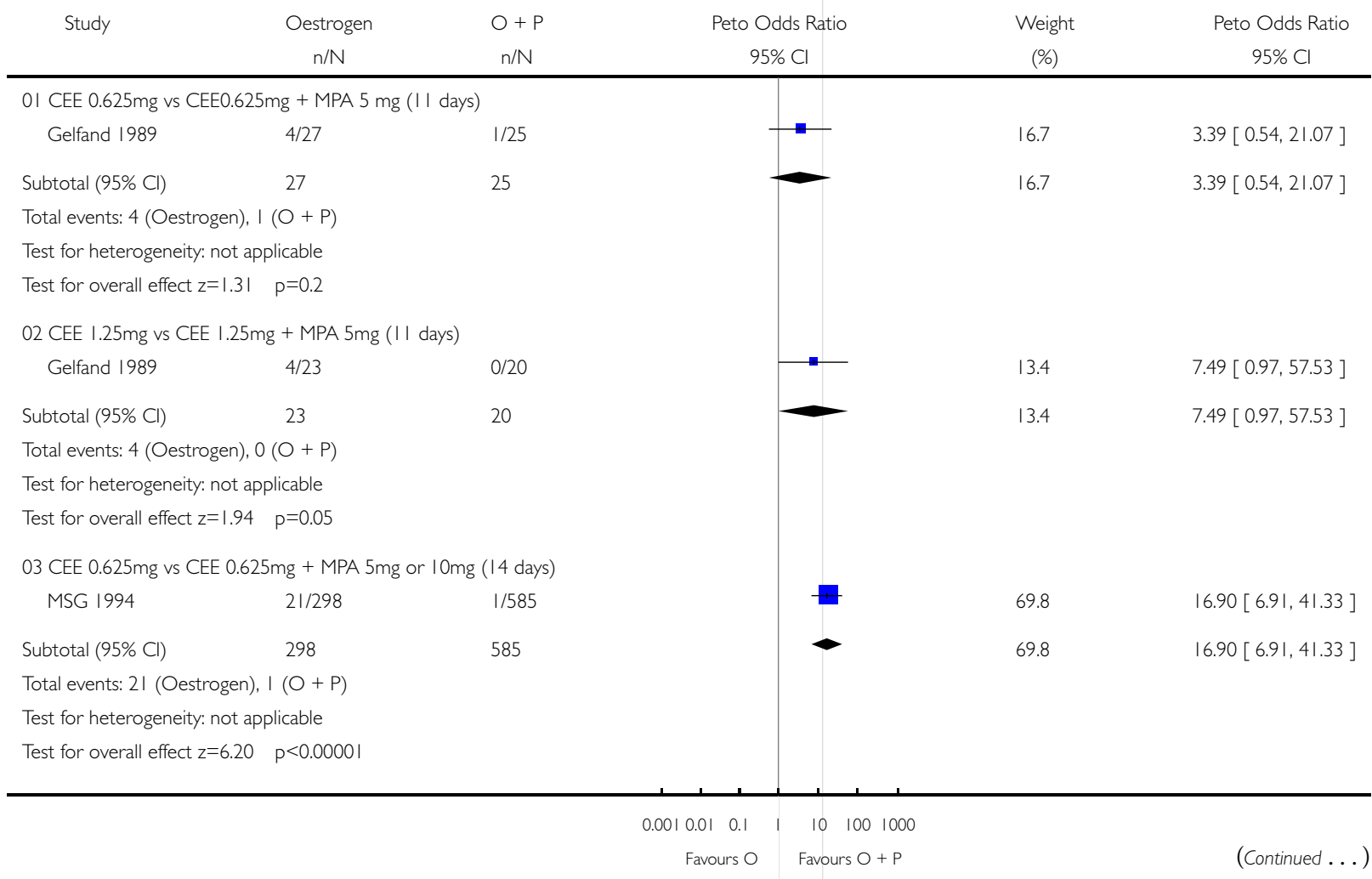




\begin{tabular}{|c|c|c|c|c|c|}
\hline Study & $\begin{array}{c}\text { Oestrogen } \\
n / N\end{array}$ & $\begin{array}{l}O+P \\
n / N\end{array}$ & $\begin{array}{c}\text { Peto Odds Ratio } \\
95 \% \mathrm{Cl}\end{array}$ & $\begin{array}{l}\text { Weight } \\
(\%)\end{array}$ & $\begin{array}{c}\text { Peto Odds Ratio } \\
95 \% \mathrm{Cl}\end{array}$ \\
\hline Total $(95 \% \mathrm{Cl})$ & 348 & 630 & $\prec$ & 100.0 & । I.58 [5.48, 24.45 ] \\
\hline \multicolumn{6}{|c|}{ Total events: 29 (Oestrogen), $2(\mathrm{O}+\mathrm{P})$} \\
\hline \multicolumn{6}{|c|}{ Test for heterogeneity chi-square $=2.60 \mathrm{df}=2 \mathrm{p}=0.27 \mathrm{I}=23.0 \%$} \\
\hline Test for overal & $p<0.0000$ & & & & \\
\hline
\end{tabular}

\section{Comparison II. Endometrial hyperplasia at 12 months}

Review: Hormone replacement therapy in postmenopausal women: endometrial hyperplasia and irregular bleeding Comparison: 05 OESTROGEN VS OESTROGEN + PROGESTAGEN (sequential)

Outcome: 02 Endometrial hyperplasia at 12 months

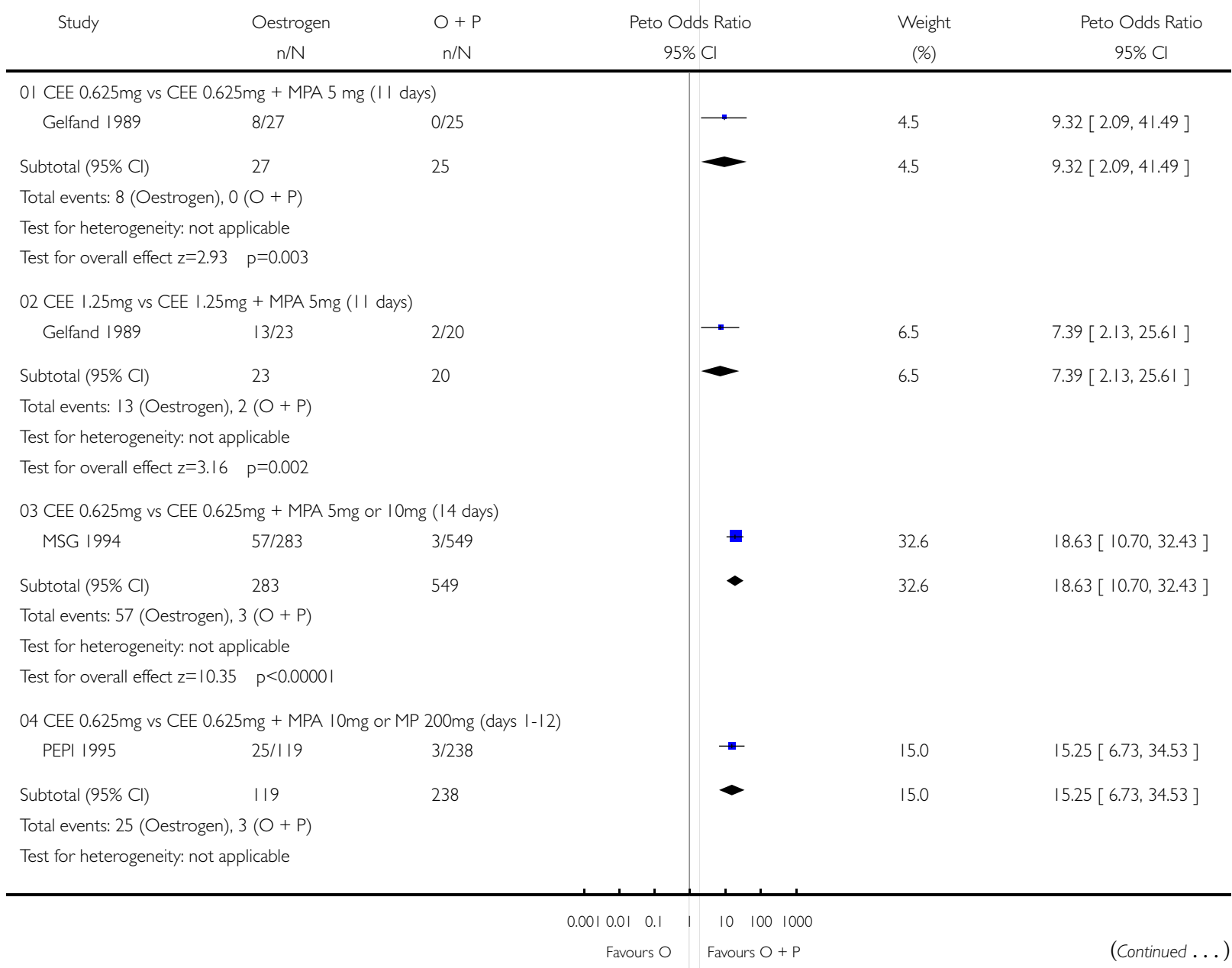




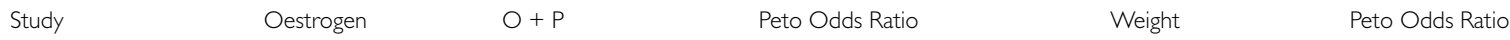

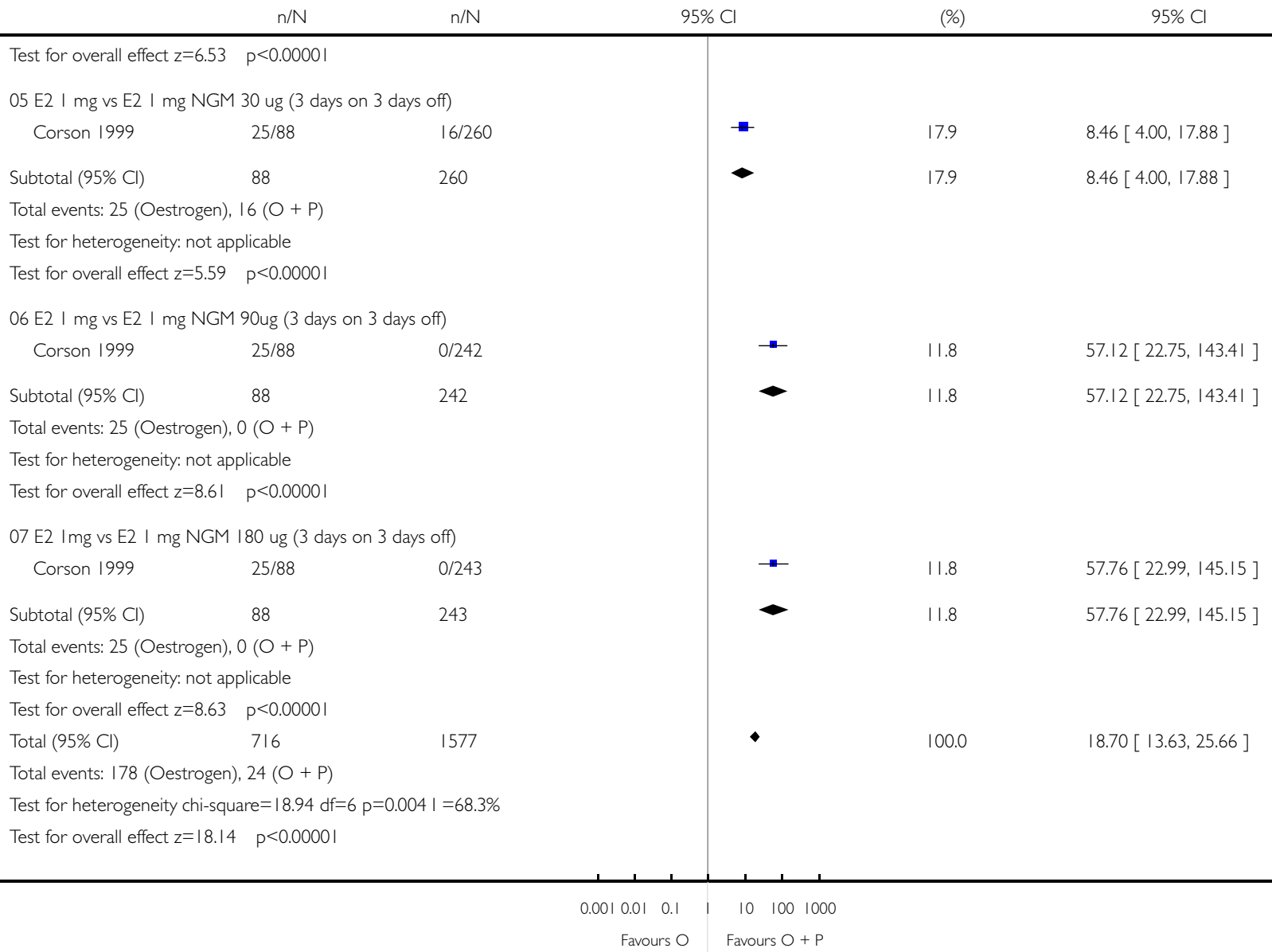

\section{Comparison II. Endometrial hyperplasia at 24 months}

Review: Hormone replacement therapy in postmenopausal women: endometrial hyperplasia and irregular bleeding

Comparison: 05 OESTROGEN VS OESTROGEN + PROGESTAGEN (sequential)

Outcome: 03 Endometrial hyperplasia at 24 months

\begin{tabular}{|c|c|c|c|c|c|}
\hline Study & $\begin{array}{c}\text { Oestrogen } \\
n / N\end{array}$ & $\begin{array}{l}\mathrm{O}+\mathrm{P} \\
\mathrm{n} / \mathrm{N}\end{array}$ & Peto Odds Ratio & $\begin{array}{l}\text { Weight } \\
(\%)\end{array}$ & $\begin{array}{c}\text { Peto Odds Ratio } \\
\quad 95 \% \mathrm{Cl}\end{array}$ \\
\hline \multicolumn{6}{|c|}{ OI CEE $0.625 \mathrm{mg}$ vs CEE $0.625 \mathrm{mg}+$ MPA IOmg or MP 200mg (days I-12) } \\
\hline PEPI 1995 & $54 / 119$ & $7 / 238$ & + & 100.0 & $19.83[11.06,35.55]$ \\
\hline Total $(95 \% \mathrm{Cl})$ & 119 & 238 & $\bullet$ & 100.0 & $19.83[11.06,35.55]$ \\
\hline \multicolumn{6}{|c|}{ Total events: 54 (Oestrogen), 7 (O + P) } \\
\hline \multicolumn{6}{|c|}{ Test for heterogeneity: not applicable } \\
\hline \multicolumn{6}{|c|}{ Test for overall effect $z=|0.03 \quad p<0.0000|$} \\
\hline \multicolumn{6}{|c|}{ 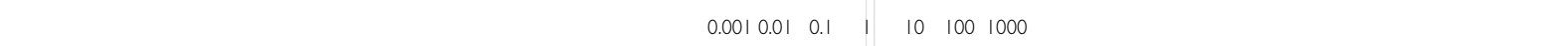 } \\
\hline & & & avours $\mathrm{O}$ & & \\
\hline
\end{tabular}




\section{Comparison II. Endometrial hyperplasia at 36 months}

Review: Hormone replacement therapy in postmenopausal women: endometrial hyperplasia and irregular bleeding Comparison: 05 OESTROGEN VS OESTROGEN + PROGESTAGEN (sequential)

Outcome: 04 Endometrial hyperplasia at 36 months

\begin{tabular}{|c|c|c|c|c|c|}
\hline Study & $\begin{array}{c}\text { Oestrogen } \\
n / N\end{array}$ & $\begin{array}{l}O+P \\
n / N\end{array}$ & $\begin{array}{c}\text { Peto Odds Ratio } \\
95 \% \mathrm{Cl}\end{array}$ & $\begin{array}{c}\text { Weight } \\
(\%)\end{array}$ & $\begin{array}{c}\text { Peto Odds Ratio } \\
95 \% \mathrm{Cl}\end{array}$ \\
\hline
\end{tabular}

OI CEE 0.625mg vs CEE 0.625mg + MPA I0mg or MP 200mg (days I- I2)

PEPI $1995 \quad 74 / 119$

Total $(95 \% \mathrm{Cl}) \quad 238$

$238 \quad \bullet \quad 100.0$

$22.56[13.49,37.7 \mid]$

Total events: 74 (Oestrogen), $12(\mathrm{O}+\mathrm{P})$

Test for heterogeneity: not applicable

Test for overall effect $z=11.89 \quad p<0.0000$

$0.0010 .010 .1 \quad 1 \quad 10 \quad 100 \quad 1000$

Favours $\mathrm{O}$ Favours $\mathrm{O}+\mathrm{P}$

\section{Comparison II. Unscheduled biopsy or D \& C}

Review: Hormone replacement therapy in postmenopausal women: endometrial hyperplasia and irregular bleeding

Comparison: 05 OESTROGEN VS OESTROGEN + PROGESTAGEN (sequential)

Outcome: 05 Additional investigations (unscheduled biopsy)

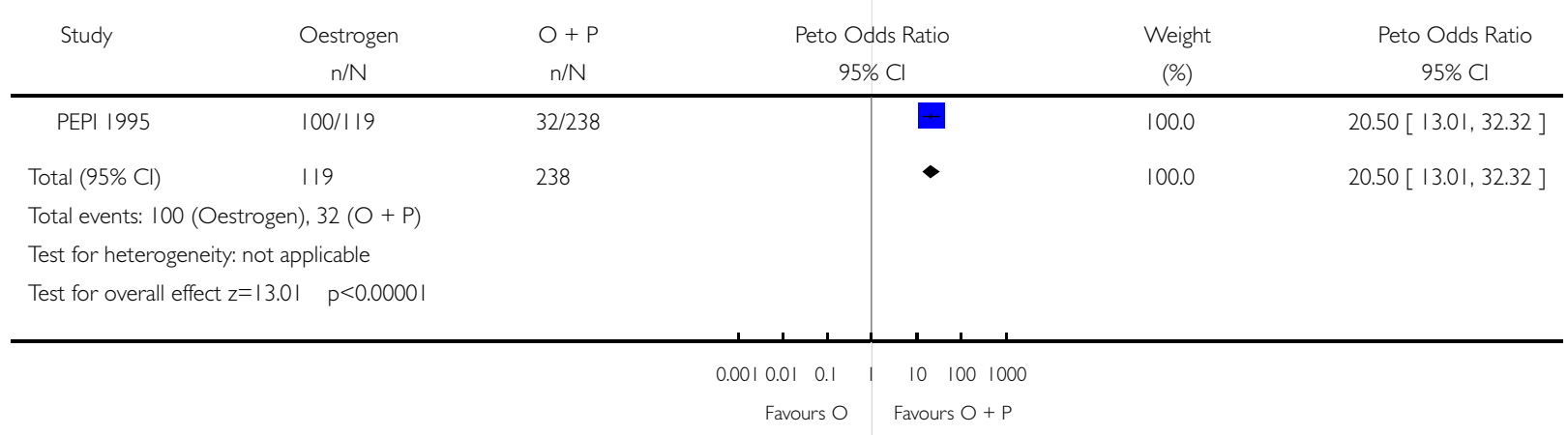




\section{Comparison II. Endometrial cancer}

Review: Hormone replacement therapy in postmenopausal women: endometrial hyperplasia and irregular bleeding Comparison: 05 OESTROGEN VS OESTROGEN + PROGESTAGEN (sequential)

Outcome: 06 Endometrial cancer

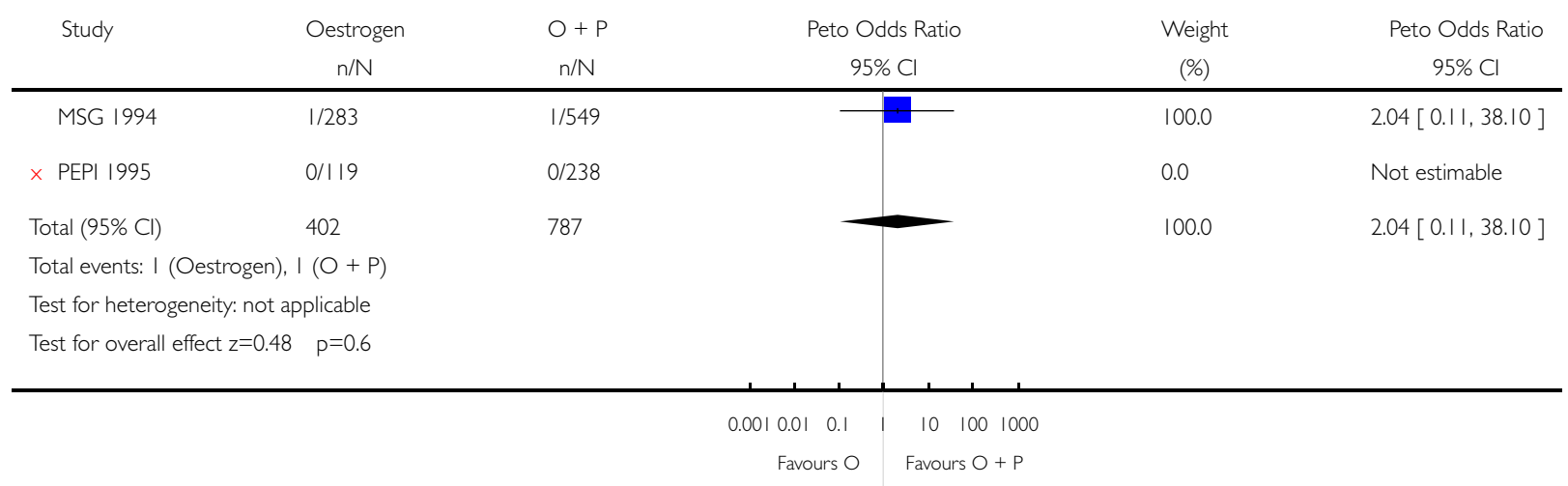

\section{Comparison II. Irregular bleeding patterns $<6$ months after $\mathbf{R x}$}

Review: Hormone replacement therapy in postmenopausal women: endometrial hyperplasia and irregular bleeding Comparison: 05 OESTROGEN VS OESTROGEN + PROGESTAGEN (sequential)

Outcome: 07 Irregular bleeding patterns $<6$ months after $R x$

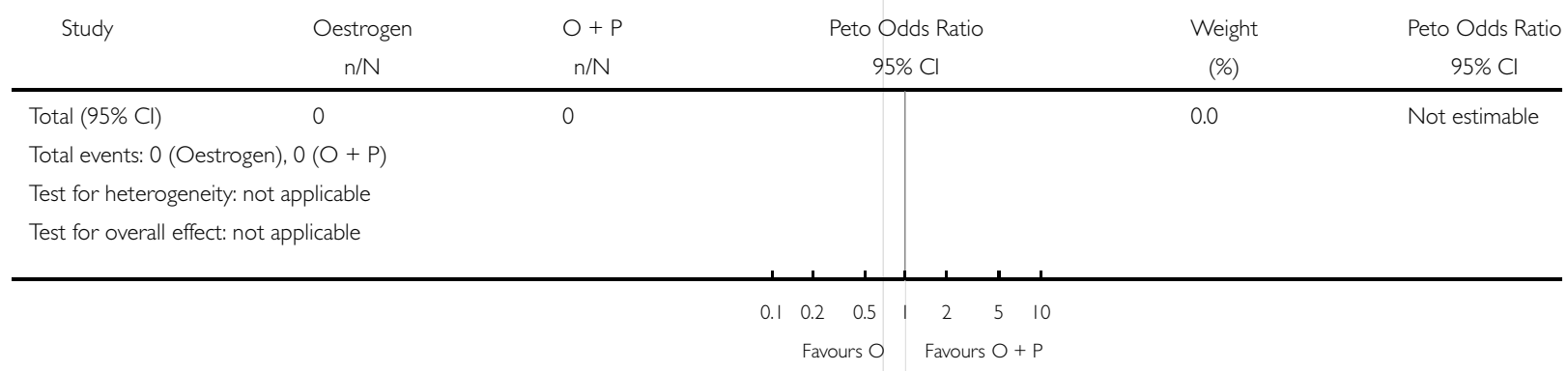




\section{Comparison II. Irregular bleeding patterns $>\mathbf{6}$ months after $\mathbf{R x}$}

Review: Hormone replacement therapy in postmenopausal women: endometrial hyperplasia and irregular bleeding Comparison: 05 OESTROGEN VS OESTROGEN + PROGESTAGEN (sequential)

Outcome: 08 Irregular bleeding patterns $>6$ months after $R x$

\begin{tabular}{|c|c|c|c|c|c|}
\hline Study & $\begin{array}{c}\text { Oestrogen } \\
n / N\end{array}$ & $\begin{array}{l}\mathrm{O}+\mathrm{P} \\
\mathrm{n} / \mathrm{N}\end{array}$ & $\begin{array}{c}\text { Peto Odds Ratio } \\
95 \% \mathrm{Cl}\end{array}$ & $\begin{array}{c}\text { Weight } \\
(\%)\end{array}$ & $\begin{array}{c}\text { Peto Odds Ratio } \\
95 \% \mathrm{Cl}\end{array}$ \\
\hline Gelfand 1989 & $27 / 50$ & $6 / 45$ & & 100.0 & $5.90[2.54,13.69]$ \\
\hline Total $(95 \% \mathrm{Cl})$ & 50 & 45 & & 100.0 & $5.90[2.54,13.69]$ \\
\hline \multicolumn{6}{|c|}{ Total events: 27 (Oestrogen), $6(\mathrm{O}+\mathrm{P})$} \\
\hline \multicolumn{6}{|c|}{ Test for heterogeneity: not applicable } \\
\hline Test for overall ef & $p=0.00004$ & & & & \\
\hline
\end{tabular}

$\begin{array}{lllllll}0.1 & 0.2 & 0.5 & 1 & 2 & 5 & 10\end{array}$

Favours $\mathrm{O}$ Favours $\mathrm{O}+\mathrm{P}$

\section{Comparison II. Number of cycles of irregular bleeding}

Review: Hormone replacement therapy in postmenopausal women: endometrial hyperplasia and irregular bleeding

Comparison: 05 OESTROGEN VS OESTROGEN + PROGESTAGEN (sequential)

Outcome: 09 Number of cycles of irregular bleeding

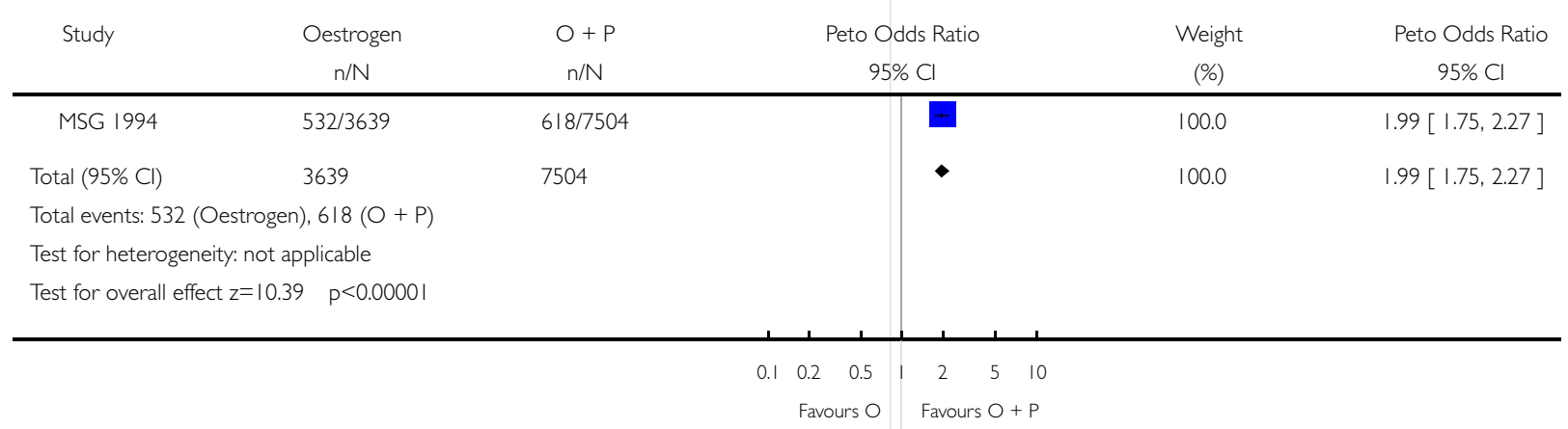




\section{Comparison II. Number of cycles of irregular spotting}

Review: Hormone replacement therapy in postmenopausal women: endometrial hyperplasia and irregular bleeding Comparison: 05 OESTROGEN VS OESTROGEN + PROGESTAGEN (sequential)

Outcome: 10 Number of cycles of irregular spotting

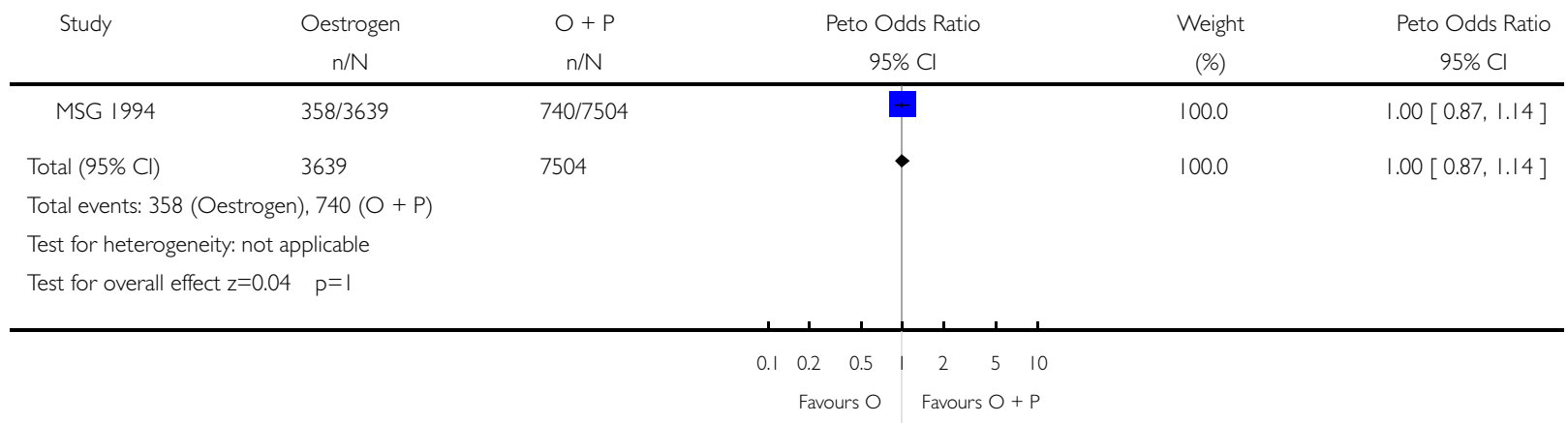

\section{Comparison II. Non adherence to therapy}

Review: Hormone replacement therapy in postmenopausal women: endometrial hyperplasia and irregular bleeding Comparison: 05 OESTROGEN VS OESTROGEN + PROGESTAGEN (sequential)

Outcome: II Irregular bleeding/spotting at 12 months

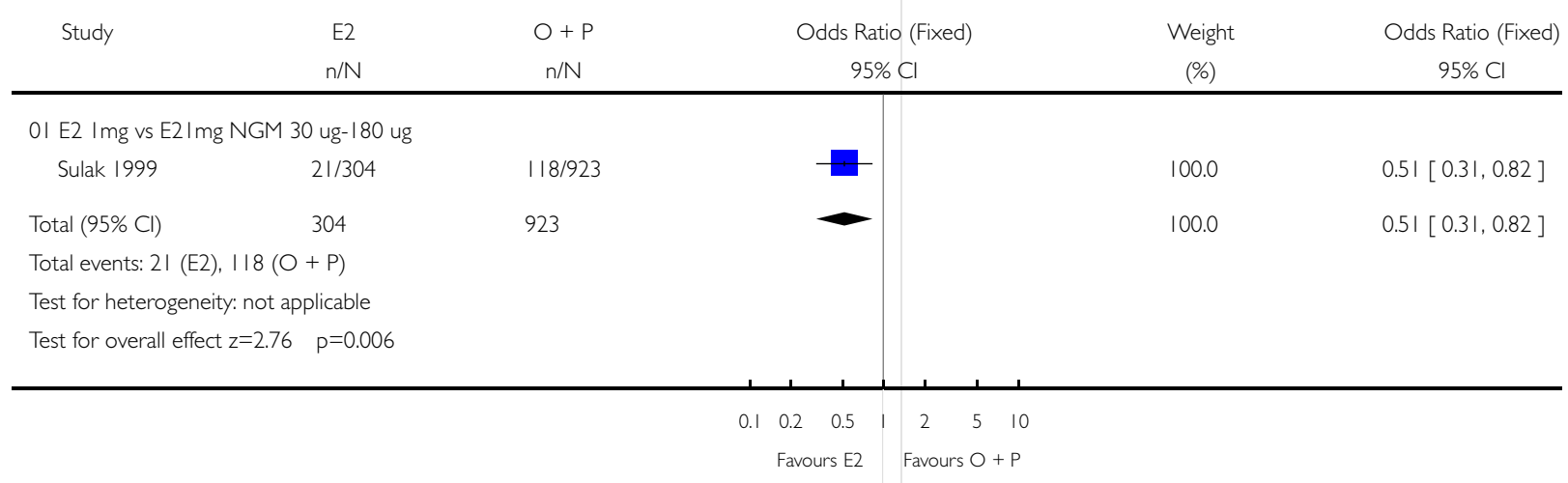




\section{Comparison II. Endometrial hyperplasia at 6 months}

Review: Hormone replacement therapy in postmenopausal women: endometrial hyperplasia and irregular bleeding Comparison: 07 OESTROGEN + PROGESTOGEN (sequential) vs PLACEBO

Outcome: 01 Endometrial hyperplasia at 12 months

\begin{tabular}{ccccc} 
Study & $\mathrm{O}+\mathrm{P}$ & Placebo & Peto Odds Ratio & Weight \\
$\mathrm{n} / \mathrm{N}$ & $\mathrm{n} / \mathrm{N}$ & $95 \% \mathrm{Cl}$ & $(\%)$ & Peto Odds Ratio \\
\hline
\end{tabular}

OI CEE 0.625mg (day I-28) + MPA IOmg or micronised prog 200mg (day I-12) PEPI $1995 \quad 3 / 238 \quad 0 / 119$

Subtotal $(95 \% \mathrm{Cl})$ $238 \quad 119$

Total events: $3(\mathrm{O}+\mathrm{P}), 0$ (Placebo)

Test for heterogeneity: not applicable

Test for overall effect $z=1.23 \quad p=0.2$

$02 \mathrm{EV} 2 \mathrm{mg}$ (day |-2|) + MPA I0mg (day |2-2|)

Heikkinen 1997

Subtotal $(95 \% \mathrm{Cl})$

$24 \quad 25$

Total events: $2(\mathrm{O}+\mathrm{P})$, I (Placebo)

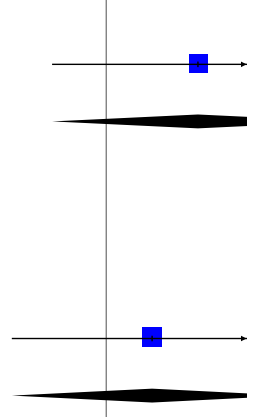

Test for heterogeneity: not applicable

Test for overall effect $z=0.63 \quad p=0.5$

03 CEE $0.625 \mathrm{mg} / \mathrm{d}$ plus medroxyprogesterone acetate $5 \mathrm{mg} / \mathrm{d}$ for 13 days every 3 months

\begin{tabular}{|c|c|c|}
\hline × Pinto 2003 & $0 / 13$ & $0 / 12$ \\
\hline Subtotal $(95 \% \mathrm{Cl})$ & 13 & 12 \\
\hline \multicolumn{3}{|c|}{ Total events: 0 (O + P), 0 (Placebo) } \\
\hline \multicolumn{3}{|c|}{ Test for heterogeneity: not applicable } \\
\hline \multicolumn{3}{|c|}{ Test for overall effect: not applicable } \\
\hline Total $(95 \% \mathrm{Cl})$ & 275 & 156 \\
\hline \multicolumn{3}{|c|}{ Total events: $5(\mathrm{O}+\mathrm{P}), \mathrm{I}$ (Placebo) } \\
\hline \multicolumn{3}{|c|}{ Test for heterogeneity chi-square $=0.20 \mathrm{df}=|\mathrm{p}=0.65|=0.0 \%$} \\
\hline Test for overall effe & $=0.2$ & \\
\hline
\end{tabular}

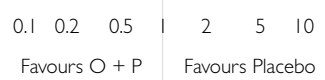




\section{Comparison II. Endometrial hyperplasia at 12 months}

Review: Hormone replacement therapy in postmenopausal women: endometrial hyperplasia and irregular bleeding Comparison: 07 OESTROGEN + PROGESTOGEN (sequential) vs PLACEBO

Outcome: 02 Endometrial hyperplasia at 24 months

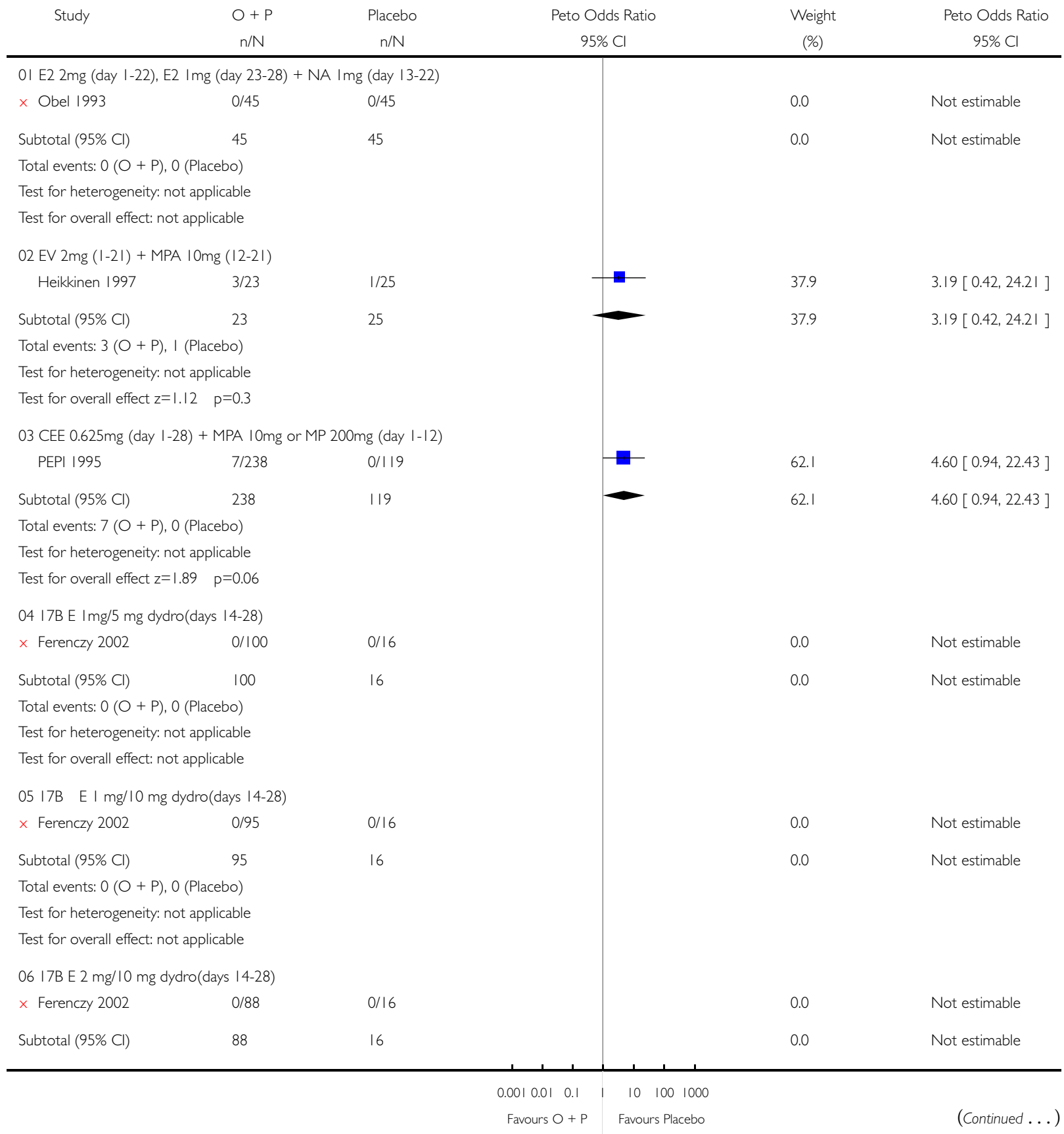

Hormone replacement therapy in postmenopausal women: endometrial hyperplasia and irregular bleeding 


\begin{tabular}{|c|c|c|c|c|c|}
\hline Study & $\begin{array}{l}\mathrm{O}+\mathrm{P} \\
\mathrm{n} / \mathrm{N}\end{array}$ & $\begin{array}{l}\text { Placebo } \\
\mathrm{n} / \mathrm{N}\end{array}$ & $\begin{array}{c}\text { Peto Odds Ratio } \\
95 \% \mathrm{Cl}\end{array}$ & $\begin{array}{c}\text { Weight } \\
(\%)\end{array}$ & $\begin{array}{c}\text { Peto Odds Ratio } \\
95 \% \mathrm{Cl}\end{array}$ \\
\hline \multicolumn{6}{|c|}{ Total events: 0 (O + P), 0 (Placebo) } \\
\hline \multicolumn{6}{|c|}{ Test for heterogeneity: not applicable } \\
\hline \multicolumn{6}{|c|}{ Test for overall effect: not applicable } \\
\hline \multicolumn{6}{|c|}{07 I7B E 2 mg/20 mg dydro(days |4-28) } \\
\hline × Ferenczy 2002 & 0/96 & $0 / 15$ & & 0.0 & Not estimable \\
\hline Subtotal $(95 \% \mathrm{Cl})$ & 96 & 15 & & 0.0 & Not estimable \\
\hline \multicolumn{6}{|c|}{ Total events: $0(\mathrm{O}+\mathrm{P}), 0$ (Placebo) } \\
\hline \multicolumn{6}{|c|}{ Test for heterogeneity: not applicable } \\
\hline \multicolumn{6}{|c|}{ Test for overall effect: not applicable } \\
\hline Total $(95 \% \mathrm{Cl})$ & 685 & 252 & - & 100.0 & $4.00[1.15,13.95]$ \\
\hline \multicolumn{6}{|c|}{ Total events: I0 (O + P), I (Placebo) } \\
\hline \multicolumn{6}{|c|}{ Test for heterogeneity chi-square $=0.08 \mathrm{df}=|\mathrm{p}=0.78|=0.0 \%$} \\
\hline Test for overall effe & $=0.03$ & & & & \\
\hline
\end{tabular}

\section{Comparison II. Endometrial hyperplasia at $\mathbf{2 4}$ months}

Review: Hormone replacement therapy in postmenopausal women: endometrial hyperplasia and irregular bleeding Comparison: 07 OESTROGEN + PROGESTOGEN (sequential) vs PLACEBO

Outcome: 03 Endometrial hyperplasia at 36 months

\begin{tabular}{|c|c|c|c|c|c|}
\hline Study & $\begin{array}{l}O+P \\
n / N\end{array}$ & $\begin{array}{l}\text { Placebo } \\
n / N\end{array}$ & Peto Odds Ratio & $\begin{array}{l}\text { Weight } \\
(\%)\end{array}$ & $\begin{array}{c}\text { Peto Odds Ratio } \\
\quad 95 \% \mathrm{Cl}\end{array}$ \\
\hline \multicolumn{6}{|c|}{ OI CEE 0.625mg (day I-28) + MPA IOmg or MP 200mg (day I-12) } \\
\hline PEPI 1995 & $12 / 238$ & $2 / 119$ & tra & 100.0 & $2.43[0.78,7.55]$ \\
\hline Total (95\% Cl) & 238 & 119 & & 100.0 & $2.43[0.78,7.55]$ \\
\hline \multicolumn{6}{|c|}{ Total events: $12(\mathrm{O}+\mathrm{P}), 2$ (Placebo) } \\
\hline \multicolumn{6}{|c|}{ Test for heterogeneity: not applicable } \\
\hline Test for overall & $p=0.1$ & & & & \\
\hline
\end{tabular}




\section{Comparison II. Endometrial hyperplasia at 36 months}

Review: Hormone replacement therapy in postmenopausal women: endometrial hyperplasia and irregular bleeding Comparison: 07 OESTROGEN + PROGESTOGEN (sequential) vs PLACEBO

Outcome: 04 Additional investigations (unscheduled biopsy)

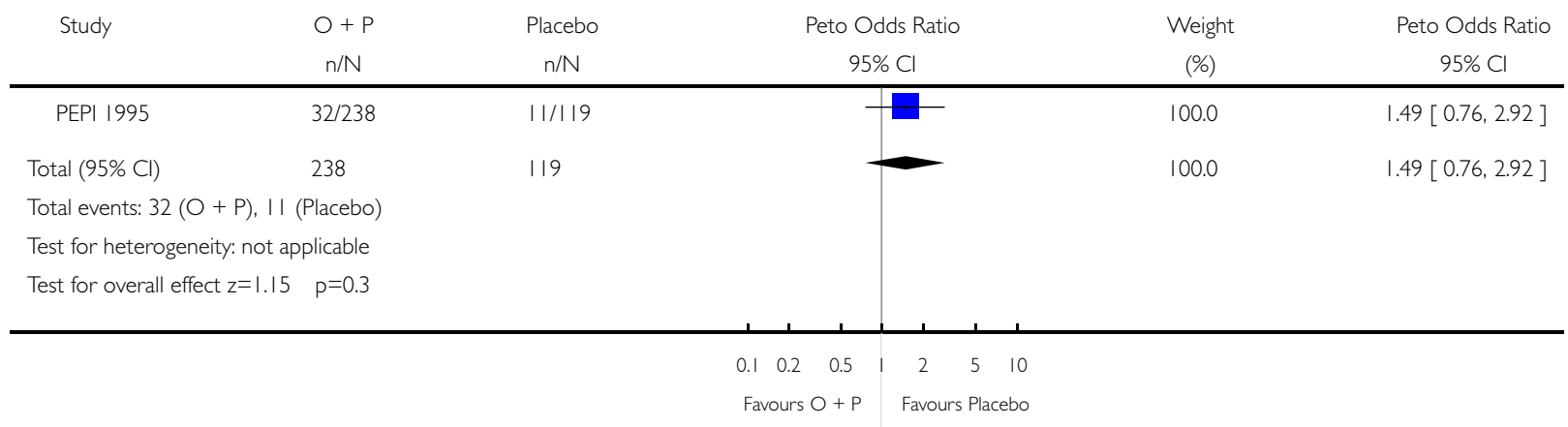

\section{Comparison II. Unscheduled biopsy or D \& C}

Review: Hormone replacement therapy in postmenopausal women: endometrial hyperplasia and irregular bleeding

Comparison: 07 OESTROGEN + PROGESTOGEN (sequential) vs PLACEBO

Outcome: 05 Endometrial cancer

$\begin{array}{llll}\text { Study } & \mathrm{O}+\mathrm{P} & \text { Placebo } & \text { Peto Odds Ratio }\end{array}$

$n / N \quad n / N$

$95 \% \mathrm{Cl}$

(\%)

$95 \% \mathrm{Cl}$

$010.625 \mathrm{mg} / \mathrm{d} \quad$ CEE $+10 \mathrm{mg} / \mathrm{d}$ MPA(day 1-12)

PEPI $1995 \quad 0 / 120 \quad$ I/30

Subtotal $(95 \% \mathrm{Cl})$

$120 \quad 30$

30

$\longleftarrow$

31.7

$0.01[0.00,0.90]$

Total events: $0(\mathrm{O}+\mathrm{P})$, I (Placebo)

Test for heterogeneity: not applicable

Test for overall effect $z=2.00 \quad p=0.05$

$020.625 \mathrm{mg} / \mathrm{d}$ CEE + 200mg/cyclic micronized progesterone(days I-12)

$\times$ PEPI $1995 \quad 0 / 120 \quad 0 / 30$

Subtotal $(95 \% \mathrm{Cl}) \quad \quad 120 \quad 30$

Total events: $0(\mathrm{O}+\mathrm{P}), 0$ (Placebo)

Test for heterogeneity: not applicable

Test for overall effect: not applicable

03 I7B E I mg/5 mg dydrogesterone

Ferenczy $2002 \quad 1 / 100$

100

Subtotal $(95 \% \mathrm{Cl})$

Total events: I (O + P), 0 (Placebo)

Test for heterogeneity: not applicable

Test for overall effect $z=0.39 \quad p=0.7$

04 I7B E I mg/10 mg dydrogesterone

$\begin{array}{cc} \\ 0.0 & \text { Not estimable } \\ 0.0 & \text { Not estimable }\end{array}$

$0.0010 .010 .1 \quad 1 \quad 10 \quad 100 \quad 1000$

Favours $\mathrm{O}+\mathrm{P} \quad$ Favours Placebo

(Continued....) 


\begin{tabular}{|c|c|c|c|c|c|}
\hline \multirow{2}{*}{$\begin{array}{c}\text { Study } \\
\times \text { Ferenczy } 2002\end{array}$} & \multirow{2}{*}{$\begin{array}{l}\mathrm{O}+\mathrm{P} \\
\mathrm{n} / \mathrm{N} \\
0 / 95\end{array}$} & \multirow{2}{*}{$\begin{array}{c}\begin{array}{c}\text { Placebo } \\
n / N\end{array} \\
0 / 15\end{array}$} & $\begin{array}{c}\text { Peto Odds Ratio } \\
95 \% \mathrm{Cl}\end{array}$ & \multirow{2}{*}{$\begin{array}{l}\text { Weight } \\
(\%) \\
0.0\end{array}$} & \multirow{2}{*}{$\begin{array}{c}\text { Peto Odds Ratio } \\
95 \% \mathrm{Cl}\end{array}$} \\
\hline & & & & & \\
\hline Subtotal $(95 \% \mathrm{Cl})$ & 95 & 15 & & 0.0 & Not estimable \\
\hline \multicolumn{6}{|c|}{ Total events: 0 (O + P), 0 (Placebo) } \\
\hline \multicolumn{6}{|c|}{ Test for heterogeneity: not applicable } \\
\hline \multicolumn{6}{|c|}{ Test for overall effect: not applicable } \\
\hline \multicolumn{6}{|c|}{05 I7B E 2 mg/ / 0 mg dydrogesterone } \\
\hline × Ferenczy 2002 & $0 / 88$ & $0 / 15$ & & 0.0 & Not estimable \\
\hline Subtotal $(95 \% \mathrm{Cl})$ & 88 & 15 & & 0.0 & Not estimable \\
\hline \multicolumn{6}{|c|}{ Total events: $0(\mathrm{O}+\mathrm{P}), 0$ (Placebo) } \\
\hline \multicolumn{6}{|c|}{ Test for heterogeneity: not applicable } \\
\hline \multicolumn{6}{|c|}{ Test for overall effect: not applicable } \\
\hline \multicolumn{6}{|c|}{06 17 B E 2 mg/20 mg dydrogesterone } \\
\hline Ferenczy 2002 & 2/96 & $0 / 15$ & + & 45.9 & $3.21[0.05,188.54]$ \\
\hline Subtotal $(95 \% \mathrm{Cl})$ & 96 & 15 & & 45.9 & $3.21[0.05,188.54]$ \\
\hline \multicolumn{6}{|c|}{ Total events: 2 (O + P), 0 (Placebo) } \\
\hline \multicolumn{6}{|c|}{ Test for heterogeneity: not applicable } \\
\hline \multicolumn{6}{|c|}{ Test for overall effect $z=0.56 \quad p=0.6$} \\
\hline Total $(95 \% \mathrm{Cl})$ & 619 & 120 & & 100.0 & $0.45[0.03,7.15]$ \\
\hline \multicolumn{6}{|c|}{ Total events: $3(\mathrm{O}+\mathrm{P})$, I (Placebo) } \\
\hline \multicolumn{6}{|c|}{ Test for heterogeneity chi-square $=4.15 \mathrm{df}=2 \mathrm{p}=0.13 \mid=51.8 \%$} \\
\hline Test for overall effe & $p=0.6$ & & & & \\
\hline
\end{tabular}

$0.0010 .010 .1 \quad 1 \quad 10 \quad 100 \quad 1000$

Favours $\mathrm{O}+\mathrm{P} \quad$ Favours Placebo

\section{Comparison II. Endometrial carcinoma}

Review: Hormone replacement therapy in postmenopausal women: endometrial hyperplasia and irregular bleeding Comparison: 07 OESTROGEN + PROGESTOGEN (sequential) vs PLACEBO

Outcome: 06 Irregular bleeding patterns $<6$ months after treatment

\begin{tabular}{|c|c|c|c|c|c|}
\hline Study & $\begin{array}{l}\mathrm{O}+\mathrm{P} \\
\mathrm{n} / \mathrm{N}\end{array}$ & $\begin{array}{c}\text { Placebo } \\
n / N\end{array}$ & Peto Odds Ratio & $\begin{array}{l}\text { Weight } \\
(\%)\end{array}$ & $\begin{array}{c}\text { Peto Odds Ratio } \\
95 \% \mathrm{Cl}\end{array}$ \\
\hline Obel 1993 & 2/48 & $3 / 48$ & + & 100.0 & $0.66[0.11,3.95]$ \\
\hline Total $(95 \% \mathrm{Cl})$ & 48 & 48 & & 100.0 & $0.66[0.11,3.95]$ \\
\hline \multicolumn{6}{|c|}{ Total events: $2(\mathrm{O}+\mathrm{P}), 3$ (Placebo) } \\
\hline \multicolumn{6}{|c|}{ Test for heterogeneity: not applicable } \\
\hline Test for overall & $p=0.6$ & & & & \\
\hline
\end{tabular}




\section{Comparison II. Irregular bleeding patterns $<6$ months after treatment}

Review: Hormone replacement therapy in postmenopausal women: endometrial hyperplasia and irregular bleeding Comparison: 07 OESTROGEN + PROGESTOGEN (sequential) vs PLACEBO

Outcome: 07 Irregular bleeding patterns $>=6$ months after treatment

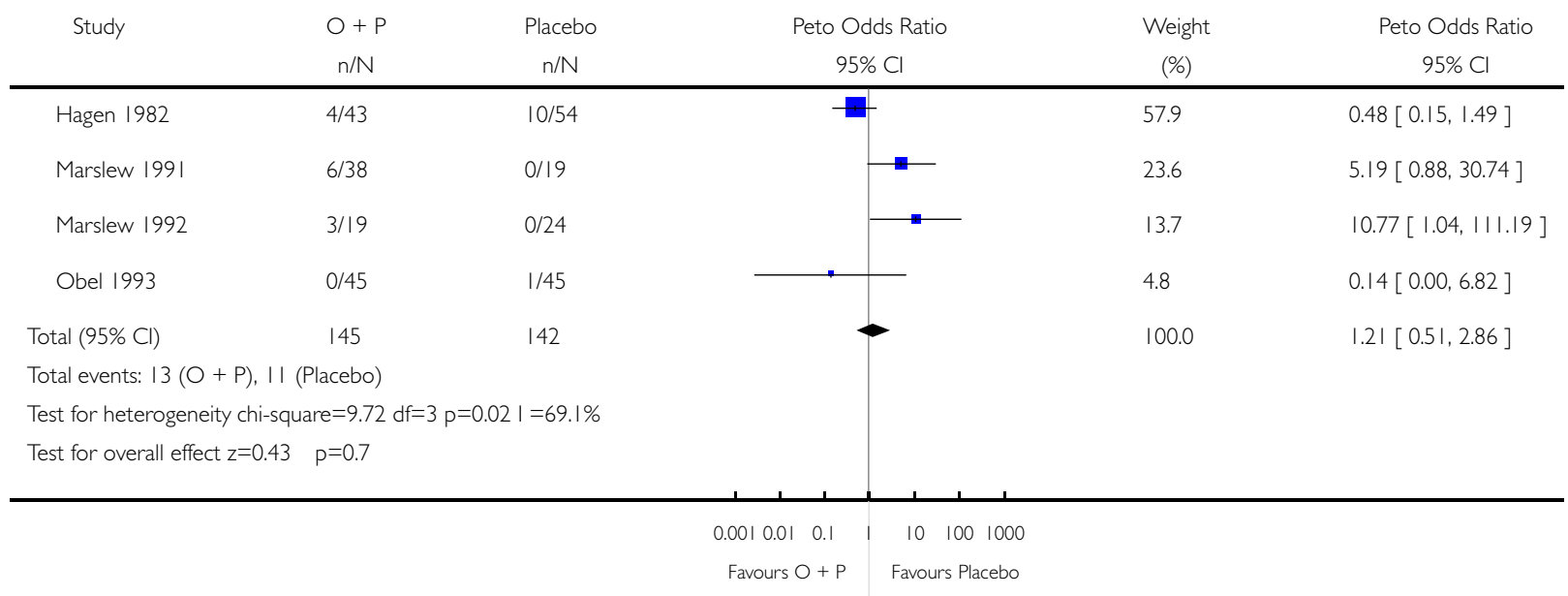

\section{Comparison II. Irregular bleeding patterns $>=6$ months after treatment}

Review: Hormone replacement therapy in postmenopausal women: endometrial hyperplasia and irregular bleeding Comparison: 07 OESTROGEN + PROGESTOGEN (sequential) vs PLACEBO

Outcome: 08 Mean number of excess bleeding episodes(36 months)

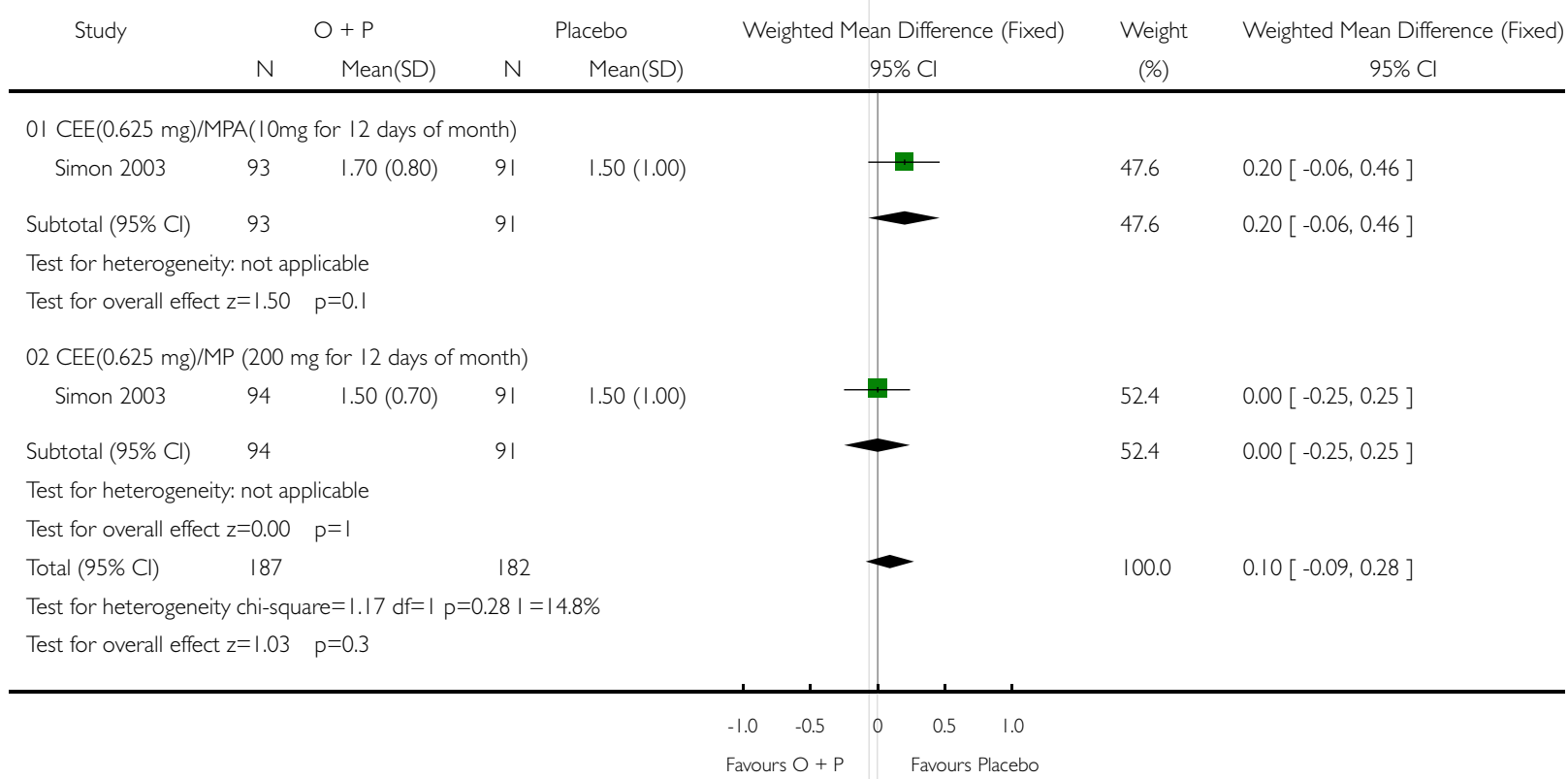




\section{Comparison II. Non adherence to therapy}

Review: Hormone replacement therapy in postmenopausal women: endometrial hyperplasia and irregular bleeding Comparison: 07 OESTROGEN + PROGESTOGEN (sequential) vs PLACEBO

Outcome: 09 Withdrawal due to adverse events

\begin{tabular}{|c|c|c|c|c|c|}
\hline \multirow[t]{2}{*}{ Study } & $O+P$ & Placebo & Odds Ratio (Fixed) & Weight & Odds Ratio (Fixed) \\
\hline & $\mathrm{n} / \mathrm{N}$ & $\mathrm{n} / \mathrm{N}$ & $95 \% \mathrm{Cl}$ & (\%) & $95 \% \mathrm{Cl}$ \\
\hline
\end{tabular}

OI I7B E I-2mg/5-IOmg dydrogesterone

Ferenczy 2002

$12 / 63$

100.0

$0.98[0.50,1.93]$

Total $(95 \% \mathrm{Cl})$

379

63

100.0

$0.98[0.50,1.93]$

Total events: 7I (O + P), I2 (Placebo)

Test for heterogeneity: not applicable

Test for overall effect $z=0.06 \quad p=1$

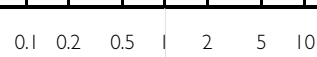

Favours treatment Favours control

\section{Comparison II. Endometrial hyperplasia at 12 months}

Review: Hormone replacement therapy in postmenopausal women: endometrial hyperplasia and irregular bleeding

Comparison: 08 OESTROGEN + PROGESTOGEN (continuous) VS OESTROGEN + PROGESTOGEN (sequential)

Outcome: 0 I Endometrial hyperplasia at 6 months

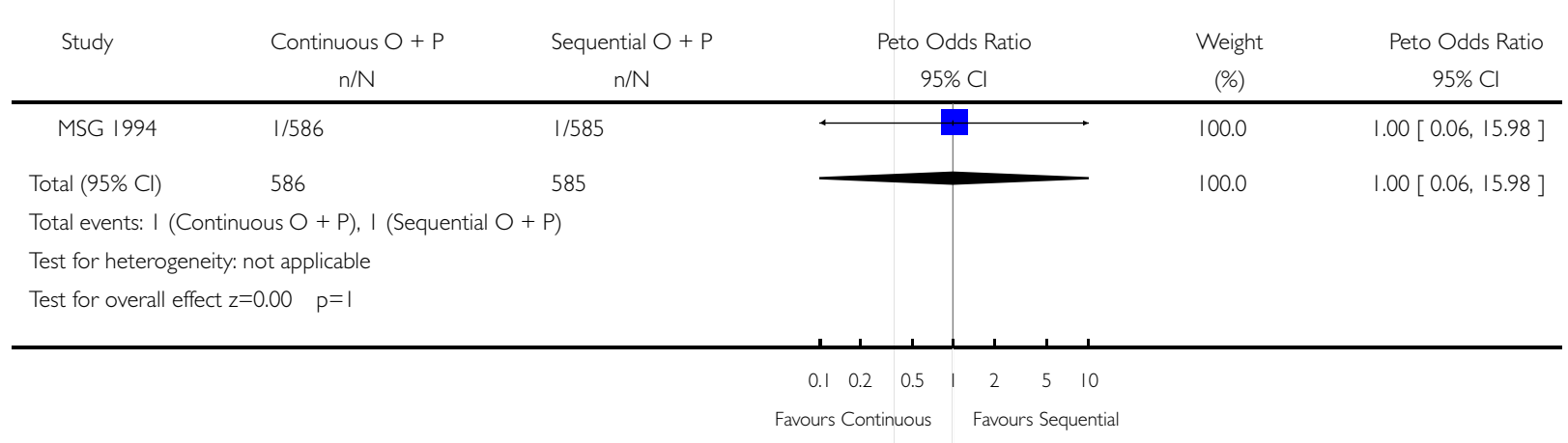




\section{Comparison II. Endometrial hyperplasia at 24 months}

Review: Hormone replacement therapy in postmenopausal women: endometrial hyperplasia and irregular bleeding Comparison: 08 OESTROGEN + PROGESTOGEN (continuous) VS OESTROGEN + PROGESTOGEN (sequential)

Outcome: 02 Endometrial hyperplasia at 12 months

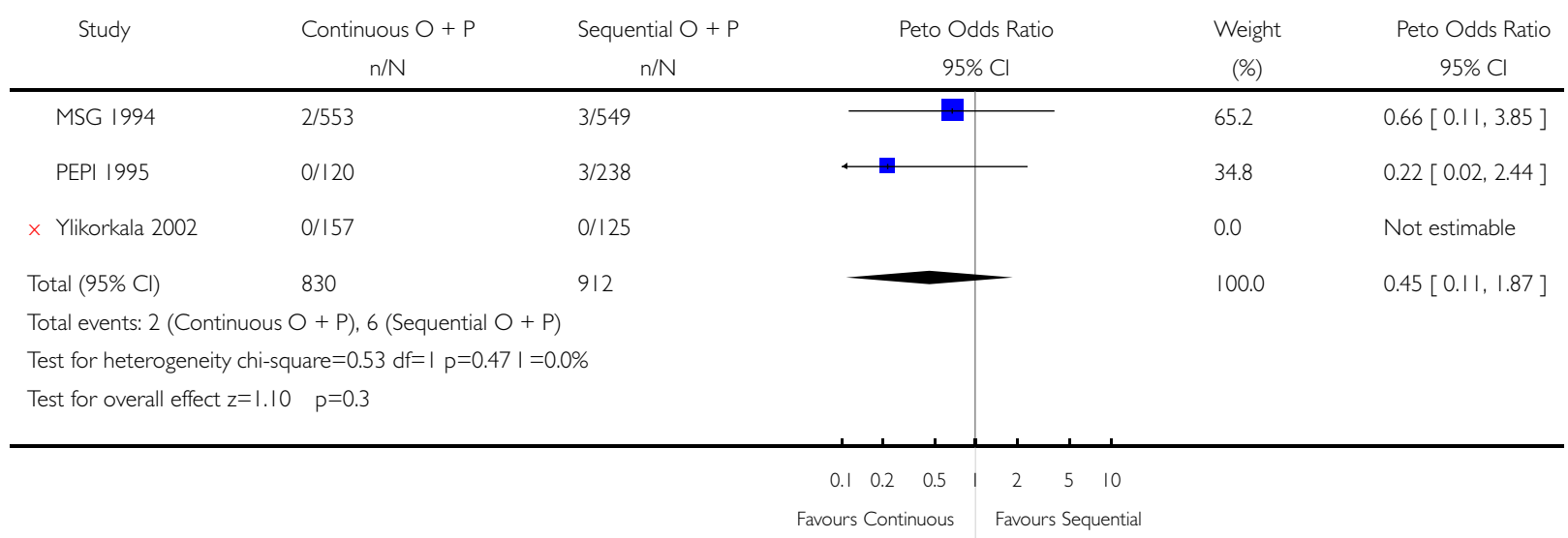

\section{Comparison II. Endometrial hyperplasia at 36 months}

Review: Hormone replacement therapy in postmenopausal women: endometrial hyperplasia and irregular bleeding Comparison: 08 OESTROGEN + PROGESTOGEN (continuous) VS OESTROGEN + PROGESTOGEN (sequential)

Outcome: 03 Endometrial hyperplasia at 24 months

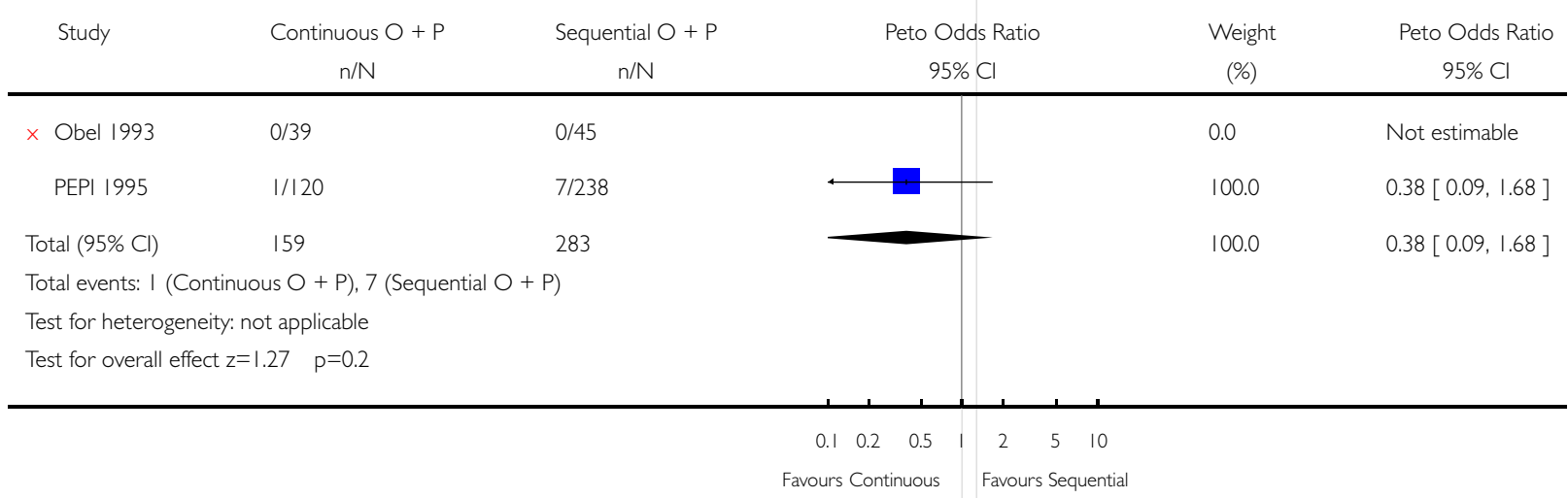




\section{Comparison II. Unscheduled biopsy or D \& C}

Review: Hormone replacement therapy in postmenopausal women: endometrial hyperplasia and irregular bleeding Comparison: 08 OESTROGEN + PROGESTOGEN (continuous) VS OESTROGEN + PROGESTOGEN (sequential)

Outcome: 04 Endometrial hyperplasia at 36 months

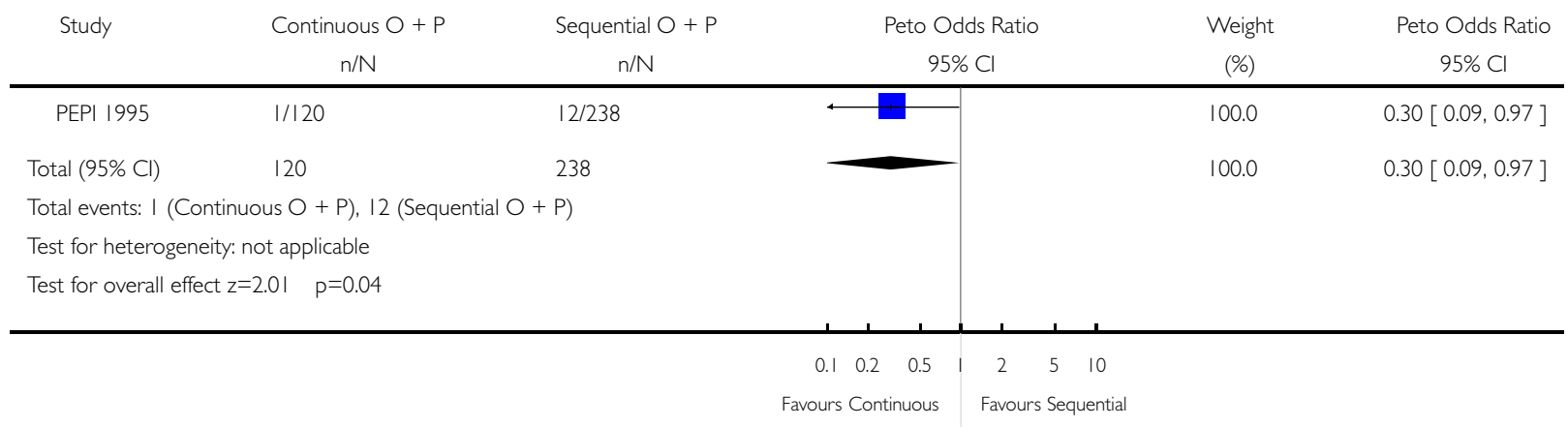

\section{Comparison II. Endometrial cancer}

Review: Hormone replacement therapy in postmenopausal women: endometrial hyperplasia and irregular bleeding Comparison: 08 OESTROGEN + PROGESTOGEN (continuous) VS OESTROGEN + PROGESTOGEN (sequential) Outcome: 05 Endometrial cancer

\begin{tabular}{|c|c|c|c|c|c|}
\hline Study & $\begin{array}{c}\text { Continuous } \mathrm{O}+\mathrm{P} \\
\mathrm{n} / \mathrm{N}\end{array}$ & $\begin{array}{c}\text { Sequential } O+P \\
n / N\end{array}$ & $\begin{array}{c}\text { Peto Odds Ratio } \\
\quad 95 \% \mathrm{Cl}\end{array}$ & $\begin{array}{l}\text { Weight } \\
(\%)\end{array}$ & $\begin{array}{c}\text { Peto Odds Ratio } \\
95 \% \mathrm{Cl}\end{array}$ \\
\hline MSG 1994 & 0/553 & 1/549 & \begin{tabular}{l|l}
-1 \\
$-1-$
\end{tabular} & 100.0 & $0.13[0.00,6.77]$ \\
\hline$\times$ PEPI 1995 & $0 / 120$ & 0/238 & & 0.0 & Not estimable \\
\hline Total $(95 \% \mathrm{Cl})$ & 673 & 787 & & 100.0 & $0.13[0.00,6.77]$ \\
\hline \multicolumn{6}{|c|}{ Total events: $\mathrm{O}$ (Continuous $\mathrm{O}+\mathrm{P})$, I (Sequential $\mathrm{O}+\mathrm{P})$} \\
\hline \multicolumn{6}{|c|}{ Test for heterogeneity: not applicable } \\
\hline Test for overall & $1.00 p=0.3$ & & & & \\
\hline
\end{tabular}

$0.0010 .010 .1 \quad 1 \quad 10 \quad 100 \quad 1000$

Favours Continuous Favours Sequential 


\section{Comparison II. Irregular bleeding patterns $<6$ months after treatment}

Review: Hormone replacement therapy in postmenopausal women: endometrial hyperplasia and irregular bleeding Comparison: 08 OESTROGEN + PROGESTOGEN (continuous) VS OESTROGEN + PROGESTOGEN (sequential)

Outcome: 06 Irregular bleeding patterns $<6$ months after treatment

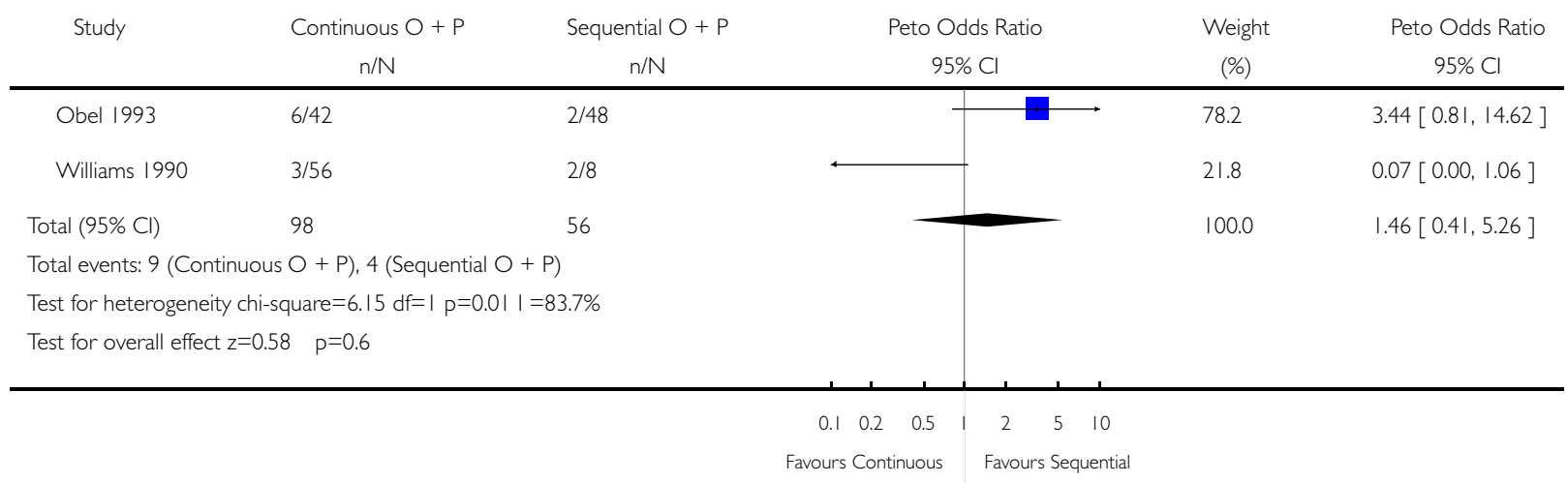

\section{Comparison II. Irregular bleeding patterns $>=\mathbf{6}$ months after treatment}

Review: Hormone replacement therapy in postmenopausal women: endometrial hyperplasia and irregular bleeding Comparison: 08 OESTROGEN + PROGESTOGEN (continuous) VS OESTROGEN + PROGESTOGEN (sequential)

Outcome: 07 Irregular bleeding patterns $>=6$ months after treatment

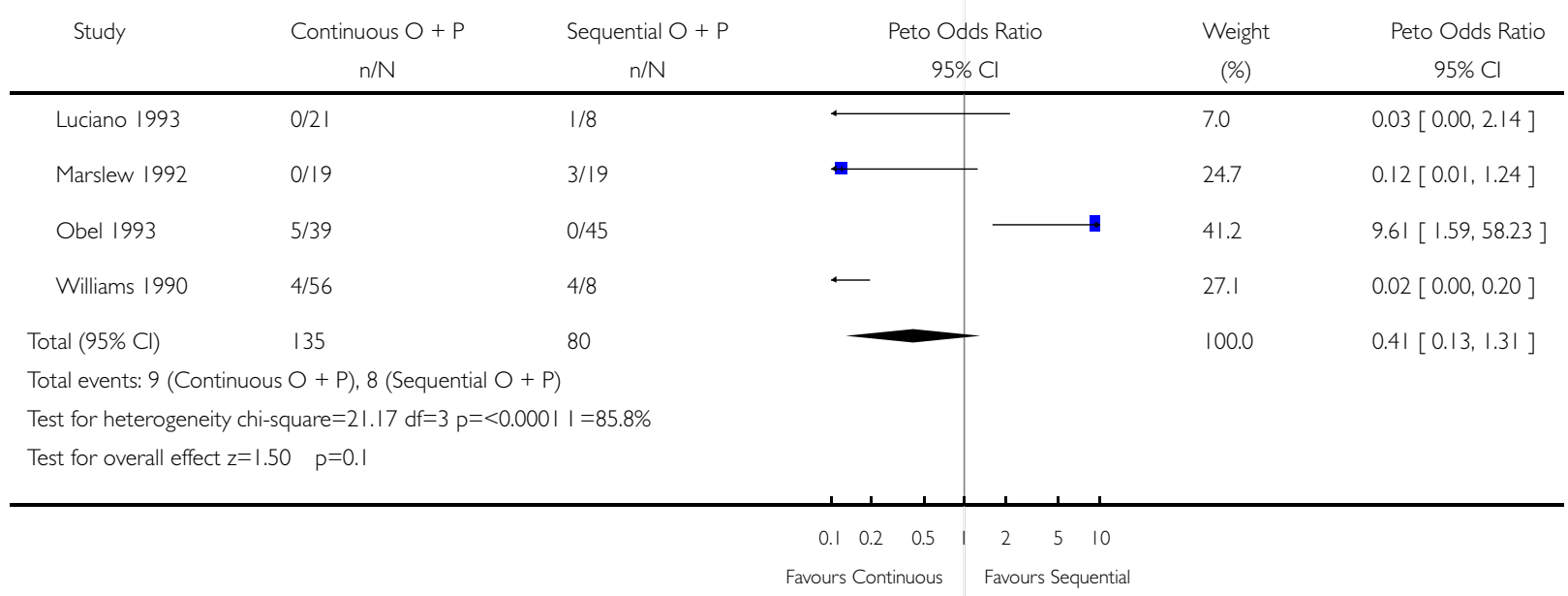

Hormone replacement therapy in postmenopausal women: endometrial hyperplasia and irregular bleeding 